\title{
What is eating them? : moral considerations in the management of obesity in the case of Prader-Willi syndrome
}

Citation for published version (APA):

van Hooren, R. H. L. C. (2007). What is eating them? : moral considerations in the management of obesity in the case of Prader-Willi syndrome. [Doctoral Thesis, Maastricht University]. Datawyse / Universitaire Pers Maastricht. https://doi.org/10.26481/dis.20071205rh

Document status and date:

Published: 01/01/2007

DOI:

10.26481/dis.20071205rh

Document Version:

Publisher's PDF, also known as Version of record

Please check the document version of this publication:

- A submitted manuscript is the version of the article upon submission and before peer-review. There can be important differences between the submitted version and the official published version of record.

People interested in the research are advised to contact the author for the final version of the publication, or visit the DOI to the publisher's website.

- The final author version and the galley proof are versions of the publication after peer review.

- The final published version features the final layout of the paper including the volume, issue and page numbers.

Link to publication

\footnotetext{
General rights rights.

- You may freely distribute the URL identifying the publication in the public portal. please follow below link for the End User Agreement:

www.umlib.nl/taverne-license

Take down policy

If you believe that this document breaches copyright please contact us at:

repository@maastrichtuniversity.nl

providing details and we will investigate your claim.
}

Copyright and moral rights for the publications made accessible in the public portal are retained by the authors and/or other copyright owners and it is a condition of accessing publications that users recognise and abide by the legal requirements associated with these

- Users may download and print one copy of any publication from the public portal for the purpose of private study or research.

- You may not further distribute the material or use it for any profit-making activity or commercial gain

If the publication is distributed under the terms of Article $25 \mathrm{fa}$ of the Dutch Copyright Act, indicated by the "Taverne" license above, 


\section{WHAT IS EATING THEM?}

Moral considerations in the management of obesity

in the case of Prader-Willi syndrome 
(c) copyright R.H. van Hooren, Maastricht 2007

ISBN 978-90-5278-670-4

Universitaire Pers Maastricht

Graphic design: Niels Maier, www.nielsmaier.nl Printed by Datawyse Maastricht

No parts of this thesis may be reproduced in any form without prior permission of the author or copyright-owning journals for previously published papers. 


\section{WHAT IS EATING THEM?}

\section{Moral considerations in the management of obesity in the case of Prader-Willi syndrome}

\section{PROEFSCHRIFT}

ter verkrijging van de graad van doctor aan de Universiteit Maastricht, op gezag van de Rector Magnificus, Prof. mr. G.P.M.F. Mols, volgens het besluit van het College van Decanen, in het openbaar te verdedigen op woensdag 5 december 2007 om 12.00 uur

$$
\text { door }
$$

Robert Hubertus Ludovicus Catharina van Hooren 


\section{Promotores}

Prof.dr. G.A.M. Widdershoven

Prof.dr. L.M.G. Curfs

Prof.dr. H.W. van den Borne

Beoordelingscommissie

Prof.dr. F.C.B. van Wijmen (voorzitter)

Dr. T.A. Abma

Prof.dr. A.Th.G. van Gennep

Prof.dr. A.J. Holland (University of Cambridge, United Kingdom)

Prof.dr. J.S. Reinders (Vrije Universiteit Amsterdam)

The studies described in this thesis were financially supported by two grants from the Netherlands Organization for Health Research and Development - Medical Sciences (ZonMw).

The financial support of the Kattendijke / Drucker Stichting and the Stichting Jan Jongmans Fonds in printing this thesis is gratefully acknowledged. 


\section{Contents}

$\begin{array}{lll}\text { Chapter } 1 & \text { General introduction } & 7\end{array}$

Chapter $2 \quad$ Values in the care for young persons with Prader-Willi syndrome: Creating a meaningful life together

Chapter $3 \quad$ Autonomy and intellectual disability: The case of prevention of obesity in Prader-Willi syndrome

Chapter $4 \quad$ Between control and freedom in the care for persons with Prader-Willi syndrome: An analysis of preferred interventions by caregivers

Chapter 5 Competence in the care for persons with intellectual disability: An alternative view $\quad 75$

Chapter 6 The role of empirical ethics in developing normative theory

Chapter $7 \quad$ Ethics of prevention: An interactive computer-tailored program

Chapter $8 \quad$ General discussion and conclusions

Appendix A Interview scheme

Appendix B Case descriptions

Summary

Samenvatting

Dankwoord

Curriculum Vitae 



\section{CHAPTER 1}

GENERAL INTRODUCTION 



\section{$1.1 \quad$ Background}

In the second half of the last century, the approach towards persons with intellectual disabilities ${ }^{1}$ has changed dramatically. A process of normalisation was initiated, with its roots in the Scandinavian welfare states, emphasizing that intellectually disabled persons should lead an existence as close to the normal as possible (Nirje, 1976; 1992; Wolfensberger, 1992). Previously, it was assumed that it would be better for persons with intellectual disabilities to live in a special institution in a separated quiet environment. Since the sixties, however, more and more people became convinced that persons with intellectual disabilities should have a place in society, with rights and duties equal to other citizens (Mans, 1998). Through the years a process of integration, de-concentration of institutions and the introduction of supported living and supported employment was developed (Ericsson, 1996; Van Gennep, 1997).

Van Gennep (2000) provides a systematic overview of the developments in conceptions about intellectual disability. Following the division in visions made by Greenspan (1999), Van Gennep distinguishes successively a defect paradigm, a development paradigm and a paradigm of citizenship. Advocates of the defect paradigm assume persons with intellectual disabilities differ in their functioning from persons without disabilities, on the basis of a (neurological) defect. In contrast to the medical defect paradigm, the development paradigm has a social scientific nature, focusing on the abilities of a person instead of a focus on his or her limitations. Where the defect vision led to segregation, the development vision led to normalisation. In the current citizenship paradigm, in which a person is seen as an individual with rights and duties, a vision of support is expressed, that leads to processes of integration and inclusion.

These changes have far reaching consequences for the care for people with intellectual disabilities. Nowadays the paradigm of citizenship dominates the field of care. Several aspects characterize this paradigm. Persons with intellectual disabilities can and should live in society as equal citizens. Moreover, the aim of society is to promote a good quality of life for each citizen. Quality of life entails the possibility to choose how to create and shape one's own existence in such a way that one is satisfied with it. This entails that persons with intellectual disabilities choose for themselves with which people to engage, how to act and realise these choices. In this way a person can get control over his existence. In order to make choices, persons with intellectual disabilities are dependent on support by others. The essence of support is that the supporting person takes into account what the disabled person can do himself, and helps him in this (Van Gennep, 2000, pp.98-99). Support emphasises that the intellectually disabled person is a subject. Since being a subject always implies a relationship to another subject (intersubjectivity), relationships form the basis of the citizenship paradigm. Through practical intersubjectivity (entering in relationships, living together, being partners) the process of shaping personality can be realized (Van Gennep, 2000, p. 142).

Freedom of choice, self-determination and responsibility of persons with intellectual disabilities have become increasingly important. Caregivers have come to acknowl- 
edge the crucial role of these values. Yet, they also are aware of the fact that person with intellectual disabilities need support, and that this may mean that their choices should not be taken for granted, but should be critically assessed in the light of the person's well-being. What persons with intellectual disabilities want in the present situation, may for instance not be beneficial to their future health. It is not always easy to decide what to do when wishes and interests conflict with one another. How should support in the light of the citizenship paradigm look like in such situations?

The case of care to persons with Prader-Willi syndrome

Such conflicts are very prominent in the care for persons with Prader-Willi syndrome (PWS). This genetic disorder, which is taken as the central case in this study, is associated with mild to moderate intellectual disabilities. A prominent feature in PraderWilli syndrome is an excessive appetite, frequently associated with overeating behaviour. It has been suggested that in PWS the normal satiety response is impaired and delayed. This overeating behaviour frequently leads to obesity, which without any dietary intervention can be severe and lead to serious health problems. How should parents and professional caregivers deal with this situation? What does full citizenship mean for these individuals, given the syndrome specific eating characteristics? Given the situation that many Prader-Willi youngsters have relatively mild intellectual disabilities, is it a violation of clients' rights if caregivers lock up food, restrict clients' social contacts and limit their expenditures for the sake of their health and quality of life (Dykens et al., 1997)? Can capacity play a role in these kind of decisions (see Holland \& Wong, 1999)? In what way do persons with Prader-Willi syndrome need to be supported? In order to answer these questions, first an overview of ethical perspectives and theoretical frameworks in the field of healthcare ethics is given.

\subsection{Approaches in health care ethics}

In the second half of the last century the position of the patient in healthcare changed. Until then physicians decided what was best for the patient. Gradually a shift was made, giving the patient more power to decide. Nowadays, a physician can no longer provide medical treatment without the patient's consent. Patient autonomy has become a central value in contemporary medicine and health care (Wear, 1993; Sullivan, 2003). In the next section the currently dominant approach in health care ethics ${ }^{2}$, the principle-based approach, is discussed. Furthermore, an analysis is made of the limitations of this approach. The limitations are discussed in the light of the object of this study. An alternative approach will be put forward. This approach will be used as the main perspective for this study. 
In the middle of the twentieth century the field of medical ethics changed rapidly, as a consequence of the progress in medicine and medical technology. Due to the increasing doubts because of the new abilities of physicians to lengthen life with far-reaching and complicated means, a new ethics on health rose. In this ethics the right to decide shifted from the physician to the patient (Widdershoven, 2000, p.16ff).

Next to the traditional principles of beneficence and non-maleficence, physicians had to take into account new principles, namely respect for patient autonomy and justice. Since the rise of the new ethics in the seventies of the last century these four principles have been outlined and still are adjusted by Beauchamp and Childress ${ }^{3}$. This codification has been accepted by many ethicists. Sometimes the principle-based methodology using these principles is even called the four-principles approach (see, for example, Gillon, 2003; Macklin, 2003). As Beauchamp (2003) explains from a methodological point of view, these principles serve as first principles and conditions (prima facie) of more specific moral conceptions. The four principles are thus global of nature and need to be specified to make them suitable for the analysis of a context, case or policy (Richardson, 1990; 2000). Nevertheless, one needs to live up to all of them. Only when principles are conflicting with one another these need to be balanced.

The principles of beneficence and of nonmaleficence are both rooted in the Hippocratic tradition. According to this tradition the physician's commitment is to promote patients' welfare interests. Physicians ought to do anything that can enhance the patient's health. For Hippocrates the principle of nonmaleficence forms a complement to the beneficence principle (Beauchamp \& Childress, 2001, p.113); the physician ought to refrain from treatments that may inflict harm. The principle of respect for autonomy is rooted in the Enlightenment tradition (Ten Have et al., 2003, p.81-82) and starts from the notion that individuals should be able to decide upon their lives themselves. The last principle, justice, introduces societal norms into health care (Widdershoven, 2000, p.22). This principle, that has gained interest through the years as a consequence of technical progress in medicine, refers to the allocation of benefits and burdens in health care (for example the allocation of scarce means like organs in organ transplantation).

Respect for autonomy and beneficence

As described in the former section, in the new ethics that started to rise in the sixties of the last century the right to decide shifted from the physician to the patient. The principle of respect for autonomy has become an important guiding principle in health care ethics. Many ethicists complain that this principle has gained too much attention. As Gillon (2003, p.310) points out, a recurrent complaint about the four principles approach is that although in theory it claims not to prioritise any one of the principles, the principle of respect for autonomy recurrently is prioritized in practice ${ }^{4}$. The principle of respect for autonomy has its origins in the work of Kant. Kant argued that respect for autonomy flows from the recognition that all persons have unconditional worth, each having the capacity to determine his or her own moral destiny 
(Beauchamp \& Childress, 2001, p.64). The concept of autonomy is also rooted in John Stuart Mill's work on liberty. Especially this conceptualization is relevant to the principle-based approach in health care ethics (Widdershoven, 2000). Mill stressed that people should have the authority to shape their lives themselves, as long as they do not interfere with the freedom of others. Mill's assumption is that the person involved only needs to have some degree of reason. According to him it can be assumed that people are capable to know themselves what is in their best interest. Mill conceives autonomy primarily as the capacity to take decisions without the interference of others (Widdershoven, 2000, p.21). Relevant for this is the distinction made by Berlin (1969) between negative and positive freedom, referring to the absence or presence of interference of others. Berlin applies this distinction in a political context, discussing the relationship between individual citizens and the government or society. Analogous to this distinction, respect for autonomy can be interpreted in two ways (Ten Have et al., 2003, p.90), a negative and positive conception. A growing number of ethicists apply the distinction between negative and positive freedom in the context of care or support (a.o. Agich, 1993; Verkerk, 1999; Widdershoven, 2000; Maeckelberghe, 2004; Widdershoven \& Berghmans, 2007). Mill's conception of autonomy is related to negative freedom, that is individual freedom of choice. This conception of autonomy also is called liberal. The principle-based approach in ethics considers respect for autonomy primarily in terms of non-interference (negative freedom); emphasis is put on the right of self-determination (Widdershoven, 2000, p.34) ${ }^{5}$.

The principle of respect for autonomy can be in conflict with the principle of beneficence. Doing good may be an important goal of medicine, but the physician's duty to act in the best interest of the patient is limited by the patient's wishes. If the patient refuses treatment or care, it is morally wrong to impose it. Given the importance of the principle of respect for autonomy, paternalistic intervention without a patient's consent is only morally acceptable when a person inflicts severe damage under conditions of incompetence (Beauchamp \& Childress, 2001, pp.59 \& 64).

\section{Criticism of the principle-based approach}

The principle-based approach formed the basis of health care ethics as an independent discipline. Despite the fact that today this approach still has a strong influence on the field of health care ethics, it also is subject to criticism.

The principle-based approach not only makes moral dilemmas visible, but also provides a specific methodology to solve them. Since the principle-based approach came into being in the United States, it is characterized by their prevailing ideology, i.e. a liberal one. Two forms of criticism of the principle-based approach can be distinguished: firstly, criticisms because this ethical approach is principle-based, and secondly, because of the filling in and the presentation of these principles, how these are interpreted and how their function is conceived (Van Bortel, 2004, p.123).

Principles are abstract and by definition indefinite. Principles are a-priori rules that do not come into being as a consequence of a process of induction but of abstraction. They are not generalizations from common empirical features. They cannot be contradicted by facts. On the contrary, they determine the empirical data. They determine 
how we see and judge. Principles demarcate the field of play, but do not tell what in a specific situation the best move is. They make us see something concrete, but they also have the consequence that we do not see other things; if another vocabulary is taken as a starting point, other things can be seen (Van Bortel, 2004, pp.141-143).

The principle-based approach is based on the concept of man as a rational, autonomous choosing individual. Critics question this liberal approach, with its focus on rationality and independence, and on individual (cognitive) problem-solving. This conception not only leads to a marginalisation of persons with diminished cognitive abilities like persons with intellectual disabilities (Reinders, 2000) or ageing people (Moody, 1992). The emphasis on autonomy as self-determination is also difficult to apply to 'normal', emancipated persons. It disregards the fact that with regard to illness and health, persons need to find ways to live with their situation together with others (Widdershoven, 2000; 2002).

Critics also point out that principle-based ethicists emphasize the rights of patients. This emphasis may lead to problems when the patients refuse to consent with treatment. The interpretation of the professional relationship in terms of rights and obligations may fall short when it results in a right to rot for a patient (Widdershoven, 2000, p.12).

Persons with Prader-Willi syndrome have a certain degree of dependency. They are dependent because of the mild to moderate intellectual disabilities or, even more important, because of the consequences of their eating behaviour. Their cognitive restrictions ask for a structured support by caregivers. A constant dietary supervision often is necessary to prevent serious obesity. This dependency is contradictory to the liberal nature of the principle-based approach to ethics, with its focus on rationality and independence. An alternative approach in health care ethics that may be a more adequate theoretical perspective to study the practice of care to persons with Prader-Willi syndrome is the ethics of care approach. This approach may be more adequate for it takes into account dependency.

\subsubsection{The ethics of care approach}

A recent alternative to the principle-based approach is the ethics of care approach. The ethics of care approach originated primarily in feminist writings (Beauchamp \& Childress, 2001, p.370). It was developed in the beginning of the eighties. An influential book was Carol Gilligan's In a different voice (1982). In the context of studying moral development and gender, Gilligan identified a 'voice of care' that tended to be associated with women and girls. In contrast to the male morality that has a justice orientation, female morality has a responsibility orientation; a view of morality in terms of responsibilities of care deriving from attachments to others (Beauchamp \& Childress, 2001, p.370).

Central to the ethics of care approach is the view that people are not independent individuals, but care for each other and are dependent on each other. The focus is on vulnerability and interdependence (Graste, 2000; MacKenzie \& Stoljar, 2000; Walker, 1998). This also applies to persons with intellectual disabilities (Reinders, 2000). On the basis of mutual dependency, personal development can be realized. Seen from the 
perspective of an ethics of care, care for another person is not exceptional but a fundamental characteristic to our human nature. Care is an intentional involvement of one person in the other (Verkerk, 1999; Meininger, 2002).

In contrast to the principle-based approach that conceives autonomy as selfdetermination (negative freedom), the ethics of care approach sees autonomy as selfdevelopment, supported by others. The self thus is conceived as a relational and embedded self. The central question is not whether people can decide for themselves without the interference of others, but whether they can create their lives together (positive freedom) in such a way that it can be perceived as a good life. From this point of view autonomy and dependency are not seen as contrasting; autonomy can be enhanced in a relationship of dependency (MacKenzie \& Stoljar, 2000).

Besides these fundamental anthropological insights, care denotes an epistemic attitude, understood as a moral ideal of attention (Verkerk, 1999). The care perspective emphasizes an alternative moral epistemology, in which attention, contextual and narrative appreciation and communication are considered as elements of moral deliberation (Walker, 1992). In short, care as an orientation can be seen as a practice, in which the concerns and needs of the other are taken as a basis for action and in which attentiveness and responsiveness are seen as epistemic virtues.

Tronto sees care as a broad activity that is fundamental to human existence. Everybody is able to care, and everybody has to care in order to keep life going. Tronto defines care as 'a species activity that includes everything we do to maintain, continue, and repair our 'world' so that we can live in it as well as possible. That world includes our bodies, our selves, and our environment, all of which we seek to interweave in a complex, life-sustaining web' (Tronto, 1993, p.103). She sees care as ongoing. Care can characterize a single activity, or it can describe a process. In this regard, caring is not simply a cerebral concern, or a character trait, but the concern of living, active humans engaged in the processes of everyday living. Care is both a practice and a disposition (id., p.104).

Care as an ongoing process consists of four analytically separate, but interconnected, phases. They are: caring about, taking care of, care-giving, and care-receiving. This process corresponds with specific moral skills and attitudes (Tronto, 1993, pp.105108).

Caring about involves the recognition in the first place that care is necessary. It involves noting the existence of a need and making an assessment that this need should be met. Caring about will often involve assuming the position of another person or group to recognize the need. Caring about presumes an attitude of attentiveness. Acts once done tend to sneak into caring activities and become habits, thereby losing sight of the real needs of the carereceiver. Attentive presence prevents caregivers from buying into what is so-called self-evident (Maeckelberghe, 2004, p.320).

Taking care of is the next step of the caring process. It involves assuming some responsibility for the identified need and determining how to respond to it. Rather than simply focusing on the need of the other person, taking care of involves the recognition that one can act to address these unmet needs. Taking care of involves notions of agency and responsibility in the caring process. Taking the responsibility in caring is the result of collective activities of different caregivers. Cooperation between different 
fields and power relations among caregivers may hinder the mapping of responsibilities (Maeckelberghe, 2004, p.320).

Care-giving involves the direct meeting of needs for care. It involves physical work, and almost always requires that caregivers come in contact with the objects of care. This phase is connected to the skill of competence. Sometimes the available resources to provide care are inadequate, making care inadequate. Or the work cannot be done competently when for example time is lacking (Maeckelberghe, 2004, p.321).

The final phase of caring recognizes that the object of care will respond to the care it receives. This phase is connected to the skill of responsiveness. It is important to include care-receiving as an element of the caring process because it provides the only way to know that caring needs have actually been met. Even if the perception of a need is correct, how the caregivers choose to meet the need can cause new problems. Being attentive to the responsiveness of the carereceiver demands being concerned with conditions of vulnerability and inequality. Analysis of the unequal distribution of power is a necessary element of a caring attitude (Maeckelberghe, 2004, p.321).

As Tronto (1993) further notes the four phases of care can serve as an ideal to describe an integrated, well-accomplished, act of care. Disruptions in this process are useful to analyze. Providing an integrated, holistic way to meet concrete needs is the ideal of care.

Given that people with intellectual disabilities are dependent and in need of support, ethics of care seems to be a relevant theoretical framework for studying ethical aspects of care for persons with Prader-Willi syndrome. Ethics of care not only provides a relevant theoretical framework, it also implies specific research methods. Whereas principlism takes a stance towards practice, judging it on the basis of the four principles, ethics of care presupposes that morality is developed in practices. Ethics of care therefore implies the need for empirical research of the practice under consideration.

\subsection{Research questions}

The ethics of care approach starts from studying moral experiences in practice. This stands in contrast with the traditional principle based approach to ethics, for the ethics of care approach doesn't start from a set of principles. Though the ethics of care approach contains several assumptions and ideas, it is more open, fed by the insights of practitioners. Central to this study is the care practice of parents and professional caregivers dealing with the prevention of obesity of persons with Prader-Willi syndrome. The main question is what good care means to these caregivers. This question will be answered by elucidating the moral values and considerations of caregivers in dealing with the prevention of obesity in persons with Prader-Willi syndrome. Furthermore, the study aims to clarify how caregivers realize these values in daily care practice. What care needs do individuals with the syndrome have and how do parents and professional caregivers in this practice meet these needs?

A second question concerns the relevance of the experiences of caregivers concerning the prevention of obesity in persons with Prader-Willi syndrome for ethics of care. Do their views on care and their caring practices support the theoretical notions and 
claims of ethics of care? Ethics of care contains normative notions, for example the notion of relational autonomy as positive freedom, and normative claims, such as the claim that engagement and dialogue are more important than letting the care-receiver decide for herself. Does the practice of care for persons with Prader-Willi syndrome exemplify these notions and does it show the relevance of these claims? How are these notions and claims specified in this specific care practice?

A third set of questions is related to the lessons for practice that can be derived from the empirical findings. What can be learned from examining caregivers' moral values and considerations, and from the way they intervene in managing the obesity prevention? Can insights in this specific care practice of preventive activities contribute to our way of approaching persons with intellectual disabilities? What are the implications for the current policy concerning people with intellectual disabilities, such as citizenship? What directions can we derive from the practice of prevention of obesity in people with Prader-Willi syndrome for practices of prevention in general? And finally, what can be learned from this study, which combines empirical research and ethical analysis, for the practice of empirical ethics? In what way do the various methods of empirical research, used in this study, contribute to empirical ethics as a relatively new discipline?

\subsection{Method}

To study the practice of the prevention of obesity in Prader-Willi syndrome in-depth qualitative interviews were conducted with 23 parents and 14 professional caregivers of 18 people with the syndrome. With the purpose of orientation and preparation several conversations were held with parents, professional caregivers and people with Prader-Willi syndrome. The interviews had an open character, following the stories told by the interviewees. Nevertheless a scheme was used with several themes and points for attention as a guideline for the interviews (see appendix A). The participants were interviewed about their views on the prevention of obesity as well as on the way in which they tried to manage the situation in everyday life. Caregivers often make moral considerations in daily practice in an implicit way. By using an open qualitative approach to look at the stories of caregivers about their experiences in daily care it is possible to make explicit these moral considerations and to elucidate the diversity and complexity of this practice.

Nine out of these 18 individuals with PWS lived at home and nine stayed in a group home. In the nine cases of those living at home, eight two-parent families were involved in eight interviews and in one case the interview was held with the mother only. In the nine cases of those living in a group home, in four cases only professional caregivers were interviewed, and in four cases both professionals as well as one parent (all mothers) were involved. In one case the interview was held with both parents while no professional caregiver was present. Of the eight cases in which professionals were involved, there were six cases in which two professional caregivers were interviewed and two cases in which one professional was interviewed. The ages of the 
persons with PWS living at home ranged from 8 to 17 years, and for those living in a group home ages ranged from 13 to 38 years.

The interviewees were contacted in cooperation with the Centre for Clinical Genetics in Maastricht, the Netherlands, and with the Prader-Willi / Angelman parent association. Interviewees were selected in such way to guarantee a balance in the geographical representation, and to guarantee a degree of diversity in age of the persons with Prader-Willi syndrome. Interviewees first received a letter by post, explaining briefly the contents of the research, mainly an explanation about the central dilemma of providing good care versus the wish to respect a person's autonomy. Also information was given about the amount of time participation would take. After the letter was sent, the selected persons were contacted by phone. None of the contacted participants refused to cooperate. The interviews were held at the family homes or in the group homes at a time that was chosen by the participants, mostly in the daytime. On average the interviews took about one hour and a half to two hours. With permission of the informants the interviews were audio-taped and the tapes were transcribed later. All transcripts were made anonymous to guarantee the privacy of the participants. When quotations from the interviews were used, these were anonymous to prevent recognition of individual participants.

A first analysis of the transcripts was made, for which the constant comparative method as described in Grounded Theory (Straus \& Corbin, 1990) was used. Interview fragments were coded, grouped and categorized. The object of using the Grounded Theory approach was to build a theoretical framework out of the data.

A second qualitative analysis was a narrative analysis of the interview transcripts as a whole. This analysis was a comparison of all cases as a whole with each other on a general level. For that purpose the interviews were coded. Codes were grouped, compared and categorized into themes. Aim of this analysis was to look at the differences between the cases in the way parents, professional caregivers and the persons with Prader-Willi syndrome communicated and what kind of attitudes were apparent.

On the basis of the narrative analysis of the interview data, a quantitative study was set up to proceed with the findings of the narrative analysis and explore the found options in that analysis further. In this quantitative study an operalisation of these options into intervention strategies was made and the preferences of caregivers for these strategies were studied.

Furthermore, an alternative approach to competence was outlined. On the basis of the insights of the qualitative study, two cases were constructed to illustrate the merits of this alternative approach.

The last part of this study was the development of a computer-tailored program for educative purposes. This program consists of two parts. The first part focuses on the moral values and considerations that play a role in the care for persons with PraderWilli syndrome. The results of the Grounded Theory analysis formed the basis for the construction of this first part. The second part focuses on the forms of interactions between caregiver and client. The results of the narrative analysis formed the basis for this part. 
The central case in this study is the practice of care for persons with Prader-Willi syndrome. To understand the complexity of this care practice, it is relevant to understand the complexity and diversity of the Prader-Willi syndrome. This syndrome consists of several main symptoms but a diverse set of other features may occur in persons with this syndrome. The variation among individuals in the occurrence and degree of symptoms contributes to the complexity of the care practice. Moreover, the essence of Prader-Willi syndrome is not only in the eating characteristics. Therefore, the complete clinical picture of this disorder is described in the following sections to get a view of all symptoms associated with this chromosomal condition.

\subsubsection{Introduction}

The association between the various symptoms of Prader-Willi syndrome was discovered and first described by three Swiss paediatricians (Prader, Labhart \& Willi, 1956). Only many years later the underlying genetic mechanism causing this syndrome became known when Ledbetter et al. (1981) found small deletions of paternal origin on the long arm of chromosome 15 at the genetic locus 15q11-13, which is the case in approximately $70 \%$ of all cases. This deletion is a de novo deletion, meaning that this deletion does not occur with one of both parents, but is a new change within the individual with PWS that occurs before or during conception. The majority of the remaining cases, $25-30 \%$, have a different genetic sub-type, a maternal uniparental disomy, which means they inherit two maternally derived chromosomes 15 but no paternal chromosome (Nicholls et al., 1989; 1998; Mascari et al., 1992; Cassidy et al., 1997). A small number of persons with PWS have other chromosomal abnormalities, such as mutations in the imprinting centre affecting paternal gene expression (Robinson et al., 1991; Buiting et al., 1995). The syndrome thus is caused by the absence of the paternal contribution in this region on chromosome 15. No single gene has yet been found to be causally associated with PWS. Although SNRPN is the strongest candidate gene, PWS is still generally considered to be a polygenic disorder, the result of the nonfunctioning of several genes (Whittington \& Holland, 2004, p.12).

Based on epidemiological data population prevalence estimates of Prader-Willi syndrome vary from 1 in 52,000 to 1 in 10,000 live born children (Burd et al., 1990; Åkefeldt et al., 1991; Whittington et al., 2001).

Studies indicate that the regulation of systems controlling growth, sexual development and eating behaviour are abnormal in a large majority of persons with PraderWilli syndrome, while those systems controlling birth processes, sleep, temperature and pain are abnormal in many with PWS but not all. All of these systems are regulated partially or wholly within the hypothalamus and it is generally agreed that some hypothalamic abnormality underlies the PWS phenotype (Whittington \& Holland, 2004). Swaab et al. (1995) studied oxytocin neurones in the nucleus paraventricularis $(\mathrm{PVN})$ of the hypothalamus. Studies revealed the satiating role these neurones play in the regulation of food-intake. Swaab et al. (1995) found a large decrease 
in the number of oxytocin-expressing neurones in the PVN and a strong reduction of the volume and total number of cells in the PVN in Prader-Willi subjects.

\subsubsection{Symptoms}

To improve the ability of clinicians to accurately diagnose the syndrome, several diagnostic criteria were developed by consensus of seven clinicians experienced with the syndrome in consultation with national and international experts. They were published in 1993 (Holm et al., 1993). The symptoms of Prader-Willi syndrome change dramatically with age (Cassidy, 1984). Infants and young children demonstrate fewer symptoms than older children and adults. Therefore, the scoring system varies depending on age. The younger group also shows other symptoms. In recent years, PWS has been increasingly regarded as a genetic syndrome, and the purpose of clinical diagnostic criteria has shifted from making a diagnosis to raising suspicion of a diagnosis of PWS (Boer, 2004, p.12).

First phase of life - hypotonia

During pregnancy mothers of Prader-Willi children often report reduced fetal activity. Profound hypotonia and poor muscle tone are characteristic in these neonates. The infant is floppy and cries weakly, is not alert and sleeps a lot. Feeding problems may occur in infancy due to a poor swallowing and sucking reflex with the need for special feeding techniques (gavage feeding or bottles with 'preemie' teats). The infant does not appear hungry and weight gain is slow. Feeding difficulties generally improve by the age of 6 months. Motor skills develop normally though with a delay. Motor milestones on average are twice as late than normal (sitting at 12-15 months, walking at 24-30 months; Borghgraef et al., 1990; Ehara et al., 1993).

Second phase of life - hyperphagia

From 12 to 18 months onward, the clinical picture changes dramatically. In contrast to the infancy period in which feeding is problematic, an uncontrollable hyperphagia now develops. The hypotonia decreases, the motor skills develop further (though with a delay) and the child sleeps less and becomes more alert. Hyperphagia - the excessive appetite and overeating - with a seemingly absence of a sense of satiation, and an obsession with food and eating together with food seeking behaviour is characteristic for children with PWS. The normal satiety response after eating is suggested to be impaired and delayed (Holland et al., 1993). In their study, Zipf and Berntson (1987) found that, when presented with a plate of sandwiches for 1 hour, the control group all finished eating after 15 minutes, whereas all but one in the PWS group continued to eat for much longer, in several cases for the whole hour. Holland et al. (1993) found similar results; the PWS group continued eating for longer and ate on average three times more calories in the hour. Lindgren et al. (2000) found that those with PWS showed nondecelerating eating curves, a slower eating rate and a longer duration of eating compared to both lean and obese children without PWS. It begins 
between the first and sixth year of life, with an average onset at age two (Butler, 1990). Food seeking behaviour problems include the raiding of garbage cans, shoplifting in food stores, and pilfering money at home and at school to buy food. In association with a disturbed energy metabolism (Mil et al., 2000a; b) this insatiable overeating behaviour can lead to extreme obesity with its negative consequences for health, such as scoliosis, respiratory and cardiac problems, hypertension, diabetes mellitus and sleep problems. Many experts emphasize the importance of early diagnosis to anticipate upon this second stage with adequate dietary management to prevent excessive or rapid weight gain (Greenswag \& Alexander, 1990). Because of the improvements in genetics and better quality of health care services, the diagnosis is now usually made within a year after birth, before the onset of the hyperphagia stage. People with PWS may have a reasonable life expectancy if obesity can be avoided (Carpenter, 1994). Cardiac failure and respiratory problems are amongst the most common cause of death (Schrander-Stumpel et al., 2004; Vogels et al., 2004).

This syndrome is associated with mild to moderate intellectual disabilities (Whittington et al., 2004). Many cases have intelligence levels in the borderline range (Curfs \& Fryns, 1992). Associated with these cognitive restrictions is a delay in speech and language development and a speech articulation defect such as hypernasal speech (Defloor et al., 2000; 2002).

Another main characteristic of Prader-Willi syndrome is hypogonadism, the underdevelopment of the sexual organs. In boys one or both testes are not descended, often accompanied by a flat, underdeveloped scrotum. Penile length is small compared to age norms. In girls the labia minora and clitoris may be underdeveloped. The maturation of the sexual organs is delayed or incomplete with delayed pubertal signs unless hormonal intervention is provided. For males this may result in small sexual organs, decreased facial and body hair and a lack of voice change. For females the breasts may be underdeveloped and a delayed onset of menstruation, or no onset at all. Infertility often occurs in both males and females (Lee, 1990; Müller, 1997; Crino et al., 2003). In the absence of growth hormone intervention, Prader-Willi syndrome is characterized by short stature; the average body length for males is $155 \mathrm{~cm}$ and for females $148 \mathrm{~cm}$ (Cassidy, 1997).

Physical characteristics in Prader-Willi syndrome include small hands with delicate and tapering fingers and small feet (acromicria) in most infants and adolescents. Hand and foot sizes correlate well with length, but not with age, and foot size tends to be lower than hand size. However, patients of normal height tend to have normally sized hands (Hudgins \& Cassidy, 1991). The face is characterized by a narrow bifrontal diameter, almond-shaped eyes, strabismus, full cheeks, and diminished mimic activity due to muscular hypotonia. Furthermore, the presence of thick viscous saliva can often be observed which tends to crust at the corners of the mouth and often covers the teeth (Cassidy, 1984). Caries are also a well-known phenomenon.

Frequently parents and caretakers notice that people with PWS seem to have a surprisingly high tolerance for pain. A high threshold for vomiting is another peculiar and unexplained observation in many individuals with PWS. When the whole family has gastroenteritis, the person with PWS may get diarrhoea but may not vomit (Holm 
et al., 1993). Physicians should be aware of these observations for they complicate the assessment of illness.

Excessive daytime sleeping frequently occurs in older children and adults with PWS. Sleep apnoea and disturbances in REM-sleep have been described. In some individuals, these symptoms abate with weight loss, although they persist in most (VelaBueno et al., 1984; Helbing-Zwanenburg et al., 1993; Holm et al., 1993;).

Behavioural profile

In addition to the unremitting food-seeking behaviour, persons with PWS show emotional and behavioural difficulties that are not related to food. Studies show a characteristic behavioural profile including frequent and severe temper tantrums, stubbornness, argumentativeness, self-injury (skin-picking) and psychotic disorders (Holm et al., 1993; Clarke et al., 1996; Verhoeven et al., 1998; 2003; Boer et al., 2002; Holland et al., 2003; Soni et al., 2007). Furthermore, PWS features a number of compulsive-like behaviours (both food- and non-food related) including hoarding of non-food items, concerns with ordering, sameness in daily routine, repetitive questioning, the need to tell or ask something, and associations have been suggested with an obsessivecompulsive disorder (OCD) (Dykens et al., 1996; State et al., 1999; Clarke et al., 2002). Though Dykens et al. (1996) concluded that increased risks of OCD are strongly indicated in people with PWS, their study as well as more recent studies show that PWS is mainly associated with compulsive behaviours, compared to persons with PraderWilli-like features (State et al., 1999) and compared to persons with similar cognitive impairments and high body mass indices (Clarke et al., 2002). Only very few obsessional thoughts were found. PWS compulsivity thus seems to differ from the typical clinical OCD picture. Clarke et al. (2002) conclude that it seems likely that the compulsive behaviours associated with PWS are similar to the compulsions seen in early childhood in children without developmental disabilities. Moreover, compulsive and self-mutilating behaviours in PWS probably begin at an earlier age than in OCD (Dimitropoulos et al., 2001; Wigren \& Heimann, 2001) and do not subside with age in adolescents (Wigren \& Hansen, 2003).

\subsection{Outline of the thesis}

Chapter two describes a first analysis of the transcripts. The constant comparative method is used as described in Grounded Theory. This analysis results in a theoretical framework, existing of three layers: values, conditions and interventions. Firstly, a number of values are described that caregivers saw as important and that motivated them in their behaviour towards the child or client. Secondly, conditions are presented that caregivers said interfered with, or enhanced, these values. These conditions reflect social contexts and situations. Thirdly, interventions are identified that caregivers apply to realize these values.

The third chapter describes the findings of a narrative analysis of the interview transcripts. Aim of this analysis is to look at the differences between the cases concerning 
the way in which parents and professional caregivers interact with the persons with Prader-Willi syndrome. In this chapter various interaction options are discussed.

Chapter four describes the results of an operationalisation of the interaction options, described in chapter three, into intervention strategies and presents an analysis of the preferences of caregivers for these strategies.

In chapter five the concept of competence is investigated. Current ethical approaches to the concept of competence tend to emphasize cognitive capacities. In this chapter an alternative view of competence is presented and elaborated upon.

In this study, empirical data were used to develop or adjust ethical theories. More and more ethics projects study specific care practices with the objective to explicate moral rules and convictions, intrinsic to these practices. Chapter six evaluates this empirical approach. Since both a qualitative and a quantitative approach have been chosen in this study to gather data, both approaches are compared and differences between them are discussed.

The findings of scientific research often do not reach persons in practice. Papers are written for scientific journals, but these journals are mostly read by (other) scientists. Chapter seven presents a computer-tailored program, which aims to educate parents and professional caregivers. The program was developed on the basis of the findings of the present study.

The last chapter discusses the broader implications of the findings of this study. Recommendations are given for future research. 


\section{Notes}

1 In this dissertation the use of the concept 'disability' was chosen, which was also the choice of IASSID, the International Association for the Scientific Study of Intellectual Disabilities. Besides 'disability' sometimes the concept 'restriction' is used. As Van Gennep (2000) points out, in the concept 'restriction' the problems of the individual are emphasized; in the concept 'disability' the emphasis is on the problems that an individual experiences in participating in society and which are mainly caused by societal factors. Intellectual disability is conceived as a societal problem and not as an individual problem.

The use of the adjective 'intellectual' was chosen to refer only to the cognitive capacities instead of 'mental' that can be broader and generally refers to psychic problems like depression. Often the term 'learning disabilities' is also used for this population (mostly in the UK) but this term may be associated more generally to school problems.

2 In this dissertation the term 'health care ethics' will be used to refer to the broadened field of ethics, that nowadays not merely studies ethical issues in medicine but more generally in health care. Besides the term 'health care ethics', that is preferred in Europe, other terms are used simultaneously to refer to this broadened field like 'health ethics' (also in Europe) and 'bio-ethics' (predominantly in NorthAmerica).

3 Their first edition of Principles of Biomedical Ethics was issued in 1979; in 2001 Beauchamp and Childress published the most recent fifth edition.

4 According to Gillon (2003) the emphasis on respect for autonomy is in many circumstances morally desirable. Furthermore, he elaborates why he is inclined to see respect for autonomy as primus inter pares -first among equals- among the four principles.

5 For a more elaborate analysis of the philosophical and ethical perspectives on autonomy, see M. Schermer (2002). The different faces of autonomy: patient autonomy in ethical theory and hospital practice. Kluwer Academic Publishers, Dordrecht. 


\section{References}

Agich G. (1993). Autonomy and long-term care. Oxford University Press, New York.

Åkefeldt, A., Gillberg, C., \& Larsson, C. (1991). Prader-Willi syndrome in a Swedish rural country: Epidemiological aspects. Developmental Medicine and Child Neurology, 33, 715-21.

Beauchamp, T.L., \& Childress, J.F. (2001). Principles of biomedical ethics (5th edition). Oxford University Press, New York / Oxford.

Berlin, I. (1969). Four essays on liberty. Oxford University Press, Oxford.

Boer, H. (2004). Behavioural studies in Prader-Willi syndrome. Maastricht University Press, Maastricht.

Boer, H., Holland, A., Whittington, J., Butler, J., Webb, T., \& Clarke, D. (2002). Psychotic illness in people with Prader-Willi syndrome due to chromosome 15 maternal uniparental disomy. Lancet, 359, 135-6.

Borghgraef, M., Fryns, J.P., \& Van den Berghe, H. (1990). Psychological profile and behavioral characteristics in 12 patients with Prader-Willi syndrome. Genetic Counseling, 38, 141-50.

Bortel, P. van (2004). Het geweld van laatste woorden. Filosofie in de marge van de gezondheidsethiek [The violence of last words. Philosophy on the margin of health care ethics]. SUN, Amsterdam.

Buiting, K., Saitoh, S., Gross, S., Dittrich, B., Schwartz, S., Nicholls, R.D., \& Horsthemke, B. (1995). Inherited microdeletions in the Angelman and Prader-Willi syndromes define an imprinting centre on human chromosome 15. Nature Genetics, 9, 395-400.

Burd, L., Vesely, B., Martsolf, J., \& Kerbeshian, J. (1990). Prevalence study of Prader-Willi syndrome in North-Dakota. American Journal of Medical Genetics, 37, 97-9.

Butler, M.G. (1990). Prader-Willi syndrome: current understanding of cause and diagnosis. American Journal of Medical Genetics, 35, 319-32.

Carpenter, P.K. (1994). Prader-Willi syndrome in old age. Journal of Intellectual Disability Research, $38,529-31$.

Cassidy, S.B. (1984). Prader-Willi syndrome. Current Problems in Pediatrics, 14, 1-55.

Cassidy, S.B. (1997). Prader-Willi syndrome. Journal of Medical Genetics, 34, 917-23.

Cassidy, S.B., Forsythe, M., Heeger, S., Nicholls, R.D., Schork, N., Benn, P., \& Schwartz, S. (1997). Comparison of phenotype between patients with Prader-Willi syndrome due to deletion $15 q$ and uniparental disomy 15. American Journal of Medical Genetics, 68, 433-40.

Clarke, D.J., Boer, H., Chung, M.C., Sturmey, P., \& Webb, T. (1996). Maladaptive behaviour in Prader-Willi syndrome in adult life. Journal of Intellectual Disability Research, 40(2), 159-65.

Clarke, D.J., Boer, H., Whittington, J., Holland, A., Butler, J., \& Webb, T. (2002). Prader-Willi syndrome, compulsive and ritualistic behaviours: the first population-based survey. British Journal of Psychiatry, 180, 358-62.

Crinò, A., Schiaffini, R., Ciampalini, P., Spera, S., Beccaria, L., Benzi, F., Bosio, L., Corrias, A., Gargantini, L., Salvatoni, A., Tonini, G., Trifirò, G., \& Livieri, C. (2003). Hypogonadism and pubertal development in Prader-Willi syndrome. European Journal of Pediatrics, 162, 327-33.

Curfs L.M.G., \& Fryns, J.P. (1992) Prader-Willi syndrome: A review with special attention to the cognitive and behavioral profile. Birth Defects: Original Articles Series, 28, 99-104.

Defloor, T., Borsel, J. van, Curfs, L. (2000). Speech fluency in Prader-Willi syndrome. Journal of Fluency Disorders, 25, 85-98.

Defloor, T., Borsel, J. van, Curfs, L. (2002). Articulation in Prader-Willi syndrome. Journal of Communication Disorders, 35, 261-82.

Dimitropoulos, A., Feurer, I.D., Butler, M.D., \& Thompson, T. (2001). Emergence of compulsive behavior and tantrums in children with Prader-Willi syndrome. American Journal on Mental Retardation, 106, 39-51. 
Dykens, E.M., Goff, B.J., Hodapp, R.M., Davis, L., Devanzo, P., Moss, F., Halliday, J., Shah, B., State, M. \& King, B. (1997) Eating themselves to death: Have "personal rights" gone too far in treating people with Prader-Willi syndrome? Mental Retardation, 35(4), 312-14.

Dykens, E.M., Leckman, J.F., \& Cassidy, S.B. (1996). Obsessions and compulsions in Prader-Willi syndrome. Journal of Child Psychology and Psychiatry, 37, 995-1002.

Ehara, H., Ohno, K., \& Takeshita, K. (1993). Growth and developmental patterns in Prader-Willi syndrome. Journal of Intellectual Disability Research, 37, 479-85.

Ericsson, K. (1996). Housing for the person with intellectual handicap. In J. Mansell \& K. Ericsson (Eds.), Deinstitutionalization and community living: Intellectual disability services in Britain, Scandinavia and the USA. Chapman and Hall, London.

Gennep, A. van (1997). Quality of community living in the Netherlands. The British Journal of Developmental Disabilities, 43(84), 1-14.

Gennep, A. van (2000). Emancipatie van de zwaksten in de samenleving. Over paradigma's van verstandelijke handicap. [Emancipation of the weakest in society. About paradigms of intellectual disability]. Boom, Amsterdam.

Gilligan, C. (1982). In a different voice: Psychological theory and women's development. Harvard University Press, Cambridge.

Gillon, R. (2003). Ethics needs principles -four can encompass the rest- and respect for autonomy should be "the first among equals". Journal of Medical Ethics, 29, 307-12.

Graste, J. (2000). Een perspectief op zorgethiek. In: J. Graste \& D. Bauduin (Eds.), Waardenvol werk. Ethiek in de geestelijke gezondheidszorg [Work of value. Ethics in mental health care], pp. 20-31. Van Gorcum, Assen.

Greenswag, L.R., \& Alexander, L.C. (1990). Management of Prader-Willi syndrome (2 ${ }^{\text {nd }}$ Edition). Springer-Verlag, New York.

Have, H.A.M.J. ten, Meulen, R.H.J. ter, \& Leeuwen, E. van (2003). Medische ethiek [Medical ethics] (2nd edition). Bohn Stafleu Van Loghum, Houten.

Helbing-Zwanenburg, B., Kamphuisen, H.A.C., \& Mourtazaev, M.S. (1993). The origin of excessive daytime sleepiness characteristics in the Prader-Willi syndrome. Journal of Intellectual Disability Research, 37, 533-41.

Holland, A.J., Treasure, J., Coskeran, P., Dallow, J., Milton, N., Hillhouse, E. (1993). Measurement of excessive appetite and metabolic changes in Prader-Willi syndrome. International Journal of Obesity, 17, 527-32.

Holland, A.J., Whittington, J.E., Butler, J., Webb, T., Boer, H., \& Clarke, D. (2003). Behavioural phenotypes associated with specific genetic disorders: evidence from a population-based study of people with Prader-Willi syndrome. Psychological Medicine, 33, 141-53.

Holland, A.J., \& Wong, J. (1999). Genetically determined obesity in Prader-Willi syndrome: the ethics and legality of treatment. Journal of Medical Ethics, 25, 230-236.

Holm, V.A., Cassidy, S.B., Butler, M.G., Hanchett, J.M., Greenswag, L.R., Whitman, B.Y., \& Greenberg, F. (1993) Prader-Willi syndrome: consensus diagnostic criteria. Pediatrics, 91, 398-402.

Hudgins, L., \& Cassidy, S.B. (1991). Hand and foot length in Prader-Willi syndrome. American Journal of Medical Genetics, 41, 5-9.

Ledbetter, D.H., Riccardi, V.M., Airhart, S.D., Strobel, R.J., Keenan, B.S., \& Crawford, J.D. (1981). Deletion of chromosome 15 as a cause of Prader-Willi syndrome. New England Journal of Medicine, 292, 63-6.

Lee, P.D.K. (1990). Endocrine and metabolic aspects of Prader-Willi syndrome. In: L.R. Greenswag \& R.C. Alexander (Eds.), Management of Prader-Willi syndrome, $2^{\text {nd }}$ Edition, pp. 32-57. Springer-Verlag, New York.

Lindgren, A.C., Barkeling, B., Hagg, A., Ritzen, E.M., Marcus, C., \& Rossner, S. (2000). Eating behavior in Prader-Willi syndrome, normal weight, and obese control groups. Journal of Pediatrics, 137, 50-55. 
Mackenzie C. \& Stoljar N. (eds.) (2000). Feminist Perspectives on Autonomy, Agency, and the Social Self, pp. 3-31.Oxford University Press, New York and Oxford.

Macklin, R. (2003). Applying the four principles. Journal of Medical Ethics, 29, 275-80.

Mans, I. (1998). Zin der zotheid. [Sense of folly, a cultural history of fools, innocents and mentally retarded people.] Bakker, Amsterdam.

Mascari, M.J., Gottlieb, W., Rogan, P.K., Butler, M.G., Waller, D.A., Armour, J.A.L., Jeffreys, A.J., Ladda, R.L., \& Nicholls, R.D. (1992). The frequence of uniparental disomy in Prader-Willi syndrome. New England Journal of Medicine, 326, 1599-1607.

Maeckelberghe, E. (2004). Feminist ethic of care: A third alternative approach. Health Care Analysis, 12, 317-27.

Meininger, H.P. (2002). Zorgen met zin. Ethische beschouwingen over zorg voor mensen met een verstandelijke handicap [Care with meaning. Ethical considerations about care for persons with intellectual disability]. SWP, Amsterdam.

Mil, E.G. van, Westerterp, K.R., Kester, A.D., Curfs, L.M., Gerver, W.J., Schrander-Stumpel, C.T., \& Saris, W.H. (2000a). Activity related energy expenditure in children and adolescents with Prader-Willi syndrome. International Journal of Obesity, 24, 429-34.

Mil, E.A. van, Westerterp, K.R., Gerver, W.J., Curfs, L.M., Schrander-Stumpel, C.T., Kester, A.D., \& Saris, W.H. (2000b). Energy expenditure at rest and during sleep in children with PraderWilli syndrome is explained by body composition. American Journal of Clinical Nutrition, 71, $752-6$.

Moody, H.R. (1992). Ethics in an aging society. John Hopkins University Press, Baltimore.

Müller, J. (1997). Hypogonadism and endocrine metabolic disorders in Prader-Willi syndrome. Acta Paediatrica Supplement, 423, 58-59.

Nicholls, R.D., Knoll, J.H., Butler, M.G., Karam, S., \& Lalande, M. (1989). Genetic imprinting suggested by maternal heterodisomy in nondeletion Prader-Willi syndrome. Nature, 342, 281-5.

Nicholls, R.D., Saitoh, S., Horsthemke, B. (1998). Imprinting in Prader-Willi and Angelman syndromes. Trends in Genetics, 14, 194-200.

Nirje, B. (1976). The normalization principle. In: R.B. Kugel \& A. Shearer (Eds.), Changing patterns in residential services for the mentally retarded. The President's Committee on Mental Retardation, Washington DC.

Nirje, B. (1992). The normalisation principle papers. Centre for Handicap Research, Uppsala.

Prader, A., Labhart, A., \& Willi, H. (1956). Ein Syndrom von Adipositas, Kleinwuchs, Kryptorchismus und Oligophrenie nach myatonieartigem Zustand im Neugeborenalter. Schweizerische Medizinische Wochenschrift, 86, 1260-1.

Reinders, J.S. (2000). Ethiek in de zorg voor mensen met een verstandelijke handicap [Ethics in the care for persons with an intellectual disability]. Boom, Amsterdam.

Richardson, H. (1990). Specifying norms as a way to resolve concrete ethical problems. Philosophy and Public Affairs, 19, 279-310.

Richardson, H. (2000). Specifying, balancing, and interpreting bioethical principles. Journal of Medicine and Philosophy, 25, 285-307.

Robinson, W.P., Bottam, A., Yagang, X., Balakrishnan, J., Binkert, F., Machler, M., Prader, A., \& Schinzel, A. (1991). Molecular, cytogenetic and clinical investigations of Prader-Willi syndrome patients. American Journal of Human Genetics, 49, 1219-34.

Schrander-Stumpel, C.Th.R.M., Curfs, L.M.G., Sastrowijto, P., Cassidy, S.B., Schrander, J.J.P., \& Fryns, J.P. (2004). Prader-Willi syndrome: Causes of death in an international series of 27 cases. American Journal of Medical Genetics, 124, 333-8.

Soni, S., Whittington, J., Holland, A.J., Webb, T., Maina, E., Boer, H., \& Clarke, D. (2007). The course and outcome of psychiatric illness in people with Prader-Willi syndrome: implications for management and treatment. Journal of Intellectual Disability Research, 51, 32-42. 
State, M.W., Dykens, E.M., Rosner, B., Martin, A., \& King, B.H. (1999). Obsessive-compulsive symptoms in Prader-Willi and "Prader-Willi-like" patients. Journal of the American Academy of Child and Adolescent Psychiatry, 38(3), 329-34.

Straus, A., \& Corbin, J. (1990). Basics of qualitative research: grounded theory procedures and techniques. Sage, Newbury Park.

Sullivan, M. (2003). The new subjective medicine: taking the patient's point of view on health care and health. Social Science \& Medicine, 56, 1595-1604.

Swaab D.F., Purba J.S. \& Hofman M.A. (1995). Alterations in the hypothalamic paraventricular nucleus and its oxytocin neurons (putative satiety cells) in Prader-Willi syndrome: a study of five cases. Journal of Clinical Endocrinology and Metabolism, 80, 573-9.

Tronto, J. (1993). Moral boundaries. A political argument for an ethic of care. Routledge, New York.

Vela-Bueno, A., Kales, A., Soldatos, C.R., Dobladex-Blanco, B., Campos-Costello, J., EspinoHurtado, P., \& Olivan-Palacios, J. (1984). Sleep in the Prader-Willi syndrome. Clinical and polygraphic findings. Archives of Neurology, 41, 294-6.

Verhoeven, W.M.A., Curfs, L.M.G., \& Tuinier, S. (1998). Prader-Willi syndrome and cycloid psychoses. Journal of Intellectual Disability Research, 42, 455-62.

Verhoeven, W.M.A., Tuinier, S., \& Curfs, L.M.G. (2003). Prader-Willi syndrome: The psychopathological phenotype in uniparental disomy. Journal of Medical Genetics, 40(10), e112.

Verkerk, M. (1999). A care perspective on coercion and autonomy. Bioethics, 13, 358-68.

Vogels, A., Ende, J. van den, Keymolen, K., Mortier, G., Devriendt, K., Legius, E., \& Fryns, J.P. (2004). Minimum prevalence, birth incidence and cause of death for Prader-Willi syndrome in Flanders. European Journal of Human Genetics, 12, 238-40.

Walker, M.U. (1998). Moral understandings: A feminist study in ethics. Routledge, New York.

Wear, S. (1993). Informed consent. Patient autonomy and clinician beneficence within health care. Georgetown University Press, Washington DC.

Whittington, J., \& Holland, A. (2004). Prader-Willi syndrome: Development and manifestation. Cambridge University Press, Cambridge.

Whittington, J., Holland, A., Webb, T., Butler, J., Clarke, D., \& Boer, H. (2001). Population prevalence and estimated birth incidence and mortality rate for people with Prader-Willi syndrome in one UK Health Region. Journal of Medical Genetics, 38, 792-8.

Whittington, J., Holland, A., Webb, T., Butler, J., Clarke, D., \& Boer, H. (2004). Cognitive abilities and genotype in a population-based sample of people with Prader-Willi syndrome. Journal of Intellectual Disability Research, 48, 172-87.

Wigren, M., \& Hansen, S. (2003). Rituals and compulsivity in Prader-Willi syndrome: profile and stability. Journal of Intellectual Disability Research, 47(6), 428-38.

Wigren, M., \& Heimann, M. (2001). Excessive picking in Prader-Willi syndrome: a pilot study of phenomenological aspects and comorbid symptoms. International Journal of Disability, Development and Education, 48, 129-42.

Widdershoven, G. (2000). Ethiek in de kliniek: Hedendaagse benaderingen in de gezondheidsethiek [Ethics in the clinic: Contemporary approaches in health care ethics]. Boom, Amsterdam.

Widdershoven, G.A.M. (2002). Alternatives to principlism: Phenomenology, deconstruction, hermeneutics. In K. Fulford, D. Dickenson, \& T. Murray (Eds.), Healthcare ethics and human values (pp. 41-8). Blackwell Publishers, Malden, Mass.

Widdershoven, G.A.M., \& Berghmans, R.L.P. (2007). Coercion and pressure in psychiatry: lessons from Ulysses. Journal of Medical Ethics, 33, 560-563.

Wolfensberger, W. (1992). Normalisation: The principle of normalisation in human services. National Institute on Mental Retardation, Toronto.

Zipf, W.B., \& Berntson, G.G. (1987). Characteristics of abnormal food-intake patterns in children with Prader-Willi syndrome and study of effects of naloxone. American Journal of Clinical Nutrition, 46, 277-81. 



\title{
CHAPTER 2
}

\author{
VALUES IN THE CARE FOR YOUNG PERSONS WITH PRADER-WILLI \\ SYNDROME: CREATING A MEANINGFUL LIFE TOGETHER
}

This chapter appeared as: Hooren, R.H. van, Widdershoven, G.A.M., Bruggen, H. van der, Borne, H.W. van den, Curfs, L.M.G. (2005). Values in the care for young persons with Prader-Willi syndrome: creating a meaningful life together. Child: Care, Health and Development, 31, 309-19. 


\begin{abstract}
Background. Caregivers sometimes feel frustrated by present-day emphasis on selfdetermination in the care for individuals with an intellectual disability. They are confronted with situations in which there is a conflict between providing high-quality care and respecting the client's autonomy. Such conflicts are prominent in the care for people with Prader-Willi syndrome. This condition is characterized by overeating behaviour which frequently leads to serious obesity. The central question in the present study is how persons involved, parents and professional caregivers, deal with the problems of the prevention of obesity in young individuals with Prader-Willi syndrome in everyday life.

Method. In-depth qualitative interviews were conducted with 23 parents and 14 professional caregivers of 18 persons with Prader-Willi syndrome. The interview data were analysed using the constant comparative method as described in grounded theory.

Results. On the basis of analysis of the interviews four values emerge that parents and professional caregivers indicate as relevant and directive to their acting towards the child or the client: physical health, well-being, freedom and responsibility, and a liveable life. Furthermore, caregivers mentioned several enabling and limiting conditions that influence these values. And they named several interventions they use to realize the values.

Conclusion. Of importance is the question how to create life in such a way that it is acceptable and meaningful for everybody involved. By building up a relationship to which acceptance and trust are central, a certain amount of independence and responsibility can be promoted. By creating trust it is possible to deal with rules in a less rigid way and to look where there is room for choices.
\end{abstract}


In the past years the care for individuals with an intellectual disability has developed into a deinstitutionalised, demand-based support system (Tøssebro et al., 1996). Freedom of choice, self-determination, and own responsibility of persons with an intellectual disability are emphasized. On the one hand, the enhancement of these values can be seen as a positive development, on the other hand it may involve certain problems. To our experiences caregivers sometimes feel frustrated by the emphasis on selfdetermination. They are confronted with situations in which there is a conflict between providing high-quality care and respecting the client's autonomy. It is not always easy to decide what to do when wishes and interests conflict with one another. Should one respect the autonomy of the intellectually disabled person or should one protect them against the adverse consequences of their choices?

Such conflicts are very prominent in the care for people with Prader-Willi syndrome (PWS). This genetic disorder is associated with a mild to moderate intellectual disability (Whittington et al., 2004). A prominent feature in Prader-Willi syndrome is an excessive appetite, frequently associated with overeating behaviour. The normal satiety response is suggested to be impaired and delayed (Holland et al., 1993), possibly caused by a hypothalamic dysfunction (Swaab et al., 1995). This overeating behaviour frequently leads to obesity, which can be severe and lead to serious health problems. How should parents and professional caregivers deal with this situation? Is it a violation of clients rights if caregivers lock up food, restrict clients social contacts and limit their expenditures for the sake of their health and quality of life, given the situation that many Prader-Willi youngsters have a relatively mild intellectual disability (Dykens et al., 1997)? Analysis of the literature shows that the discussion on this issue is quite black-and-white. It seems as though health and autonomy are the only values which matter, and that one has to choose between the two. Given the physiological basis of overeating behaviour, the capacity to make decisions may be lacking, which suggests that autonomy should not prevail (Holland \& Wong, 1999). In a previous article (Van Hooren et al., 2002) we argued that there can be room for interventions other than leaving the choice to the individual with Prader-Willi syndrome or taking over the decision. We found interventions in which parents and staff tried to promote the person's autonomy, not by giving freedom of choice, but by fostering selfunderstanding and self-development. In this article we will extend our analysis, by focusing on the values of parents and professional caregivers. Are they only interested in health and autonomy, or are there also other important aims in dealing with people with Prader-Willi syndrome? What strategies do caregivers develop in order to achieve central values?

\section{$2.2 \quad$ Method}

To gain an insight in the values underlying the practice of care, in-depth qualitative interviews were conducted with 23 parents and 14 professional caregivers of 18 persons with Prader-Willi syndrome. Nine out of these 18 individuals with PWS lived at 
home and nine stayed in a group home. In the nine cases of those living at home, eight two-parent families were involved in eight interviews and in one case the interview was held with the mother only. In the nine cases of those living in a group home, in four cases only professional caregivers were interviewed, and in four cases both professionals as well as one parent (all mother) were involved. In one case the interview was held with both parents while no professional caregiver was present. Of the eight cases in which professionals were involved, there were six cases in which two professional caregivers were interviewed and two cases in which one professional was interviewed. The ages of the persons with PWS living at home ranged from 8 to 17 years, and for those living in a group home ages ranged from 13 to 38 years.

The interviewees were contacted in cooperation with the Centre for Clinical Genetics in Maastricht, the Netherlands, and with the Prader-Willi / Angelman parent association. Interviewees were selected in such way to guarantee a balance in the geographical representation, and to guarantee a degree of diversity in age of the persons with Prader-Willi syndrome. Interviewees first received a letter by post, explaining briefly the contents of the research, mainly an explanation about the central dilemma of providing good care versus the wish to respect a person's autonomy. Also information was given about the amount of time participation would take. After the letter was sent, the selected persons were contacted by phone. None of the contacted participants refused to cooperate. With permission of the informants the interviews were audio-taped and the tapes were transcribed later. In the present paper quotations out of the transcripts, which are fragments of spoken language, were translated by the first author. The translation was done as close as possible to the literal words of the interviewees.

The interview data were analysed using the constant comparative method as described in grounded theory (Strauss \& Corbin, 1990) with the object of concept and theory development. Interviews were coded. Codes were grouped, compared, and categorized into concepts. Analysis of the interviews by means of this coding resulted in a theoretical framework, that exists of three layers; values, conditions and interventions (see figure 1). Firstly, a number of values were found, indicating what caregivers saw as important and which motivated them in their behaviour towards the child or client. These values are outlined in this paper and are elucidated with quotations from the interviews. Secondly, conditions are discussed that interfered with, or that enhanced these values. These conditions reflect social contexts and situations. Thirdly, interventions are presented that were applied by caregivers to realize these values. In figure 1 an overview is given of this theoretical framework, in which arrows show the direct connections between elements of the three layers. These direct relations will be explained in the results section. 


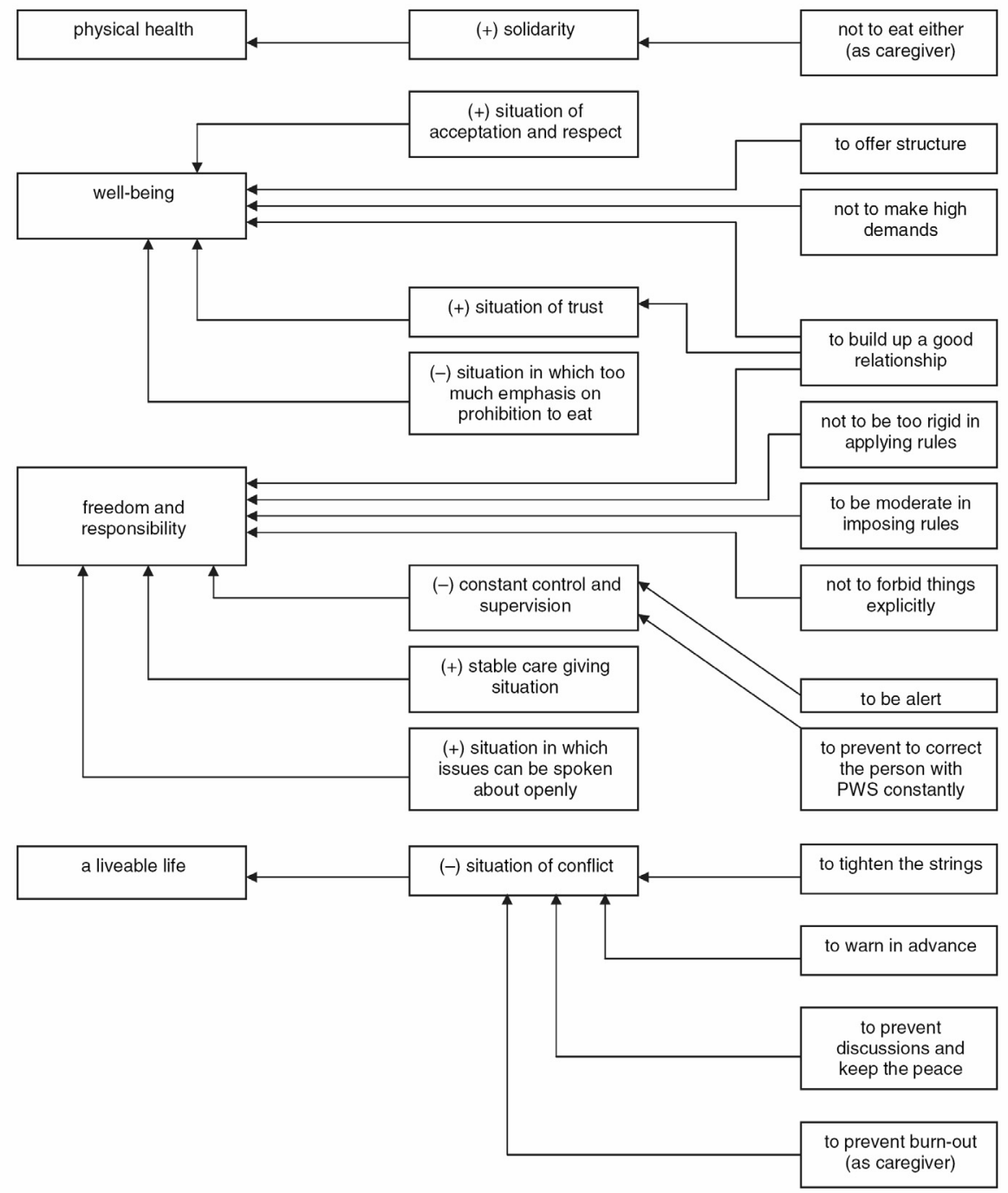

Figure 1. Theoretical framework. PWS, Prader-Willi syndrome. 
To establish the different aspects of trustworthiness several techniques were used (Lincoln \& Guba, 1985). The activities in the field that increased the probability of high credibility were prolonged engagement and persistent observation. During analysis peer debriefing was used, a review process in cooperation with colleagues and experts with experiences in Grounded Theory, health ethics and Prader-Willi syndrome. By means of thick description transferability was established. On a regular base dependability audit meetings were effectuated to guarantee the dependability of the different steps in the research process. Also regularly confirmability audit meetings were held to guarantee the confirmability of the data. These meetings also were held with the experts. They read the transcripts of the interviews and checked the coding, categorization and interpretations of the data. The checks in these meetings only resulted in small adjustments in each step of the process. The discussions with the experts resulted in the construction of a three layer framework; a division into values, conditions and interventions.

\section{$2.3 \quad$ Values}

On the basis of analysis of the interviews four values emerge that parents and professional caregivers indicate as relevant and motivating their acting towards the child or the client.

\section{Physical health}

One of the most important issues for parents and professionals is the health of the child or client. Primarily this means that they try to keep the body weight in balance. This is to prevent the person from becoming excessively obese with the consequence of hardly being able to move anymore. Caregivers try to establish that the child is able to be actively involved in sports like swimming, to promote the physical health and condition. The aim is also to prevent the occurrence of physical problems like scoliosis and pain in the ankles.

Mother: "She is getting so obese, that she soon will not be able anymore to walk. That her back will be bent. Personally, I say she can be obese. Because she can't help it. I don't think it is beautiful, but she does not need to be thin for me because that is more beautiful. But because she is able to move better, to run, to swim. And I would regret it if she became so obese she could hardly move anymore. In the apartment next to hers lives a person with Prader-Willi syndrome, who mostly sits crooked on her chair. She is a little fat tub. Then I think, I don't want that. Because you don't need to limit things anymore. Then she is restricted, she cannot do anything anymore. She cannot do horse-riding anymore, which she likes a lot." 
Well-being

Apart from physical health, well-being is an important value that caregivers aim for. According to parents, well-being is related to feeling pleasant and being comfortable. Professional caregivers speak in terms of quality of life.

Father: And she really is a typical Prader-Willi child. If she feels fine, then she is easier to get on with, then she is much more pleasant. Then you can see, she feels comfortable with herself. And that is something we want to keep up to as long as possible, until it goes wrong.

Though obesity needs to be prevented, this is not always the most relevant thing. Sometimes well-being is seen as more important than good health.

Pedagogue: He is like he is, with a certain overweight. And let that boy be happy with that. And let us at least create his environment in such a way that he can be happy in it. Well, that is to my opinion an important starting point. [...] We look at the quality of life he is having now. What are you doing when you go into that? What kind of quality are we then talking about?

Freedom and responsibility

Despite the syndrome and its limitations, caregivers indicate that there should be a certain amount of freedom and space for the child or client.

Pedagogue: When she just started with her diet, she was very preoccupied with the question whether she still had something to choose. That is so important, even if it is only the colour of the jam, doesn't matter what. But just the idea that she has nothing to choose anymore, that is the issue. To let people have some freedom of choice, you should do your best to see where they do have it.

Parents and caregivers suggest that the child should be able to take a certain amount of responsibility for its own health, next to the responsibility that parents and caregivers have.

Mother: We try as much as possible to stimulate her own responsibility. For example, she needs to do her homework herself, we don't go after that. By stimulating her own responsibility in all these other domains, so that she gets the feeling being trusted, we try to achieve that she is able to deal with food in a better way. 
A liveable life

Next to the well-being of the child or client, also the well-being of other members in the family or other residents in the group home is relevant. The problem behaviour of the person with PWS can be a burden to other members of the primary social environment as well. Efforts of parents and professional caregivers are aimed at maintaining the situation as manageable as possible by keeping the peace in the home or in the family. Also relevant is self-protection of parents and professionals. They try to avoid becoming burnt-out by the situation.

Interviewer: When she still was living at home, was the situation still fairly bearable, under control?

Father: Well, actually not. Especially not in the last year. That was also the reason why we said "this can't go on like that". It was because of the pressure she exerts by her way of acting. It is in her character. As long as everything goes the way she wants it. And she will do anything to get what she wants, until we say "that is enough". But before we get so far to say that, then we are also already across the limit. And then we can block it, but already so much has happened then. And then we said, this is at the expense of ourselves, of our health, of our relationship.

\subsection{Enabling and limiting conditions}

Several conditions may foster or hinder the realization of different values. These conditions are frequently related to the social context.

\section{Conditions influencing health}

A health promoting condition for clients is an atmosphere of solidarity among the family or group in which the client lives. When others don't eat, it is easier for the person with PWS not to eat itself.

Father: It was often the case that she was not allowed to eat, so we didn't do that either. That we also did sometimes when there were birthdays. Just that one of the two of us didn't do that either, that you show some solidarity. That makes it easier for her of course, when the other doesn't do it [eat] either.

\section{Conditions influencing well-being}

With regard to well-being, parents and professional caregivers mention two conditions. A condition which is perceived to promote well-being is a situation in which the child or client feels accepted and respected. 
Mother: That is also a kind of acceptance of the child. That you accept him like he is, with that overweight.

Another condition which parents and professionals consider to be conducive for wellbeing is a situation of mutual trust. In such a situation rules need not be followed too rigidly and there is room for comfort and quality of life.

Pedagogue: Caregivers that are close to her really leave the bread on the table, knowing she will not touch it. That is their experience. So also in that there is some margin, it only takes a lot of the surroundings. People who understand how it works and who can build up a relationship. And to my opinion, things could be less rigid. [...] If you are very healthy, but unhappy, what is the quality of life then?

If too much emphasis is put on the restriction to eat, this may interfere with the wellbeing of the person with PWS, which may lead to an obsession with food.

Pedagogue: And that strengthens my theory that the more rigidly you deal with food, the more you put attention on it, then it is only about that in life.

\section{Conditions influencing freedom and responsibility}

With regard to the value of freedom and responsibility, several promoting and limiting conditions can be distinguished. A condition which is perceived as negative in relation to freedom is a situation of continuous and strict supervision and control.

Pedagogue: Not only you are marked, but it also happens that people are always going to watch you. So essentially you don't have any freedom left from the moment that people know that about you. And everybody does it, often with good intentions, but that doesn't mean it happens in a pleasant way. But they do it always unasked. Professional caregivers are hired to do it on request, but a lot of other people in their surroundings make unasked-for remarks. It is the same story with obese people who never can eat a piece of pie, because they feel the looks of everybody around them. And with Prader-Willi syndrome it is even worse. It is present every day, every minute. When they walk past the kitchen, they surely feel those looks. There is nothing wrong with feeling that, and they have to be watched. So in that sense you could say they are sentenced to life imprisonment, always being followed by video camera, so to speak.

Even if limitations are needed to prevent over-eating, some opportunities for the child or client to make individual choices can be important. In cooperation with professional caregivers or parents the person may explore possibilities for individual choices. In a stable caregiver - care receiver relationship situations may be explored in which "not everything is put behind bars". 
Caregiver: It is so important that things are stable.

Pedagogue: Yes, then you can deal with it less in a less strict way, then you don't need to put everything behind bars.

Freedom is perceived to be closely related to independence and feelings of responsibility. Responsibility is fostered in a situation in which issues can be spoken about openly between caregiver and client.

Father: In our opinion it must be possible to talk about her behaviour. Because she is doing pretty well on a number of other domains... on the one hand you think, a group home, she is doing much too good for that. She will need to be independent to a greater extent, and she will really need to bear responsibility. But completely independent, it is still the question if this happens. Well, these are motives to go at it again every day.

\section{Conditions influencing a liveable life}

In relation to the value of a liveable life, situations of conflict were perceived as limiting conditions.

Mother: No discussions, because that ends in a lot of arguing. And then everybody is upset. Because she talks and shouts so loudly. Some are afraid of it, they are not used to that at all, they don't know what is happening to them.

\section{$2.5 \quad$ Interventions}

Conditions that have an effect on the realisation of the above described values cannot always be influenced. These values have been identified as the outcomes of the analysis. However, caregivers mentioned several interventions they used to realize specific values.

To keep body weight in balance, parents and professional caregivers indicate that it is necessary to stay alert.

Father: Well, if she doesn't really have the feeling that we keep an eye on her, then she would take more [food] than she was going to.

Mother: But you have to be alert all the time, because in times...we now have a period of lots of disease and lots of worries, and then you go eat more yourself too.

It is however not always desirable to keep the situation under control completely: 
Mother: I also think, you don't always see everything. For instance at his work. I could go over there and talk about it and tell that they should keep an eye on him. But that I find...he is becoming older and then you can hardly expect of people that they watch him constantly. At school it still works.

To show solidarity with the child, parents don't eat certain things themselves.

Mother: And to participate in that yourself. [...] That you especially in the beginning show solidarity.

While solidarity was also mentioned as a condition, a situation that can be created, it is at the same time a concrete intervention to show that solidarity by not eating either as a caregiver.

An intervention that is perceived to promote well-being is offering structure. Structure provides clearness, overview and order, which prevents unrest.

Mother: If things are unexpected...if things are unclear. Then she can't understand it, and she becomes restless. And now she has been living in a different home since October, and now things are more fixed and there is more structure. And for the managers, they thought "well, that will not work at all". Well, it appears to work perfectly with her. Certain times, rules, clearness. She goes well with that.

Caregiver: A pretty fixed programme, pretty structured. She indicates herself that she finds that pleasant. These are agreements that are made with her.

An intervention that is seen as helping the person with PWS to feel comfortable, is not to demand too much, so that the person can do things in their own tempo. According to the caregivers it is also found to be important that not too much emphasis is put on food.

Caregiver: He always needed to sleep, which now doesn't happen anymore. He nods off a little, but not anymore that extreme and long. But what also matters is that now he can do things more in his own tempo. I think that his tempo...

Interviewer: It was too high?

Caregiver: Yes, often demands are too high...we should let them follow their own tempo. What you could also see was that his temper tantrums decreased. As soon as they have the feeling that they have found their niche, a pleasant and respected place, then this becomes much more important than that food. [...] Many of us see that it is not only about focusing on food. I have the impression that he hasn't gained much weight, and I think they have quite a liberal policy in the home, in which the focus is not only on food, but where people take care of him. 
Not to be too rigid in applying rules is also an important intervention according to parents and professionals. It should be taken care for that things are not limited too much so that freedoms are not restricted to a great extent.

Caregiver: We started to give her quite some freedom. When we found out she had Prader-Willi syndrome, that freedom was much more limited. She was not allowed to go into the kitchen, not to go into the cupboard. She was restricted to a great extent. The result was that she began to search for food in the village and in the rooms of other residents. We couldn't let that go on. Then we let it go a bit. In the beginning, she sometimes had her bag full of candy and she went to the snack bar. But now this happens less often. That obsession, like it was some years ago, has lessened. Our attitude towards her has changed. We don't run after her constantly anymore. That also caused a lot of resistance from her side. So we gave her more room, though we did give her the idea that we kept an eye on her. That worked.

There are also limits to giving room and not restricting things too much. This because of the lack of self-control, as the following fragment shows.

Father: As long as she lives, she will not fully be able to take care of herself. That is not possible. If someone says 'you should give her the possibility to do what she wants to', that is possible until a certain point, and then it should stop. Because she hasn't got a brake on her own will. Because she wants everything, she wants to eat everything, wants to have everything. If you don't tell her 'Okay, now it's over', then she will continue to eat until she drops.

Another intervention is to be moderate in imposing rules. Due to an excess of rules (concerning food) it can happen that the normal life is not at the centre anymore, and it is only about food.

Pedagogue: And the other things hardly come out well anymore. I mean, the normal life should come at the first place. What is fun to you, what do you want to do, and how do you want to live. Well, and you can limit that so enormously by setting rules, so that it is only about food.

Besides dealing with rules in a subtle way, it is also relevant for freedom that parents or professional caregivers do not forbid things explicitly.

Mother: I never said 'she can't have anything'. I never forbid something or said 'you can't try this at all'. [...] only, I always have said 'for you only a little bit, because it is not that good for you'. And that she understood, and she was satisfied with it. 
Mother: If you deal with it in a tense way...she cannot have this and she cannot have that, she has to follow this diet or that diet, because that child needs to be slim. Then I don't think you achieve something.

Building up a good relationship is an intervention that according to caregivers can promote well-being and freedom. A key issue in this relationship is trust. Such a relationship makes it possible to deal with rules in a less strict way. At the same time, a stable relationship provides more possibilities to act in a consistent way.

Caregiver: First you need to build up a band of trust with her, if you want her to listen to you. If you want her to take you seriously.

An intervention that is aimed at the realisation of freedom and responsibility is the prevention of correcting the child or client constantly.

Pedagogue: In this they are very vulnerable. Actually they do it wrong every day. It is very unpleasant if you have to live with the thought that you cross the line every day. According to me nobody of us can. And that always provokes a reaction, a reaction like 'you have to do it even better'. And in fact you know it in advance. Imagine that you are corrected all day, while you can not help it, but people look at you in such a way.

For the last value, creating a liveable life, several interventions can be distinguished. A first intervention is to tighten the strings. By doing this caregivers try to prevent outbursts and keep the situation manageable.

Mother: She was busy with it on all fronts, that she was deciding. Then the complete family was suffering. I can imagine that people say 'oh, she is at home all day today, then there will be a lot of yelling'. And those scenes happened four, five times a day. That is very bad. And since that last meeting, they have tightened the strings. Well, I don't understand it, but everything is going well now.

Advance warning may prevent the situation getting out of hand.

Mother: When you go somewhere, you should in fact always warn her in advance: 'Think about it, you have been warned'. That you don't end up in a scene, because then it is over. And she keeps herself to that pretty well. And if you don't say this, things can get out of hand sooner.

Furthermore the situation can be kept manageable and conflicts can be prevented by not entering into discussions and not starting to negotiate, but avoiding discussions and keeping the peace. 
Caregiver: We just don't go into discussions with her. Sometimes people are tempted to do it. But you just notice that when you go into discussions with her, you just make it more difficult for her. Then there would be no end to it.

A difficult thing within the family or group, if there are more children or residents, is to spread the attention well. The person with Prader-Willi syndrome often demands so much attention and has such specific problems, that there is the risk that you wrong other children.

Mother: After all those years with her, I really thought I had spread my attention, but that is not the case. No matter how hard you try your best. I spoke to a lot of other mothers and then you think 'you see, it just is not possible'. Such a child gives a pressure, an attention, you just cannot give your other children as much attention, it just isn't possible. I once even said 'for her I could have had three children'...you are so much occupied with her.

Creating a liveable life also presupposes that the parent or professional caregiver thinks about him- or herself.

Father: We are not burning down ourselves for the children, so far that we don't have a choice anymore at the end, and are not able anymore to influence the circumstances like they are then. [...] If you saw that family, they completely went under. And that really was an example for us how it should not go. Then we said, we will not let it come so far.

The interventions show that it is of importance not only what you do as a caregiver, but most certainly how you do it. Of importance is not to be too rigid in applying rules, as well as the extent to which they are imposed. This can be realized best by being sensitive to developing a good relationship with the child or client and giving careful consideration to a supportive living environment.

\subsection{Discussion}

In the care for persons with Prader-Willi syndrome various values play a role. A first value is the health of the child or client. That is self-evident, since the urge to overeat is a constant risk for obesity and damage to the person's health. Besides health, other values are involved. Parents and professional caregivers see it as important that the person with PWS feels good. Parents are happy when the child feels comfortable. Professional caregivers emphasize that the client needs to have a good quality of life. Though obesity needs to be prevented, this should not be done at the expense of everything. Happiness is more than health. For caregivers it is important that the person with PWS learns to lead its own life. A central value in this is freedom. This freedom is not conceived as being able to do what one wants to, but being able to bear responsibility. This implies a positive notion of freedom, not freedom from intervention, but 
freedom to create one's own life (Berlin, 1969; Benn, 1988). For this, support and help is needed. This corresponds with a relational concept of autonomy. In the concept of relational autonomy, the development of the self is seen as a process, which can only take place in the context of relationships with others (Mackenzie \& Stoljar, 2000).

Another important value is creating a liveable life for other people involved: parents, brothers or sisters or other residents. Despite the emphasis on health, parents and professional caregivers clearly pay attention to the broader context in which the person with PWS lives. They emphasize the need of keeping life bearable (under difficult circumstances), and taking care for the situation together. These values correspond with an ethics of care to which dealing with dependency through a joint responsibility is central (Tronto, 1993; Walker, 1998). This shared responsibility means that within a good caregiver-client relationship room is created for making agreements together.

Parents and professional caregivers mention a number of conditions that influence the extent to which desired values can be realized. Solidarity, a feeling of acceptance and respect, and a situation in which issues can be discussed openly play a positive role. In this again an emphasis on the relational character of the existence can be seen. The experience of a joint commitment and attention has a positive influence on the described values. Negative are constant supervision, and an obsessive orientation on (limiting) the eating behaviour and conflicts.

Caregivers also indicate which actions they take to help realise the values that are perceived to be important. They mention being alert, offering structure, being moderate in imposing rules, building up a relationship, keeping the peace, and spreading attention. These interventions have the character of a process. It is not a matter of choosing between letting go or intervening, but of creating a context in which the joint life can be shaped further. By offering structure the person can be helped to take responsibility for their behaviour. According to caregivers, interventions require tact and the ability to find the right balance. It is important to be alert without permanent control, to offer structure without limiting the behaviour too rigidly. Furthermore, it is important to find a balance within the family or the group of residents. This entails finding a balance between attention for the person with PWS and for other family or group members. In that balance caregivers should also take care for themselves.

Parents and professional caregivers try to realize the same values for their child or client. There are however also differences between them. Parents talk about feeling pleasant or comfortable with oneself, professionals about quality of life. Furthermore, professional caregivers talk more in terms of making agreements and taking decisions. A possible explanation for this is that parents may be emotionally involved with the children in an other way than professional caregivers. The latter frequently have a more professional attitude. Parents are inclined to act more on the basis of a vision on education, professional caregivers act more on the basis of a care plan. Despite this difference in language however, it is striking that the nature of the strategies and interventions that are used do not differ significantly between parents and professional caregivers. 
In summary, caregivers do not focus only on the question whether one should intervene or not. They try to create conditions for living that are acceptable and meaningful for everybody involved. They aim to maintain life by building up a relationship to which acceptance and respect are central. In this relationship a certain amount of independence and responsibility can be developed. In a permanent and stable context of care, in which there is room for creating trust, it is possible to deal with rules in a less rigid way and to look where there is room for choices. This gives way to a life which is characterized by a process of mutual commitment, support, care and shared responsibility. 


\section{References}

Benn, S.I. (1988). A theory of freedom. Cambridge University Press, Cambridge.

Berlin, I. (1969). Four essays on liberty. Oxford University Press, Oxford.

Dykens, E.M., Goff, B.J., Hodapp, R.M., Davis, L., Devanzo, P., Moss, F., Halliday, J., Shah, B., State, M. \& King, B. (1997). Eating themselves to death: Have "personal rights" gone too far in treating people with Prader-Willi syndrome? Mental Retardation, 35(4), 312-314.

Holland, A.J., Treasure, J., Coskeran, P., Dallow, J., Milton, N. \& Hillhouse, E. (1993). Measurement of excessive appetite and metabolic changes in Prader-Willi syndrome. International Journal of Obesity, 17, 527-32.

Holland, A.J. \& Wong, J. (1999). Genetically determined obesity in Prader-Willi syndrome: the ethics and legality of treatment. Journal of Medical Ethics, 25, 230-236.

Hooren, R.H. van, Widdershoven, G.A.M., Borne, H.W. van den \& Curfs, L.M.G. (2002). Autonomy and intellectual disability: the case of prevention of obesity in Prader-Willi syndrome. Journal of Intellectual Disability Research, 46(7), 560-568.

Lincoln, Y.S. \& Guba, E.G. (1985). Naturalistic inquiry. Sage, Newbury Park.

Mackenzie, C. \& Stoljar, N. (Eds.) (2000). Relational autonomy: Feminist perspectives on autonomy, agency, and the social self. Oxford University Press, Oxford.

Strauss, A. \& Corbin, J. (1990). Basics of qualitative research: grounded theory procedures and techniques. Sage, Newbury Park.

Swaab, D.F., Purba, J.S. \& Hofman, M.A. (1995). Alterations in the hypothalamic paraventricular nucleus and its oxytocin neurons (putative satiety cells) in Prader-Willi syndrome: A study of five cases. Journal of Clinical Endocrinology and Metabolism, 80, 573-9.

Tøssebro, J., Aalto, M., Brusén, P. (1996). Changing ideologies and patterns of services. In: Intellectual disabilities in the Nordic Welfare States (eds. J. Tøssebro, A. Gustavson, G. Dyrendahl), Norwegian Academic Press, Norway.

Tronto, J. (1993). Moral boundaries. A political argument for an ethic of care. Routledge, New York.

Walker, M.U. (1998). Moral understandings: A feminist study in ethics. Routledge, New York.

Whittington, J., Holland, A., Webb, T., Butler, J., Clarke, D., \& Boer, H. (2004). Cognitive abilities and genotype in a population-based sample of people with Prader-Willi syndrome. Journal of Intellectual Disability Research, 48(2), 172-187. 



\title{
CHAPTER 3
}

\author{
AUTONOMY AND INTELLECTUAL DISABILITY: THE CASE OF \\ PREVENTION OF OBESITY IN PRADER-WILLI SYNDROME
}

This chapter appeared as: Hooren, R.H. van, Widdershoven, G.A.M., Borne, H.W. van den, Curfs, L.M.G. (2002). Autonomy and intellectual disability: the case of prevention of obesity in Prader-Willi syndrome. Journal of Intellectual Disability Research, 46 (7), 560-568. 


\begin{abstract}
Background. The policy concerning care for people with intellectual disability (ID) has developed from segregation via normalization towards integration and autonomy. Today, people with ID are seen as citizens who need to be supported to achieve a normal role in society. The aim of care is to optimize quality of life and promote selfdetermination. The promotion of autonomy for people with ID is not easy and gives rise to ethical dilemmas. Caregivers are regularly confronted with situations in which there is a conflict between providing good care and respecting the client's autonomy. This becomes evident in the case of prevention of obesity in people with Prader-Willi syndrome (PWS).

Method. As part of a study about the ethical aspects of the prevention of obesity, indepth qualitative interviews were conducted with the parents and professional caregivers of people with PWS.

Results. In analysing interviews with parents and formal caregivers, the present authors found that the dichotomy between respecting autonomy and securing freedom of choice on the one hand, and paternalism on the other hand, is too crude to do justice to the process of care. The stories indicated that caregivers see other options and act in other ways than to intervene without taking into account the wishes of the individual with PWS. The present authors elaborated these options, taking models of the physician-patient relationship as a heuristic starting point. They extended the logic of these models by focusing on the character of the process of interaction between caregiver and care receiver, and on the emotional aspects of the interactions.

Conclusion. This approach results in more attention to processes of interpretation, deliberation and joint learning.
\end{abstract}


In line with developments in other Western countries, the normalization and integration of people with intellectual disability (ID) into society is currently an important policy issue in the Netherlands. Processes of de-institutionalisation and individualization have been initiated. Smaller residential places have been created. Notions such as 'supported living' and 'assisted independent living' have been promoted, emphasizing that people with ID should live in smaller groups with more independence and responsibility. Similar developments can be seen in the domain of work; for example, supported employment, in which working with assistance in a 'normal' work environment is promoted. Caregivers also increasingly recognize the needs of those with ID with respect to leisure activities.

For people with ID, these changes seem to be beneficial. Achieving autonomy is an important goal in human life in general, as well as in the life of people with ID. Nevertheless, caregivers may sometimes feel frustrated by the focus on autonomy. They may be confronted with situations in which there is a conflict between providing high-quality care and respecting the client's autonomy. It is not always easy to decide what to do when wishes and interests conflict with one another. Should one respect the autonomy of the person with ID, or should one protect him or her against the averse consequences of his or her choices?

These conflicts are very prominent in the care for people with Prader-Willi syndrome (PWS). This genetic disorder is associated with mild to moderate ID (Curfs, 1992). A prominent feature in PWS is an excessive appetite, which can easily lead to overeating behaviour. The normal satiety response is suggested to be impaired and delayed (Holland et al., 1993), possibly because of a hypothalamic dysfunction (Swaab et al., 1995). This overeating behaviour in PWS frequently leads to obesity, which can be severe and lead to serious health problems. How should parents and professional caregivers deal with this situation? Should they leave the choice to the person her or himself, or should they actively intervene and try to prevent obesity?

\subsection{Subjects and methods}

As part of a study of the ethical aspects of the prevention of obesity, in-depth qualitative interviews were conducted with the parents $(n=23)$ and professional caregivers $(n=14)$ of people with PWS $(n=18)$. Nine out of these 18 individuals with PWS lived at home and nine stayed in a group home. The ages of the people living at home ranged from 8 to 17 years, and for those living in a group home ages ranged from 13 to 38 years. The parents and caregivers were interviewed about their views on prevention of obesity as well as on the way in which they actually tried to manage the situation in everyday life.

First, an analysis was made from the perspective of autonomy as self-determination. This analysis showed that a more differentiated framework is needed. A framework of models of physician-patient relationships was taken as a heuristic starting point to analyse the interviews with parents and professional caregivers. In this broader 
analysis, the eating problems were looked at in the broader context of the person's life history, and attention was paid to all kinds of problem behaviour related to the eating behaviour. The logic of these models was extended by focusing on the character of the process of interaction between caregiver and care receiver, and on the emotional aspects of the interactions.

\subsection{Results}

Autonomy versus paternalism

The ethical principle of respect for autonomy has become an important value in healthcare in recent decades (Beauchamp \& Childress, 1994). To respect autonomy is to acknowledge a person's right to hold views, to make choices and to take actions based on personal values and beliefs (id.; p.125). Doing good may be an important goal of medicine, but the physician's duty to act in the best interest of the patient is limited by the patient's wishes. If the patient refuses treatment or care, it is morally wrong to impose it. Given the importance of the principle of respect for autonomy, paternalistic intervention without a patient's consent is only morally acceptable when a person inflicts severe damage under conditions of incompetence (Beauchamp \& Childress 1994; p.123, 126). Three kinds of abilities are used, either alone or in combination, to determine competence: (1) the ability to express a preference or choice; (2) the ability to understand and appreciate one's situation; and (3) the ability to reason through a consequential life decision. In medicine, a sliding-scale strategy might be used. As an intervention increases the risk for patients, the level of ability required for a judgment of competence to elect or refuse the intervention should be increased. As the consequences for well-being become less substantial, the level of capacity required for competence should be decreased (Beauchamp \& Childress; pp. 137-8).

Both Dykens et al. (1997) and Holland and Wong (1999) point out the physiological basis of the overeating behaviour. According to Holland and Wong, the capacity to make decisions on matters of eating and weight may be lacking because of the strong and overwhelming biological drive. Since there can be little control over such a biological drive, intervention in eating would be justified, even if the person did not consent. Looking at the data from this point of view, respect for autonomy cannot be found. A clear example of this is the following comment by the mother of a girl with PWS:

[...I]t is said in the United States, let them eat themselves to death, then they have had at least a happy life. Well, this is very radical. Can we ever determine that overeating will make them really happy? If we look at our daughter, we are glad that she is not too fat. She seems to be happy when she is able to run a little, can play a ball game, take part in walking contests and fits in a normal bathing suit and so on. She does not have to be beautiful, if only she is able to feel comfortable with herself. Well, that already is quite a battle, and for that it is necessary that people decide for her what she can and cannot eat. 
The attitude of this parent is not to respect autonomy in the sense of selfdetermination. The person with PWS is not given the freedom to decide for her or himself about her or his eating behaviour. Since the alternative to respect for autonomy is paternalism, the conclusion seems to be that the mother quoted above (like many other Dutch parents and professional caregivers) takes a paternalistic stance. However, this conclusion is one-sided. Descriptively, it does no justice to the fact that parents and professional caregivers differ in their approach. Although all the present subjects set limits to the freedom of the individual with PWS, they do so in various ways. Normatively, it implies a depreciation of the genuine attempts of parents and caregivers to find a morally acceptable solution to a difficult situation, a solution in which the individual is not just confronted with limitations, but also supported in finding ways of dealing with the problems in life resulting from their condition.

The present authors found that none of the interviewed caregivers opted to leave the choice entirely to the person with PWS. Nevertheless, they did not simply choose to intervene without taking into account the wishes of the individual with PWS:

Interviewer: Do you think it is necessary to lock the kitchen?

Father: No, not in our case. We want him to learn to cope with it himself. We can talk about it with him very well, and he also is fairly wise. That doesn't mean he never takes something out of the cupboard in secret.

Mother: We try to stimulate as much as possible her own responsibility. For example, she needs to take care of her homework herself, we don't go after that. By stimulating the own responsibility in all these other areas, so that she feels being trusted, we try to manage that she can cope with food in a better way.

In the above extracts, autonomy is promoted, not by giving freedom of choice, but by fostering self-understanding and self-development. The focus is not on negative freedom, but on positive freedom (Berlin, 1969). From this perspective, autonomy is not a matter of self-determination, but of self-realisation.

\section{Four concepts of autonomy}

In analysing the interviews of caregivers, the present authors found that the alternative between respecting autonomy and securing freedom of choice on the one hand, and paternalism on the other hand, is too crude to do justice to the process of care. The stories indicated that caregivers see other options and act in other ways. Therefore, a more differentiated framework is needed (Reinders, 2000). This can be found in the work of Emanuel and Emanuel (1992). These authors go beyond the dichotomy of autonomy and paternalism by adding two other possible approaches: (1) interpretation and (2) deliberation. Moreover, Emanuel and Emanuel (1992) show that a specific conception of patient autonomy can be distinguished in each of the four approaches. Apart from autonomy as freedom of choice, these authors develop three other con- 
cepts of autonomy. Thus, autonomy is not just the opposite of paternalism for Emanuel and Emanuel.

On the basis of empirical research in oncology, Emanuel and Emanuel (1992) outlined four different kinds of physician-patient interaction: (1) the paternalistic model, (2) the informative model, (3) the interpretive and (4) the deliberative model. These models will be sketched briefly below. Given the importance of (the lack of) capacity in the debate on PWS, the different conceptions of capacity required for competence will be made explicit in each of these models.

According to the first model, i.e. the paternalistic model, the physician encourages the patient to consent to the medical intervention chosen by him. In this model, the physician acts as the patient's guardian. Patient autonomy is conceived as patient assent to the physician's determinations of what is best. The conception of capacity is the ability to cooperate.

The second model is the informative model. The objective of the physician-patient interaction is for the physician to provide the patient with all the relevant information so that the patient can select the medical intervention she or he wants. The physician then executes the selected interventions. In this model, the physician is a purveyor of technical expertise, providing the patient with the means to exercise control. The conception of patient autonomy is patient control over medical decision making. Capacity is conceived as the ability to understand the provided information, to weigh this information against one's own values and to take decisions.

In the third model, the interpretive model, the physician helps to elucidate the patient's values and to make clear what she or he actually wants. This model assumes that the patient's values are not always fixed and known to the patient. These values are often inchoate and conflicting. Therefore, the physician works with the patient to reconstruct the patient's goals and aspirations, commitments, and character. The physician is a counsellor, engaging the patient in a joint process of understanding. Patient autonomy is viewed as self-understanding: the patient comes to a better understanding of who she or he is, and how the various medical options bear on her or his identity. The conception of capacity is the ability to understand one's own values and to clarify the relevance of these values.

The fourth model is the deliberative model. Like the third model, this model sees as the aim of the physician-patient interaction as being to help the patient to determine and to choose the best values for her or his health, but unlike the interpretive model, the values of the patient not only need to be elucidated, they also are open for development and revision through moral discussion and deliberation. The physician can suggest that certain health-related values are more worthy and should be aspired to. In this model, the physician's role is that of a teacher or friend. The conception of patient autonomy is moral self-development: the patient is empowered not simply to follow unexamined preferences or examined values, but to consider, through dialogue, alternative health-related values, their worthiness, and their implications for treatment. Capacity is conceived as the ability to learn and develop one's own values. 
Paternalism, interpretation and deliberation

Taking the models of Emanuel and Emanuel (1992) as a heuristic starting point, the interviews with parents and professional caregivers were analysed by the present authors. In this analysis, the focus was not on discrete decisions, but on the general patterns of interaction between caregivers and people with PWS. The focus was not merely on rational, but also on emotional aspects. Very few expressions were found which clearly corresponded to the informative model. The interviewed caregivers hardly opted for leaving the choice totally to the person with PWS. The utterances of the caregivers often had a paternalistic tone. Nevertheless, there were also elements in the stories showing that the process of care was directed towards fostering selfunderstanding or moral development on the part of the individual with PWS. The stories were never totally in accordance with only one model. However, one of the models was quite often dominant. Thus, cases of paternalism, of interpretive interaction and of deliberative interaction could be distinguished. A case of each will be presented briefly with indications of elements which are not in line with the dominant model.

\section{Paternalism}

John is a 17-year-old boy with PWS who lives with his parents. He has two older sisters who both have left the house. John's parents are very protective in their education. They try as much as possible to control John's eating problems by supervising him.

Mother: One gets used to it. I am so used to keep an eye on him.

Father: That's right. If he is preparing food, even when he is only peeling potatoes, or picking salad, and it is quiet for, let's say, three minutes, then you have to take a look. If you hear that a door opens, you have to go and see. Because then you have the idea, What is he after? and it is quite possible that he is getting a new bag of potatoes, but you don't know that. So, you hear the door...

Little is discussed with John, and his parents often act on what they think is the best way of dealing with him. In that sense, this situation can be classified as paternalistic. Another example follows:

Mother: He is...we are on a diet for him, because he...

Father: Absolutely nothing by himself, oh no.

Mother: He accepts it...

Father: He is putting on an act when he says he is on a diet. He only says that to please us, to show us 'You see, how good I am. Look how wise I am', something like that he says then. 'Isn't that good of me?' But only so because we are there.

Mother: But the advantage is that he accepts the fact that he has to be on a diet. Some time ago, he was on a camp, a trip with mildly intellectually disabled 
people. And then we arranged with one of the leaders to keep an eye on the food, and John agreed. But if someone would say to him, do you want to have a hamburger, or a piece of bread, he would always say yes.

The parents arrange with the camp leaders how to deal with the eating problems on the basis of what they think is best for John. He is not involved in the decision. Autonomy in this case is conceived as John's assent to the parents' decisions of what is best. In the end, John and his parents are tuned to one another. He both agrees with his parent's paternalistic interventions and induces them. It is hard to say which of the parties is primarily responsible for the paternalistic character of this interaction. It is a rather well balanced process in which all parties play their role.

\section{Interpretation}

Peter is a 29-year-old man with PWS who has been living in a home for individuals with ID for over 10 years. In contrast to John's case, the caregivers look for what Peter wants himself. Nevertheless, they do not merely respond to his concrete wishes, but try to find solutions which really fit Peter. Thus, the interaction can be characterized as interpretive. An example is the search for work for Peter within the institute. Peter was offered a job in which he is responsible for the transport of residents from the homes to the sheltered workshops and he is very pleased with this job, as a caregiver describes:

He indicated himself that he wanted to do some more things and that he wanted to be more independent. And then it was decided to do something like this with residents. He is doing fine and enjoys working with especially the younger residents, well, and therefore we work on that, then we give him this possibility. [...] Here in the institute appropriate work for him was searched for.

Peter indicates himself what his wishes are, and together with his caregivers appropriate work is being found. This kind of interaction fits well with the concept of actual autonomy developed by George Agich. According to Agich (1993; p. 107), a choice that enhances autonomy is a choice that is meaningful for individuals, and allows them to express and develop their own individuality.

The following example also shows the interpretive relationship between Peter and his caregivers:

Caregiver1: Lately he indicated that he preferred bathing in the evening...

Caregiver2: Well, he was on the morning schedule, and wanted to change that to the evening, because in the morning he didn't have enough time and had to hurry too much and it all was too busy for him which frustrated him a lot. And then, at a sudden moment he indicated, 'Can't we...can't we change that?' And then we looked at it, well, is it also possible to let him bath in the evening, well, he agreed on that and he now is fine with it. 
In this interaction, both the caregivers and Peter search for and elucidate his values. Thus, Peter's autonomy is conceived as self-understanding.

Some aspects of the way in which the caregivers deal with Peter can be interpreted as paternalistic. The caregivers try to prevent conflicts about food as much as possible; for example, by preparing all the food in the central kitchen and serving it in special trays, as one of them describes:

Only Peter gets separately, a special menu which is distributed in three different trays. They already adapt that in the kitchen to his syndrome. Because he already is inclined to obesity. The other residents just get from the pan, we just dish it up, that is no problem. In advance this is determined that way. If he would have to dish up the food himself, that would easily cause more problems.

Nevertheless, there are also examples of a more open attitude, including even deliberative elements, according to a caregiver:

Peter has a fairly high intellectual level, an IQ of about 68-70. You can at certain moments also on this point deliberate with him adequately. Nonetheless, he tries to look for the limits, but at certain moments he can be quite motivated to do something about his weight. And in that we also give him some responsibility, knowing that those limits and his search for the limits always are present. [...] In itself, if we look at how things go...we give him room to go to town alone, and look at how this works in the end, how his weight evolves through the years, then we think that we found a very reasonable balance in that. In giving and taking...otherwise, especially his weight would have gained very much.

This joint process of searching for a balance, to both give and take, has deliberative elements. When looking at the case in general, however, it can be classified as predominantly interpretive since the care givers act mainly from their experience about Peter, knowing how to react to him and helping him to find out what is really appropriate in his situation.

\section{Deliberation}

Emma is a 30-year-old woman with PWS who lives in a special home for people with ID. At first, the caregivers acted rather paternalistic towards Emma, but within a short time, they were confronted with resistance from her side because of this kind of approach. Learning from this, the caregivers started handling things differently:

Caregiver1: Even your attitude towards Emma has changed quite a bit, hasn't it?

Caregiver2: Yes, we are not on top of her anymore all the time. To that Emma resisted a lot. And that of course is logical. Especially when there were substi- 
tute caregivers, because you first have to build a relationship of trust with her, before she listens to you, before she takes you seriously. Yes, there was constantly a conflict, or a fight or aggression, it just didn't work that way. So we gave her some more space, but let her feel we know constantly were she is, but not that she has the feeling we are constantly on top of her, and that works.

Gradually, the interaction between Emma and her caregivers becomes more deliberative. Both sides try to seek for agreement, try to get in line with each other, as one caregiver explained:

What I like is the construction you figured out if there is a party. Because in the past she got dietary products or sugar-free products, but in consultation with Emma, because she also indicated that herself, you did choose for another formula. She says she prefers half a piece of real pie over a whole piece of sugar-free pie.

There is a joint process of learning in which both parties change their views and in this way make progress. Values are not fixed, but come into being through a constant dialogue between all the parties involved. There is a willingness to learn from each other with the aim of creating a better situation for everyone involved. The caregivers put energy in offering security and protection to create a situation in which the client can develop herself as much as possible.

The following story, told by Emma's mother, shows that the interaction with Emma is a continuous process of learning for all of the parties involved:

[...W]e just entered [the home], and another resident, Julie, came walking into the hall, and she said, 'How is Emma? How is her health?' So I said to her, 'Oh, Emma is doing fine, all goes fine, let's hope it stays like this', and Julie walks with me to the stairs... and Emma heard this, and began to grumble, 'And don't I have any privacy at all anymore!' I thought, 'What is happening to her?' She was angry and slammed the door and said 'Go home!' Well, I went. That is the best to do, otherwise she can go on for quite a while, till an hour and a half later, and having a normal conversation with her is not possible at all then. So, I just went home. Then something had to be returned to her and I thought, Well, let father do this. When Emma saw her father, she said, 'Oh, is mum angry with me?' Later, she came back to it, 'Well, mum, I can't do anything about it, but I think...' I said, 'Emma, you didn't even know what I said to Julie. And you went out of your mind, reproaching me. I couldn't talk to you anymore, so I just went out. But you shouldn't be that blunt. If somebody politely asks "how are you doing?", then one should reply to that'.

Because her mother does not simply accept everything Emma says and does not react the way Emma wants her to, the effect is a learning moment for her daughter. By walking away when her daughter is having a temper tantrum, she makes Emma start 
thinking about her unreasonableness. In this case, autonomy thus is conceived as moral self-development.

Sometimes, the interaction between Emma and her caregivers looks deliberative, but may actually be not as much of a dialogue as it seems. An example of this occurred when her mother explained to her that she could no longer keep her rats, which she used to have as pets:

[...] I said, 'Well, Emma, now listen to me very carefully. Imagine our neighbour was keeping rats, like you, and these rats would come into our garden and would come into our house, within no time the place would be full of rats'. I said, 'The first time I would see one, I would call the police, because he should get rid of them. And in your case, it is exactly the same, it just isn't possible. Think about that carefully, because this just causes problems, it just is not possible, before you know it rats will be all over the place, because this happens very fast.' I told her, 'Everything will be arranged'. Well, nothing further, no discussions anymore, and they are all gone now. But you always just have to invent something to make it acceptable for her that it cannot go on like this.

Although a lot of reasons are provided, in the end Emma is merely informed about the decision which had already been made in advance. There is no room for discussion. Interestingly, although Emma accepted the situation, she does not really seem to have learned from it. The arguments showed her that resistance is useless, but that does not mean that she regards them as reasonable. If we compare this example to the one described above, Emma's potential for learning to behave differently and to develop herself seems to be promoted more by emotional responses than by rational argument.

\subsection{Discussion}

Autonomy is an important issue in care for people with ID, but it is often unclear how autonomy can be promoted so that people with ID are actually helped to live their life in a way that really suits them. In contemporary ethical debates, autonomy is opposed to paternalism. The emphasis is on freedom of choice, without external interference. This conception of autonomy falls under the heading of negative freedom (Berlin, 1969). One may doubt whether this conception of autonomy is relevant for people with ID.

In this study, the present authors did not find parents or professional caregivers who were prepared to leave choices completely up to the child with PWS. Nevertheless, this does not mean that caregivers necessarily take a paternalistic stance. The authors found forms of interaction in which parents and staff tried to promote the person's autonomy, not by giving freedom of choice, but by fostering self-understanding and self-development. In these instances, the focus was not on negative freedom, but on positive freedom (Berlin, 1969). From this perspective, autonomy is not a matter of self-determination, but of self-realisation. In the interpretive and the deliberative 
model, autonomy is not the opposite of dependency. This is in line with the notion of relational autonomy, developed by authors coming from feminism and ethics of care (Mackenzie \& Stoljar, 2000). In the concept of relational autonomy, the development of the self is rather seen as a process which can only take place in the context of relationships with others. A relational model focuses on the social context in which people live (Agich, 1993). It leaves room for interventions of caregivers, aiming at empowerment (Moody, 1992). By emphasizing the need for joint work aiming to maintain and repair the world so that people can live in it as well as possible, the development of autonomy is seen as an interactive process in which people become both more themselves and more interrelated (Tronto, 1993; Widdershoven, 1999).

A relational model of autonomy appears to be more suitable for the care for people with ID than a conception of autonomy in terms of self-determination, focusing on independence (Widdershoven \& Sohl, 1999). Especially in this field of care, decisions cannot be left to the care receiver alone. This does not mean that the caregiver always has to decide what is best. A paternalistic intervention can be justified when overeating behaviour is extreme. However, other ways of interaction are possible in daily practice, even regarding eating and weight, depending on the drive for food. In these other types of interaction, the care receiver is actively involved in the process of decision making. A risk in both the interpretive and deliberative models is that they may, in fact, function as a disguised form of paternalism (Emanuel \& Emanuel, 1992). Caregivers should always be aware of this risk, especially when dealing with people with ID. Paternalism is at odds with interpretation and deliberation. The role of the caregiver in the interpretive process is only to help to elucidate those values which are relevant to the care receiver, and in the deliberative model, it is the aim of the caregiver to persuade the client of the worthiness of certain values, not to impose those values paternalistically.

Emanuel and Emanuel (1992) claimed that the deliberative model is the ideal form of interaction. As the present study shows, care for those with ID can take the form of a mutual endeavour in which both parties learn new ways of dealing with the situation. This can be conceptualised as a form of deliberation, not through intellectual operations such as argumentation, but also through more emotional forms of responsiveness. This implies a specification of the deliberative model of Emanuel and Emanuel. Deliberation is not only, and not primarily, a process of rational argument. First and foremost, it is a way of finding new perspectives by opening up one's horizon in response to others (Widdershoven, 1999). As such, it is not only applicable to interactions between well-educated rational people, as Emanuel and Emanuel seem to presuppose, but also to interactions between people who may lack the ability to reason objectively and independently, but who may be no less able to learn from one another. By broadening our conceptions of autonomy, deliberation and learning, and reframing them in a relational way, we can hope to develop a framework which does more justice to the specific situation of people with an ID and those who care for them. 


\section{References}

Agich G. (1993). Autonomy and long-term care. Oxford University Press, New York.

Beauchamp T.L. \& Childress J.F. (1994). Principles of biomedical ethics (4th Edition). Oxford University Press, Oxford.

Berlin I. (1969). Four essays on liberty. Oxford University Press, Oxford.

Curfs L.M.G. (1992). Psychological profile and behavioral characteristics in the Prader-Willi syndrome. In: Prader-Willi syndrome and other chromosome 15q deletion disorders (ed. S.B. Cassidy), pp. 211-221. Springer-Verlag, Berlin-Heidelberg.

Dykens E.M., Goff B.J., Hodapp R.M., Davis L., Devanzo P., Moss F., Halliday J., Shah B., State M. \& King B. (1997). Eating themselves to death: Have "personal rights" gone too far in treating people with Prader-Willi syndrome? Mental Retardation, 35, 312-314.

Emanuel E.J. \& Emanuel L.L. (1992). Four models of the physician-patient relationship. JAMA, 267, 2221-6.

Holland A.J., Treasure J., Coskeran P., Dallow J., Milton N. \& Hillhouse E. (1993). Measurement of excessive appetite and metabolic changes in Prader-Willi syndrome. International Journal of Obesity, 17, 527-532.

Holland A.J. \& Wong J. (1999). Genetically determined obesity in Prader-Willi syndrome: the ethics and legality of treatment. Journal of Medical Ethics, 25, 230-236.

Mackenzie C. \& Stoljar N. (eds.) (2000). Feminist Perspectives on Autonomy, Agency, and the Social Self, pp. 3-31.Oxford University Press, New York and Oxford.

Moody H.R. (1992). Ethics in an aging society. Johns Hopkins University Press, Baltimore.

Reinders J.S. (2000). Ethiek in de zorg voor mensen met een verstandelijke handicap (Ethics in the care for persons with intellectual disabilities). Boom, Amsterdam.

Swaab D.F., Purba J.S. \& Hofman M.A. (1995). Alterations in the hypothalamic paraventricular nucleus and its oxytocin neurons (putative satiety cells) in Prader-Willi syndrome: a study of five cases. Journal of Clinical Endocrinology and Metabolism, 80(2), 573-79.

Tronto J. (1993). Moral boundaries. A political argument for an ethic of care. Routledge, New York.

Widdershoven G.A.M. (1999). Care, cure and interpersonal understanding. Journal of Advanced Nursing, 29, 1163-69.

Widdershoven G. \& Sohl C. (1999). Interpretation, action, and communication: four stories about a supported employment program. In: Telling tales: on evaluation and narrative (ed. T.A. Abma), pp. 109-130. JAI Press, Stamford. 



\title{
CHAPTER 4
}

\author{
BETWEEN CONTROL AND FREEDOM IN THE CARE FOR PERSONS \\ WITH PRADER-WILLI SYNDROME: AN ANALYSIS OF PREFERRED \\ INTERVENTIONS BY CAREGIVERS
}

This chapter appeared as: Hooren, R.H. van, Widdershoven, G.A.M., Candel, M.J.J.M., Borne, H.W. van den, Curfs, L.M.G. (2006). Between control and freedom in the care for persons with Prader-Willi syndrome: An analysis of preferred interventions by caregivers. Patient Education and Counseling, 63 (1-2), 223-31. 


\begin{abstract}
Objective. The present study examined caregivers' preferences for intervention strategies in dealing with the dilemma of respecting autonomy of intellectually disabled persons versus providing high-quality care.

Methods 24 Parents and 14 professional caregivers of persons with Prader-Willi syndrome were asked to rate four different kinds of intervention strategies according to their preferred way of dealing with 8 presented cases.

Results. In general, caregivers preferred to intervene more actively in eating problems compared to behavioural problems, more in acute than in chronic situations, and more in situations at home than in community-based settings. Significant differences were found between parents and professionals.

Conclusion. Parents and professionals prefer intervening above laissez faire. Parents prefer active intervention stronger than professionals.

Practice implications. Awareness of various intervention strategies can help caregivers to develop a practice that does justice to the need for intervention on the one hand, and the possibility of using a variety of intervention strategies on the other hand. Communication about intervention strategies might foster understanding between professional caregivers and parents and improve mutual cooperation.
\end{abstract}


In general, persons with an intellectual disability are less or more dependent on care providers. This may conflict with the recent developments in the field that aim at the promotion of self-determination, freedom of choice and own responsibility for persons with an intellectual disability. Caregivers sometimes are confronted with situations in which clients make choices that have adverse consequences for their health. They may feel frustrated by the emphasis on self-determination; they struggle with the question whether they should respect their client's autonomy or protect them and intervene.

Besides a paternalistic intervention on the one hand, and not intervening at all on the other hand, other approaches are possible. In these alternative approaches caregivers promote the client's autonomy, not by giving freedom of choice, but by fostering selfunderstanding and self-development. The focus in these approaches is not on negative freedom (freedom of choice without external interference), but on positive freedom (Berlin, 1969); from this perspective autonomy is not a matter of selfdetermination, but of self-realization. Autonomy thus is not the opposite of dependency, but can be enhanced in relationships with supportive others.

The present article describes the results of an operalisation of these approaches into intervention strategies and analyses the preferences of caregivers for these strategies.

The setting in which we worked is the case of Prader-Willi syndrome. In the care for individuals with Prader-Willi syndrome, the conflict between autonomy and providing high-quality care is very prominent. This genetic disorder is associated with a mild to moderate intellectual disability (Whittington et al., 2004). A characteristic feature of persons with Prader-Willi syndrome is an excessive appetite, frequently associated with overeating behaviour. The normal satiety response after eating is suggested to be impaired and delayed (Holland et al., 1993), possibly caused by a hypothalamic dysfunction (Swaab et al., 1995). This overeating behaviour frequently leads to obesity, which can be severe and lead to serious health problems. Other behavioural problems which are frequently observed in persons with Prader-Willi syndrome are temper tantrums and the tendency to be argumentative, oppositional behaviour, rigidity, manipulation, possessive behaviour and stubbornness (Holm et al., 1993). How do parents and professional caregivers deal with this situation? Should they leave the choice to the person her or himself, or should they actively intervene and try to prevent obesity?

Previous studies showed that fathers and mothers of children with Prader-Willi syndrome differ in their perception of and coping with behavioural problems of their child (Van den Borne et al., 1999; Van Lieshout et al., 1998a). However, little is known about how professional caregivers experience behavioural problems and deal with them. Is the parent-child relationship different from a professional-client relationship, and are there differences between parents and professionals in how far they want to go in restricting the freedom of the child or client? 
Studies of behavioural problems in persons with Prader-Willi syndrome show that besides problems related to food and overeating, problems occur that are not related to food (Curfs et al., 1991; Dykens et al., 1996; Dykens \& Kasari, 1997; Van Lieshout et al., 1998b). This raises the question whether parents and professionals deal differently with eating problems in comparison to behavioural problems not related to eating. Sometimes there is little time to think about the most appropriate reaction to problem behaviour. When a decision has to be made quickly, this might lead to a different approach then when there is time for reflection and deliberation. Are parents and professional caregivers more guiding and directive in situations that have a more acute character than in situations that are more chronic of nature?

A further question relates to the living situation of persons with Prader-Willi syndrome. Is there a difference between living at home with the parents versus living in community-based facilities supervised by professional caregivers? Community-based living conditions are known to provide more freedom of behaviour compared to living in an institution. Studies showed that persons with an intellectual disability who lived in a community-based setting with less restrictions functioned more autonomously, were more independent, experienced more choice-making opportunities, and were more satisfied with their social life compared to persons that lived in larger scale (institutional) group homes. Community-based environments also were found to enhance the self-determination of persons with an intellectual disability (Barlow \& Kirby, 1991; Schwartz, 1995; Felce et al., 2000; Wehmeyer \& Bolding, 2001).

In a previous study, we showed that in the prevention of obesity for persons with Prader-Willi syndrome there is more at stake than the dichotomy of autonomy for the person with Prader-Willi syndrome versus paternalism by the caregiver. In analysing interviews with parents and professional caregivers, more subtle ways of dealing with overeating could be distinguished besides leaving the choice to the individual with Prader-Willi syndrome or taking over the decision (Van Hooren et al., 2002). The more subtle interventions we found, corresponded with models of physician-patient interaction, developed by Emanuel and Emanuel (1992). The central question in the present study is how caregivers, both parents and professionals, value these various intervention approaches and which they prefer in specific situations.

Emanuel and Emanuel (1992) have outlined four different models of physicianpatient interaction: (1) the paternalistic model, (2) the informative model, (3) the interpretive model and (4) the deliberative model.

According to the paternalistic model the physician encourages the patient to consent to the medical intervention chosen by him. In this model, the physician acts as the patient's guardian.

In the informative model the objective of the physician-patient interaction is for the physician to provide the patient with all the relevant information so that the patient can select the medical intervention she or he wants. The physician then executes the selected interventions. In this model, the physician is a purveyor of technical expertise, providing the patient with the means to exercise control. 
In the interpretive model the physician helps to elucidate the patient's values, and to make clear what she or he actually wants. This model assumes that the patient's values are not always fixed and known to the patient. These values often are inchoate and conflicting. Therefore, the physician works with the patient to reconstruct the patient's goals and aspirations, commitments, and character. The physician is a counsellor, engaging the patient in a joint process of understanding.

The deliberative model, like the interpretive, sees the aim of the physician-patient interaction as helping the patient to determine and to choose the best values for her or his health. But unlike the interpretive model, the values of the patient not only need to be clarified, they also are open for development and revision through moral discussion and deliberation. The physician may suggest that certain health-related values are more worthy and should be aspired to. In this model, the physician's role is that of a teacher or friend.

Thus, these models of interaction go further than just a way of communicating; they embody an attitude and role towards the client.

In analysing interviews with parents and professional caregivers in a previous study (Van Hooren et al., 2002), as described earlier in this introduction, we found ways of dealing with the prevention of obesity that correspond with these models of physician-patient interaction. Since these models were developed by Emanuel and Emanuel (1992) based on empirical research on the vision of physicians with respect to their relationship with patients, we translated the models from the cure to the care setting. In this translation we extended the logic of these models by focusing on the character of the process of interaction between the caregiver and the care receiver with Prader-Willi syndrome and by focusing on the emotional aspects of this interaction[16]. The informative model, in which the caregiver in his role as technical expert provides the client with all the relevant information, mainly focuses on a professional caregiver. The paternalistic, interpretive and deliberative models however can be interpreted in a broader way and can also be applied to parents, for these latter three models embody respectively a guardian, advisory and teaching role. Since none of the caregivers in the previous study (Van Hooren et al., 2002) opted to leave the choice entirely to the person with Prader-Willi syndrome, the limited focus on interaction in the informative model is not a relevant obstacle in the present study.

In this study the following specific questions were formulated:

I How do caregivers (parents and professionals) value the various intervention approaches we found and extended (Van Hooren et al., 2002) on the basis of the models of Emanuel and Emanuel (1992)? Do caregivers prefer to leave the choice to the child / client with Prader-Willi syndrome or do they prefer to intervene in problem situations?

II Does the sort of problem (eating versus behaviour) influence caregivers in their preferences for the various intervention models? Is there a difference in these preferences between situations in which eating problems play a role and situations in which behaviour problems are central? 
Is there an effect of the acuteness of the situation on the preferences for the various intervention approaches of caregivers? Is there a difference in these preferences between acute and non-acute problem situations?

Does the living situation of the person with Prader-Willi syndrome influence caregivers' preferences in the intervention models? Is there a difference between living at home and living in community-based settings in these preferences by caregivers?

III Are there differences between parents and professional caregivers in how they value the various intervention approaches, and which they prefer in which situation (dependent of the sort of problem, the acuteness of the situation, the living setting, and the effect of an explanation of the various intervention approaches)?

\subsection{Method}

\subsubsection{Sample}

In the present study a total of 14 professional caregivers and 24 parents of persons with Prader-Willi syndrome participated. The group of 14 professionals consisted of 2 psychologists, 3 pedagogues, 1 care coordinator, 5 personal caregivers and 3 caregivers connected to the group in which the client with Prader-Willi syndrome lives. The group of 24 parents consisted of 10 fathers and 14 mothers.

These participants all have been part of a previous qualitative study in which they were interviewed about their ideas with respect to the prevention of obesity of their child and their preventive behaviour (Van Hooren et al., 2002; 2005). Initial contacts with parents and professional caregivers were made in cooperation with the Centre for Clinical Genetics in Maastricht, the Netherlands, and with the Dutch Prader-Willi Parent Association.

\subsubsection{Procedure and measurements}

Several intervention strategies have been developed on the basis of the models of physician-patient interaction developed by Emanuel and Emanuel (1992). In two meetings, one with parents and one with professional caregivers, these intervention strategies have been explained and discussed (paternalistic, informative, interpretive and deliberative strategies, see table 1). The aim of the meetings was to invite participants to reflect upon the issue of respect for autonomy in relation to interventions to prevent obesity. Furthermore, the meetings were aimed at creating awareness for alternative ways of intervening approaches besides paternalism.

Eight cases that focused on a specific problem related to the Prader-Willi syndrome were presented to parents and professionals. The cases were constructed on the basis of previous study of the daily practice of care for individuals with Prader-Willi syndrome (Van Hooren et al., 2002; 2005). The eight cases (see appendix B) were varied on three dimensions: (1) eating problem versus behavioural problem, (2) acute versus chronic situation, (3) living at home versus living in community-based settings. 
On the basis of the four models, four kinds of strategies have been developed. These have been described in two lines on cards. Of each strategy a short and a long version was made. The participants were asked to lay out these cards in order of preference for each of the eight cases that were presented to them. The four strategies were formulated on the cards as follows:

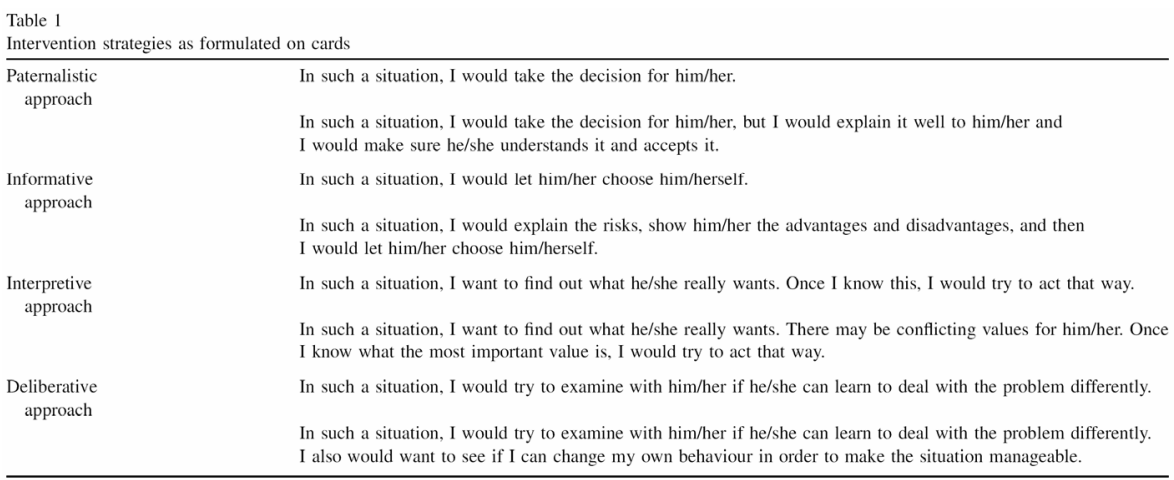

The parents and professionals were asked to rate the different intervention strategies according to their preferred way of dealing with the problem two times, before the explanation and discussion of the models, and afterwards. This was done to find out if an explicit explanation and discussion of the four interaction models created a learning effect.

\subsubsection{Statistical analysis}

The data collected through preference rankings of the intervention strategies were subjected to a multidimensional scaling procedure (Alscal) (Cox \& Cox, 2001). This allows for exploring how parents and professional caregivers perceive the different interaction strategies and how they form their preferences for these different strategies. In this procedure dimensions are uncovered explaining subjects' preferences for the different cases. The intervention strategies are represented as points in an $n$ dimensional space, and subject-case combinations as ideal points. The idea is that strategies that are closest to an ideal point (for a specific subject-case combination) in this space have the largest preference for the subjects in this case, whereas strategies that are farthest away from the ideal point have the smallest preference. Both the subject-case combinations and strategies have a position on each of these dimensions, which can be interpreted as a cognitive dimensions underlying subjects preferences on intervention strategies for a particular case.

The ideal-points form the dependent variable for further analyses. It is investigated how the ideal points change as a function of situational factors (which characterize the cases), as a function of the personal factors (parents versus professionals), and as a function of the intervention. Since there are multiple measurements (i.e. ideal point 
scores) within each subject, therefore leading to dependencies among observations, multilevel analysis (Snijders \& Bosker, 1999) is an appropriate technique to investigate these issues. The following factors were included as independent variables in the model: acuteness of the situation (acute $=1$ versus chronic $=0$ ), type of problem (eating $=1$ versus behavioural $=0$ ), location of the situation (living at home $=1$ versus community-based setting $=0$ ), type of respondent ( parent $=1$ versus professional caregiver $=0$ ), and intervention (before $=0$ or after the intervention $=1$ ).

\subsection{Results}

The Alscal analysis shows that with one dimension only, $99 \%$ of the variance in the preference data could be explained. The addition of more dimensions revealed only very few extra explained variance. Moreover, these extra dimensions were difficult to interpret.

This one dimension seems to represent the amount of active intervention that parents and professional caregivers perceive with respect to the different interaction strategies. The scores of the different interaction strategies on these dimensions are given in Table 2.

Table 2

Scores and ordering of intervention strategies on one dimension

\begin{tabular}{|c|c|c|c|c|}
\hline \multirow[t]{2}{*}{ Intervention strategy } & \multicolumn{3}{|l|}{ Scale value } & \\
\hline & Total group & Parents & Professionals & \\
\hline Paternalism (short version) & 1.6390 & 1.6446 & 1.9543 & \multirow[t]{8}{*}{ Most intervening } \\
\hline Paternalism (long version) & 0.8638 & 0.7074 & 1.3851 & \\
\hline Deliberation (short version) & -1.1893 & -1.2502 & -1.3164 & \\
\hline Interpretation (long version) & -1.3443 & -1.3796 & -1.5082 & \\
\hline Deliberation (long version) & -1.3697 & -1.4031 & -1.5304 & \\
\hline Interpretation (short version) & -1.8124 & -1.8611 & -1.9138 & \\
\hline Information (long version) & -1.9215 & -1.8887 & -2.1096 & \\
\hline Information (short version) & -2.8001 & -2.8117 & -2.8996 & \\
\hline
\end{tabular}

The two paternalism strategies were situated at one extreme of the dimension by the respondents, the two information strategies at the other extreme. In between were the deliberation and interpretation strategies, both close to each other, with the short and long versions in about the same range or level. Both the group of parents and the group of professional caregivers situated these strategies in the same order.

\subsubsection{Effects: all respondents together}

In all cases intervening strategies were preferred over strategies in which the choice is left to the child / client. Table 3 summarizes the results of a multilevel analysis of the data for the total group of respondents, both the parents and the professionals. As table 3 shows, effects of all variables were significant. 
Table 3

Main effects for the total group

\begin{tabular}{lccc}
\hline & $\begin{array}{l}\text { Regression } \\
\text { coefficient }^{\mathrm{a}}\end{array}$ & S.E. & $t$-Value \\
\hline Sort of problem & -0.269 & 0.070 & $-3.84^{* * * *}$ \\
Acuteness of situation & -0.482 & 0.080 & $-6.03^{* * *}$ \\
Living situation & 0.675 & 0.065 & $10.38^{* * *}$ \\
Moment of measurement & -0.132 & 0.064 & $-2.06^{*}$ \\
Sort of respondent & -0.472 & 0.138 & $-3.42^{* * *}$ \\
\hline
\end{tabular}

${ }^{a}$ The more negative the regression coefficient, the higher the preference for active intervention.

$\begin{array}{rl}* & p<0.05 \\ p & <0.001 .\end{array}$

All respondents indicated that they prefer strategies with a more active intervention character when the central dilemma was an eating problem when compared to a behavioural problem. In other words, when a behavioural problem was involved, more importance was given to the perspective of the child / client than with an eating problem. In the cases in which an acute problem was central, respondents expressed the wish to intervene more actively than in cases with problems of a chronic character. It also became clear that they would intervene less actively in community-based settings than in situations at home. Furthermore, the group of professionals appeared to be more reserved in intervening than the group of parents.

With regard to the moment of measurement a significant effect was found, though less significant compared to the other effects. At the second measurement, more interventions were preferred by the respondents compared to the first measurement

Table 4

Main effects specified for professional caregivers and parents

\begin{tabular}{|c|c|c|c|}
\hline & $\begin{array}{l}\text { Regression } \\
\text { coefficient }^{\mathrm{a}}\end{array}$ & S.E. & $t$-Value \\
\hline \multicolumn{4}{|l|}{ Sort of problem } \\
\hline Professionals & -0.103 & 0.123 & -0.84 \\
\hline Parents & -0.359 & 0.080 & $-4.49^{* * * *}$ \\
\hline \multicolumn{4}{|c|}{ Acuteness of situation } \\
\hline Professionals & -0.322 & 0.123 & $-2.62^{* *}$ \\
\hline Parents & -0.562 & 0.080 & $-7.03^{* * * *}$ \\
\hline \multicolumn{4}{|l|}{ Living situation } \\
\hline Professionals & 0.591 & 0.123 & $4.80^{\text {*a: }}$ \\
\hline Parents & 0.720 & 0.094 & $7.66^{* * * * 4}$ \\
\hline \multicolumn{4}{|c|}{ Moment of measurement } \\
\hline Professionals & -0.118 & 0.114 & -1.04 \\
\hline Parents & -0.172 & 0.074 & $-2.32^{*}$ \\
\hline
\end{tabular}

a The more negative the regression coefficient, the higher the preference for active intervention.

${ }^{*} p<0.05$.

$p<0.01$.

**** $p<0.001$. 
To see whether the effects, described in section 3.1, were the same for parents and for professional caregivers, separate multilevel analyses have been done for each of these groups of respondents. The main effects for each group are summarized in table 4 .

Professional caregivers showed no significant differences between eating and behavioural problems in the preferred degree of intervention. Parents preferred more intervention in situations with eating problems than in situations with behavioural problems. Both parents and professionals preferred to intervene more actively in acute situations compared to situations with a more chronic character. This effect of acuteness of the situation on the preferred degree of intervention was however stronger for parents than for professionals. Both parents and professionals preferred less intervention in community-based situations than in situations at home. This change in the preferred degree of intervention was larger for parents than for professionals. With regard to the moment of measurement professional caregivers didn't show any clear differences in preferences between the first and second measurement. Parents preferred to intervene more actively at the second measurement compared to the first.

\subsection{Discussion and conclusion}

\subsubsection{Discussion}

The main results of this quantitative study, in particular the ordering of the four intervention strategies (Table 2), show that both the group of parents and the group of professional caregivers preferred intervening over not intervening in dealing with different problems in the care for persons with Prader-Willi syndrome. This finding corresponds with the results of our previous qualitative research (Van Hooren et al., 2002).

Furthermore, the rating of the informative strategies - in which choices are left totally to the person with Prader-Willi syndrome - by both groups as least preferable, corresponds with the limitations of a concept of autonomy as freedom of choice and as independent decision making of the intellectually disabled individual.

The total group of caregivers (both parents and professionals) preferred to intervene more actively in eating problems compared to behavioural problems. This corresponds with results of previous qualitative research (Van Hooren et al., 2002; 2005) in which both parents and professionals gave more opportunities for deliberative processes when dealing with behavioural problems. It further corresponds with the findings in those previous studies in which caregivers indicated that persons with PraderWilli syndrome have great difficulty keeping control over their eating behaviour -a well documented phenomenon in the literature on this syndrome (Holland \& Wong, 1999)- for which an approach with a non-intervening character would probably not be effective, and even harmful to the health of the individual. 
In several situations the group of professionals appeared to be more reserved towards intervening than the parent group. A possible explanation for this finding is that parents may be more emotionally involved with their children and may have a different perspective on relating to their children as compared to professional caregivers. Parents may be more inclined to act on the basis of a vision on education while professional caregivers may act more on the basis of a care plan (Van Hooren et al., 2005). Care plans may be influenced by institutional policy developments, aimed at enhancing self-determination, freedom of choice and own responsibility.

Another explanation for the more reserved attitude of professionals towards intervening may be that professional caregivers in general are less experienced with persons with Prader-Willi syndrome and the specific eating problems associated with this condition, compared to parents of children with this syndrome, but may have more experience in dealing with behavioural problems in general. From their experience with behavioural problems professional caregivers may be more inclined to interact with the client in a deliberative way, rather than being directive and controlling.

In the procedure respondents were offered the eight cases twice, before and after an explanation and discussion of the various interaction models. Professionals didn't show any clear changes in valuing the various interaction approaches between the first and second measurement. Parents however preferred to intervene more actively at the second measurement compared to the first. An explanation for this higher preference by parents to intervene after the explanation and discussion may lie in the discussion phase itself. Through a discussion with other parents and an exchange of similar experiences in raising children with Prader-Willi syndrome, parents may have discovered that more parents then they initially expected prefer to intervene with eating problems of their child. This may have had a confirmative and reinforcing effect on their initial opinions.

The present study shows a first step to proceed in a quantitative way with findings of a previous qualitative study aimed at getting insight in the practice of how caregivers value and deal with the prevention of obesity in the care for persons with PraderWilli syndrome. Most expectations, based on previous qualitative research (Van Hooren et al., 2002; 2005), have been confirmed in this quantitative study. However, two critical notes about the study design should be made.

In the design of this pre-test post-test study the time between pre-test and post-test differed for parents and professionals. Professionals filled in the post-test after the intervention (explanation and discussion) on the same day, while parents filled in the second measurement at a later point in time (on average about four days after the intervention). This may have influenced our findings, although we do not know what kind of influence this may have had.

A second weakness in our study was that we did not check the validity of the intervention. We are not sure if the parents and professionals fully understood the meaning and the (dis)advantages of the various models of intervening. Other ways of presenting and explaining these models, like the use of role-play or other less cognitive teaching methods, might be more effective to make these ways of intervening and their benefits more concrete. 


\subsubsection{Conclusion}

Both the parent group and the group of professional caregivers of persons with Prader-Willi syndrome prefer intervening above laissez faire. The group of professional caregivers appears to be more reserved towards intervening than the group of parents in several situations.

Differentiations are made by both groups of caregivers in the preferred degree of intervention, dependent on the sort of problem offered. Professionals however do not differentiate in their preference for the degree of intervention between eating problems and behavioural problems, in contrast to parents.

\subsubsection{Practice implications}

This study focused on preferences for intervention strategies by caregivers in a specific practice of care to persons with an intellectual disability and specific health related problems, the practice of care to individuals with Prader-Willi syndrome. The preference for intervening over not intervening by caregivers, both parents and professionals, has consequences for current policy, focusing on the enhancement of selfdetermination of clients. The citizenship paradigm should take into consideration that specific health problems of persons with an intellectual disability, like those in Prader-Willi syndrome, may imply the need for intervention. This means that autonomy and intervening should not be opposed to one another, but need to be combined. The focus should be on developing intervention strategies which help persons with an intellectual disability to actively deal with their situation.

Caregivers may feel the need to intervene, but they should be aware that different problems call for different kinds of interventions. Where a more active intervention may be helpful in an acute situation, and in situations with serious eating problems, strategies with a less active intervening attitude may form an alternative when dealing with more chronic situations with less prominent, behavioural problems.

The significant differences between the preferences of parents and professional caregivers that were found in this study may support the fact that in practice more and better communication between professional caregivers and the parents of clients is needed.

A last implication of this study refers to the fact that many persons, both caregivers and scientists, often see Prader-Willi syndrome as a condition that is not manageable at all. The findings of this study suggest that in this a differentiation can be made. 


\section{References}

Barlow, J., \& Kirby, N. (1991). Residential satisfaction of persons with an intellectual disability living in an institution or in the community. Australia and New Zealand Journal of Developmental Disabilities, 17, 7-23.

Berlin I. (1969). Four essays on liberty. Oxford University Press, Oxford.

Borne, H.W. van den, Hooren, R.H. van, Gestel, M. van, Rienmeijer, P., Fryns, J.P., Curfs, L.M.G. (1999). Psychosocial problems, coping strategies, and the need for information of parents of children with Prader-Willi syndrome and Angelman syndrome. Patient Education and Counseling, 38, 205-216.

Cox, T.F., \& Cox, M.A.A. (2001). Multidimensional scaling. Chapman \& Hall, London.

Curfs, L.M.G., Verhulst, F.C., Fryns, J.P. (1991). Behavioural and emotional problems in youngsters with Prader-Willi syndrome. Genetic Counseling, 2, 33-41.

Dykens, E.M., Kasari, C. (1997). Maladaptive behavior in children with Prader-Willi syndrome, Down syndrome and non-specific mental retardation. American Journal on Mental Retardation, 102, 228-37.

Dykens, E.M., Leckman, J.F., \& Cassidy, S.B. (1996). Obsessions and compulsions in Prader-Willi syndrome. Journal of Child Psychology and Psychiatry, 37, 995-1002.

Emanuel E.J. \& Emanuel L.L. (1992). Four models of the physician-patient relationship. JAMA, 267, 2221-6.

Felce, D., Lowe, K., Beecham, J., Hallam, A. (2000). Exploring the relationships between costs and quality of services for adults with severe intellectual disabilities and the most severe challenging behaviours in Wales: A multivariate regression analysis. Journal of Intellectual $\&$ Developmental Disability, 25, 307-326.

Holland, A.J., Treasure, J., Coskeran, P., Dallow, J., Milton, N., Hillhouse, E. (1993). Measurement of excessive appetite and metabolic changes in Prader-Willi syndrome. International Journal of Obesity, 17, 527-32.

Holland, A.J. \& Wong, J. (1999). Genetically determined obesity in Prader-Willi syndrome: the ethics and legality of treatment. Journal of Medical Ethics, 25, 230-236.

Holm, V.A., Cassidy, S.B., Butler, M.G., Hanchett, J.M., Greenswag, L.R., Whitman, B.Y., \& Greenberg, F. (1993) Prader-Willi syndrome: consensus diagnostic criteria. Pediatrics, 91, 398-402.

Hooren, R.H. van, Widdershoven, G.A.M., Borne, H.W. van den \& Curfs, L.M.G. (2002). Autonomy and intellectual disability: the case of prevention of obesity in Prader-Willi syndrome. Journal of Intellectual Disability Research, 46(7), 560-568.

Hooren, R.H. van, Widdershoven, G.A.M., Bruggen, H. van der, Borne, H.W. van den, Curfs, L.M.G. (2005). Values in the care for young persons with Prader-Willi syndrome: creating a meaningful life together. Child: Care, Health and Development, 31, 309-19.

Lieshout, C.F.M. van, Meyer, R.E. de, Curfs, L.M.G., Koot, J.M., \& Fryns, J.P. (1998a). Family contexts, parental behaviour, and personality profiles of children and adolescents with Prader-Willi, Fragile- $X$, and Williams syndrome. Journal of Child Psychology and Psychiatry, 39, 699-710.

Lieshout, C.F.M. van, Meyer, R.E. de, Curfs, L.M.G., Koot, J.M., \& Fryns, J.P. (1998b). Problem behaviors and personality of children and adolescents with Prader-Willi syndrome. Journal of Pediatrics Psychology, 23, 111-20.

Schwartz, C. (1995). Assessing levels of personal autonomy among Israeli adults with intellectual disabilities living in group homes and apartment settings. Australia and New Zealand Journal of Developmental Disabilities, 20, 41-50.

Snijders, T., \& Bosker, R. (1999). Multilevel analysis: An introduction to basic and advanced multilevel modelling. Sage, London. 
Swaab D.F., Purba J.S. \& Hofman M.A. (1995). Alterations in the hypothalamic paraventricular nucleus and its oxytocin neurons (putative satiety cells) in Prader-Willi syndrome: a study of five cases. Journal of Clinical Endocrinology and Metabolism, 80, 573-9.

Wehmeyer, R, \& Bolding, N. (2001). Enhanced self-determination of adults with intellectual disability as an outcome of moving to community-based work or living environments. Journal of Intellectual Disability Research, 45, 371-83.

Whittington, J., Holland, A., Webb, T., Butler, J., Clarke, D., \& Boer, H. (2004). Cognitive abilities and genotype in a population-based sample of people with Prader-Willi syndrome. Journal of Intellectual Disability Research, 48, 172-87. 


\section{CHAPTER 5}

COMPETENCE IN THE CARE FOR PERSONS WITH INTELLECTUAL DISABILITIES: AN ALTERNATIVE FRAMEWORK

Widdershoven, G.A.M., Hooren, R.H. van, Berghmans, R.L.P., \& Curfs, L.M.G. Competence in the care for persons with intellectual disabilities: An alternative view. Manuscript Submitted for Publication. 


\begin{abstract}
Competence is a central issue in the care for persons with intellectual disabilities. If a person is competent, she is allowed to make decisions; if not, others will do so. Competence is a normative concept. It implies a threshold. It is dichotomous: a person is either competent or not competent. Competence is related to and can vary with concrete situations. The current criteria for competence set a high standard: people have to be able to communicate a decision, to understand information, to apply information to their situation and to reason about all aspects of the decision. Moreover, the emphasis is on cognitive capacities. This makes that persons with intellectual disabilities will often fail the test. An alternative approach is proposed, focusing on emotions and practical rationality. It is argued that this approach, which makes use of life story work and observations of behavioural patterns, is more adequate for the care for persons with intellectual disabilities. This is illustrated with two case examples of individuals with Prader-Willi syndrome.
\end{abstract}


Adult persons have the right to make decisions about their own life. In the care for persons with intellectual disabilities decisions are no longer taken without involving the client himself. In contrast with the period in which the medical model dominated and the caregiver decided, in the current citizenship model persons with intellectual disabilities play a central role in the care process. This is in line with developments in society and in health care. The patient, client or resident is no longer seen as an object of care, but also and foremost as a subject of care. Autonomy has become a central value in society and in health care. Autonomy means that one can make one's own decisions, even if these decisions are harmful to one's health. This presupposes that one is able to decide for oneself. Therefore a certain degree of competence is essential.

When is a person able to make a decision? In health care in general this question is not easy to answer. The question is even more difficult to answer in the care for persons with intellectual disabilities. Making high demands upon competence includes the risk that in important issues little space is left for the own choice of the person involved. This is not imaginary in the care for persons with intellectual disabilities. If on the other hand demands are low, there are hardly possibilities to ignore a person's wishes, even if this has serious consequences for his or her well-being. An additional problem is that criteria for competence tend to focus on cognitive capacities (Berghmans, 2001). It is questionable whether only these capacities are relevant for the concept of competence. Moreover, in persons with intellectual disabilities, cognitive capacities are often restricted. The cognition based approach of competence may lead to an improper marginalisation of people with intellectual disabilities in the decision making process.

This article aims to offer a reflection on the concept of competence, based upon practice. First several general characteristics of the concept will be discussed. Next, four criteria of competence will be distinguished. We will show that the standard interpretation of these criteria puts a one-sided emphasis upon cognitive capacities. We will make a plea for an alternative approach that starts from emotions and practical knowledge. Our reflection will be illustrated with two case examples.

\subsection{Two cases}

The two case examples described below concern a genetic condition, Prader-Willi syndrome. This syndrome is associated with mild to moderate intellectual disability (Whittington et al., 2004), though quite some cases have intelligence levels in the borderline range (Curfs, 1992). A characteristic feature of persons with Prader-Willi syndrome is an excessive appetite, frequently associated with overeating behaviour. The normal satiety response after eating is suggested to be impaired and delayed (Holland et al., 1993), possibly caused by a hypothalamic dysfunction (Swaab et al., 1995). This overeating behaviour frequently leads to obesity, which can be severe and lead 
to serious health problems. The overeating behaviour includes food-seeking activities like the raiding of garbage cans, shoplifting in food stores, and pilfering money at home and at school to buy food. Other behavioural problems frequently observed in persons with Prader-Willi syndrome, are temper tantrums and the tendency to argue, to show oppositional behaviour, rigidity, manipulation, possessive behaviour and stubbornness (Holm et al., 1993).

Bob

Bob is a 19-year-old young man with Prader-Willi syndrome. He has a mild intellectual disability and has recently left the parental home to move to a residential group home.

Bob works in a department store. In this store he assists in replenishing the stocks. Bob enjoys this work very much. His job coach is generally satisfied with Bob. Bob understands what he needs to do and he learns quickly. A problem for the job coach is Bob's tendency to argue about working hours. If he doesn't feel like working anymore, he looks for excuses to go home earlier. He says that since he doesn't get paid properly, it cannot be expected that he works all the time. The job coach at times becomes tired of all the arguments brought up.

To keep Bob's weight under control but also to give him some freedom of choice, the caregivers have decided to work with a food control program ${ }^{1}$, in consultation with Bob and his parents. Bob has learned quite quickly how the food program works. He knows by heart the amount of calories of all kinds of food. Bob constantly wants to change things in his diet and wants to discuss over and over what he can and cannot have to eat. At first, his caregivers seriously start deliberating with Bob to fit in his wishes in the diet, but Bob is never satisfied and constantly suggests new combinations of food. The deliberations increasingly result in fierce debates in which Bob more and more gets temper tantrums. The permanent discussions have a negative influence on Bob's feeling of happiness and on the relationship between Bob and the caregivers. Furthermore, Bob has been putting on weight since the introduction of the food program. However, Bob wants to continue with the program. After all, it gives him the opportunity to make his own choices.

Jodie

Jodie is a 25-year-old woman with Prader-Willi syndrome. She has a mild intellectual disability. Jodie has been living in a group home for several months. Before she moved to the group home, she used to live with her parents. Her parents were very strict and kept Jodie under control.

As part of a supported employment program Jodie works at a small insurance office. In this office Jodie makes coffee, administrates and distributes the post and now and then copies documents. From the start, Jodie was enthusiastic about her work. She 
tended to ask for more tasks. Jodie's job coach had concerns about this. When Jodie got too many responsibilities, she made mistakes, and the situation would get out of hand. Jodie was not able to see what amount of work she could handle. In order to prevent stress, the job coach gave more structure to Jodie's work, and limited the number of tasks. After working in this more structured way for a while, and with the constant help of her job coach, Jodie got used to it and learned what she needed to do and what not. She now feels more relaxed at work.

Jodie likes living in the group home. She has a good contact with the other residents. The caregivers of Jodie have been working with a food control program for her since she moved into the group home. The caregivers opted for this program because the program creates the opportunity for Jodie to express her food preferences within healthy limits. Although Jodie has already worked with the food cards for a while, she still doesn't know exactly what foods are healthy to eat and what are not. But she is getting used to the program quite well and the caregivers notice that Jodie is very satisfied with the variation and the choices the program offers. The caregivers do need to assist Jodie a lot in composing new diets. Once the changes in the diet are made, Jodie is pleased with the result, especially with the variety of things she can eat.

When the caregivers introduced the food program, Jodie's parents had their doubts. They never gave Jodie much choice at home. They always decided themselves what Jodie got to eat, which worked well and never really led to problems with Jodie. Since the introduction of the program Jodie has gained a few pounds of weight. Jodie's parents claim that Jodie is not able to make choices herself about food. Letting her continue to use the program does not make sense since she does not understand it, and will make choices that are detrimental to her health.

In these cases the issue is not so much whether these persons with Prader-Willi syndrome can control their drive for food or not, but whether they can (learn to) deal with the food program and be part of the decision making process in a meaningful way.

\subsection{General characteristics of the concept of competence}

Competence is a highly debated concept. Despite the different positions that are taken, there are several characteristics that are accepted in general.

In the first place competence is a normative concept (Appelbaum \& Roth, 1982; Charland, 2001; Berghmans \& Widdershoven, 2003). It not only concerns the (actual) question whether someone is able to do something, but also and especially the (normative) question whether someone is able to do something well enough. When a person is considered competent, he is allowed to decide on the care. Are Bob's requests to change his diet valid? Such a question cannot be answered by observation only; it refers to normative expectations and arrangements. 
The notion of competence is relative (Wikler, 1979). In many cases it is not a matter of 'all or nothing', but of 'more or less'. The same individual can at one time be more, and at another time be less competent to execute a certain task. And some persons are more competent than others with regard to certain tasks. As a relative concept the notion of competence allows a comparison between persons, as well as a comparison of the competence of a person in time. Both the moment of assessment and the circumstances, in which competence is assessed, can make a difference. In a stress situation, Jodie is less able to see what work she can manage than in less complex and more structured circumstances. In the former situation she is less competent than in the latter.

Competence is a threshold concept. Although competence is a matter of degree, the consequences of applying the concept have an 'all or nothing' character (Buchanan \& Brock, 1989, p. 28). It is hard to imagine that a person is considered 'partly' competent to give permission for a treatment (like a change in the diet in the case of Bob), or 'to a limited extent' competent to take a decision about his or her life. One can indeed state that a person is more competent than another person, or that a person in a certain situation is more competent than in another, but in concrete situations of choice an allor-nothing judgement has to be given, and a certain threshold needs to be taken as a criterion (Buchanan \& Brock, 1989).

Competence is a task-specific concept. It is always related to a specific judgement (Appelbaum et al., 1987). Few people are fully incompetent to execute tasks. An exceptional case is a person in a coma. Most people are competent to make certain decisions or execute particular tasks, but less competent or incompetent with regard to other decisions or tasks. With regard to the food program, Bob has the capacity to learn the amounts of calories of all kinds of food, whereas Jodie has not. If this capacity is seen as crucial, Bob would be competent for this task, and Jodie would lack competence. For other tasks, the situation might be different.

In sum, competence as the ability to make decisions is a normative notion, it is a threshold concept, and it contains an 'all-or-nothing' judgement with regard to the decision making of a person in a concrete situation. The question now is how to decide whether a person is competent. For this purpose, several criteria have been formulated in the literature.

\subsection{Criteria for competence}

In the literature - which is mostly related to psychiatry - various criteria for competence are proposed (Welie, 2001). The classification of Grisso and Appelbaum (1995) covers most of the current criteria. They distinguish four criteria: the capacity to make and express a choice, the capacity to understand information, the capacity to appreciate one's own situation, and the capacity to reason. We will briefly explain these criteria and give some comments. 
The first criterion involves the capacity to make and express a choice. This criterion does not put a high standard; it merely demands that it should be clear that a person makes a choice. This apparently simple criterion distinguishes persons who are completely unable to make their wishes or choices known (like people in a coma) and persons with whom communication is possible. Nevertheless problems can arise, and it will often be necessary to interpret wishes or choices of persons. This is for example the case with persons with severe cognitive problems. When dealing with the capacity to make and express a choice, an active attitude of the person who judges is necessary. One should not exclusively have an eye (and ear) for verbal communication (and the interpretation of verbal utterances), but also for non-verbal communication.

The first criterion is very broad. As soon as we can speak of a choice, the person involved is competent. This minimal criterion offers - independently applied - maximum protection to the right to self-determination. The question however is what the practice of the right to self-determination means in a concrete case. Looking at the cases, Bob is competent according to this criterion, and his wish to continue with the food program is valid, no matter what his reasons are for this. Jodie is also competent, according to this criterion, since she expresses satisfaction with the program.

Application of this criterion brings along the risk that 'choices' of persons are respected that can have adverse consequences for their health or well-being, while insight is lacking in the quality of the decision making of the person involved. What motivations lay behind the wish to want something or not, what reasons a person has for a certain decision, and whether he understands the consequences, is not relevant if one only uses this criterion.

\section{b. the capacity to understand information}

The second criterion focuses on the capacity to understand information, related to the specific decision. Comprehension of information usually is conceived as the ability to understand matters that are relevant with regard to informed consent. The Dutch legal doctrine (WGBO, article 7: $448 \mathrm{BW}$ ) specifies the following elements:

- the nature and the aim of the examination or treatment, deemed necessary by the caregiver, and of the required actions;

- the expected consequences and risks for the health of the patient;

- other possible methods of examination or treatment;

- the health condition and prospects of the person with regard to the domain of examination or treatment.

The ability to understand relevant information needs to be distinguished from the actual understanding of that information. A person can have the ability to understand something, but because of impediments may lack actual comprehension. These impediments can have an internal nature, for example (temporary) confusion or stress. 
They can also have an external nature, for example because the information is offered incomplete or is not presented clearly structured, or because this does not sufficiently fit to the (intellectual) frame of reference of the person involved.

This criterion emphasises the cognitive capacities of the person involved to understand information. For Bob and Jodie the relevant question is whether they understand the purpose and the consequences of the food program. Bob seems to understand how the program works, since he even knows by heart the amounts of calories of foods. Jodie has less understanding of the program, she does not seem to see how it really works.

This criterion is stricter than the first one. It excludes more situations. However, the question can be raised whether comprehension of information is sufficient to consider a person competent. What if a person does understand that something can be hazardous in general, but thinks that that he himself is immune for danger? This leads to the third criterion.

\section{c. the capacity to appreciate one's own situation}

The third criterion highlights the capacity to apply information to the individual situation of the person involved. It entails the capacity to appreciate one's own situation. 'Appreciation' of the nature of the situation and the possible consequences implies the acknowledgement of the fact that relevant information actually is applicable to the own situation of the person involved (Berg et al., 1996; Appelbaum \& Grisso, 1995; Grisso et al., 1995).

The appreciation criterion meets several objections against the exclusive use of the former two criteria. It implies other requirements than just making a choice or understanding information. It involves the relation between the information and one's own situation. Do Bob and Jodie meet this criterion? Bob seems to meet it; he understands that the food program can be used to make decisions about his diet, and to make combinations of food that suit him. For Jodie it is less likely that she meets this criterion. Given that she does not really understand how the program functions in general (see criterion b.), she is not able to apply the program to her own situation. The caregivers guide her through the program, and Jodie does not seem to understand how the results come about, although she is pleased with them.

\section{d. the capacity to reason}

Apart from the capacity to make a choice, the capacity to understand information and the capacity to appreciate that information, a fourth criterion is described in the literature, namely the capacity to reason. This involves the skills to use logic in comparing treatment options and their benefits and disadvantages (Appelbaum \& Grisso, 1995). This criterion relates to those cases in which a person evidently is able to make a choice, understand information and value the situation, but draws strange conclu- 
sions when it comes to the question what treatment is advisable in the light of the relevant facts and values (Berg et al., 1996, pp.357-358).

In the literature this criterion is interpreted in a cognitive way. Eight cognitive functions are mentioned as necessary for rational thinking: 1 . seeking information; 2 . consequential thinking; 3. comparative thinking; 4. complex thinking; 5. generating consequences; 6. weighting consequences; 7. transitive thinking; and 8. probabilistic thinking (Grisso et al., 1995, pp.134-135). Interpreted in this way, the criterion sets high standards for the decision-making process. Bob seems to fulfil them more or less. $\mathrm{He}$ is able to think in terms of consequences, able of comparative thinking, see through consequences and weighing them and think in terms of chances. Knowing the calorie amounts of food products by heart, he can make comparisons. He knows that in composing his diet, choosing one food product has the consequence that another product has less chance of getting fitted in too. Jodie has much less insight in the food program, and seems not able to make use of it to make the relevant choices for herself.

The four criteria presuppose and complement each other. This leads to the conclusion that they are all relevant. This puts high demands upon people's capacities (Berghmans et al., 2004). Moreover, the criteria focus on cognitive capacities. This makes the demands for people with intellectual disabilities even higher. The consequence of using the criteria in the way just described will be that many persons with intellectual disabilities will fail to meet the standard, and will not be considered competent to make decisions about their lives and care. This is evident in the case of Jodie. On the other hand, people who do meet the criteria will get the opportunity to make their own decisions, even if one may doubt whether they are really able to integrate the consequences of their choices into their own life. The case of Bob shows that he is able to use the food program to make suggestions for dietary changes. Yet, one may wonder whether the constant discussions about the program with his caregivers and the temper tantrums are really a sign of handling the food program in a balanced way. In both cases the question can be raised whether enough justice is done to the abilities of the person involved and whether there is enough room for the caregivers to offer good care. Is there no way to involve Jodie's experience with the food program in the process of decision making? Is there no possibility to raise doubts about the way in which Bob handles the food program?

\subsection{Emotions and practical rationality}

The criteria discussed above strongly emphasize cognitive capacities. Understanding information, applying it to one's own situation and being able to reason adequately, are regarded as skills related to procedural processing of information. It may be doubted whether these criteria do justice to matters that are relevant in decision making, especially with regard to crucial issues in life (Berghmans \& Widdershoven, 
2003). The question is also whether these criteria are appropriate for the assessment of decision-making capacity by persons with intellectual disabilities.

In ordinary life, emotions play an important role. In making friends or starting relationships, in choosing an education or employment, in buying a house, emotional aspects are at stake. What matters is whether a person is interested in, has confidence in, believes in, is prepared to invest in the object of choice. The emphasis is not only on benefits, but also and especially on the question whether the choice fits to who a person is and wants to be. That appears pre-eminently from the emotions related to such choices. According to Nussbaum (1990) emotions are essential to moral action. Emotions are a source of knowledge because they give vital information about how a person experiences a situation. This experience is related to the aims, values and states of affairs that are relevant to the person. Such vital forms of appreciation are not opposed to more conceptual forms of knowledge. Emotions can be considered as preconceptual ways of knowing and appreciating the situation. While rational choice theories suspect emotions, in ordinary life radical choices without any emotion are considered suspect. Charland (1998) therefore pleads for giving emotions a role in the conceptualisation of competence.

Major life decisions (decisions about relationships, education, work, a house or children) require the disposal of practical rather than theoretical rationality (Benaroyo \& Widdershoven, 2004). This implies practical knowledge about what is right in the situation, and about one's own possibilities and limits. Practical knowledge is not a form of knowing that, but of knowing how (Ryle, 1949). It is embedded in action, and is developed further through action. Practical knowledge demands experience. It is not based upon reflection on the consequences of the decision, but on previous experience with similar situations and skill in applying the required procedures for it. Again, emotional aspects play an important role. From someone who makes a major life decision, we expect a certain involvement with the situation, based upon experience and skill.

In choices of persons with intellectual disabilities, emotions and practical rationality are clearly relevant. Choices with regard to care require experience, involvement and engagement. When theoretical rationality is present only to a limited extent, practical rationality can still be possible. The case of Jodie is a good example. In terms of calories she doesn't know what healthy food is. She is however able to integrate the use of the food program into her practical way of dealing with food. On the basis of her theoretical knowledge of the food program she is not able to make a well-considered decision, but in her action she shows she is able to manage the situation. It could be argued that this can be relevant for the decision whether to continue the food program or not. Although Jodie cannot understand the facts and consequences of the program, it does fit into her life pattern. It structures her practice of dealing with food and provides her with stability. Once she has a clear structure, she knows how to handle the situation, which makes her feel more comfortable. This is also evident in 
her work. From the viewpoint of practical rationality Jodie can therefore be seen as competent to make a decision regarding the continuation of the program.

For Bob the situation is different. Theoretically he can understand the food program, but the question remains whether he can also integrate it practically into his life. Although he knows the food cards by heart, he does not use them to make a balanced diet, but to start discussions with his caregivers, often ending in fierce debates and temper tantrums. The same can be seen in his work, where Bob has the tendency to argue with his job coach. It can be seriously doubted whether Bob can manage the food program and make it meaningful for structuring his life. From the perspective of practical rationality, Bob's way of dealing with the food program is not as competent as he himself seems to think. Therefore, caregivers might be entitled to try and make him use the program differently, or to suggest other ways of dealing with food choices, although Bob wants to stick to the food program.

Emotions and practical rationality throw a new light on the competence of persons with intellectual disabilities. Cognitive capacities are not decisive. Jodie has less cognitive capacities than Bob, but with regard to the food program she has more skills to manage it in a practical way and use it to compose her diet. Bob understands the food program cognitively well, but is not able to deal with it in a practical way. From the perspective of practical rationality, Jodie is competent, and Bob is incompetent. This conclusion is exactly opposite to the conclusion following from the cognitive interpretation of the criteria.

A further question is how to actually apply an approach of competence in terms of emotions and practical rationality. How to assess competence on the basis of emotions and practical rationality? Emotions are expressed in stories, and can also be elaborated and developed in them. In stories people show what really matters to them, how they view the world, and what they value. Stories also put those things that obviously matter in a broader perspective, the perspective of a personal (life) history. The life story elucidates the values of a person and unifies them. Working with life stories can give insight in issues that are relevant to persons with intellectual disabilities (Meininger, 2005). The question whether someone's choice is meaningful and fits into his life can be answered through the life story. In the case of Jodie the life story can elucidate what structure and support mean to her. In this way her attitude towards the food program can be placed in a broader perspective. In the case of Bob his life story can make clear his character, which is associated with his tendency to argue. This does not mean that one should accept this tendency without further ado. The challenge for the caregivers will be to find ways for Bob to combine his need for expressing himself with the development of a more adequate way of handling the program.

Next to emotions, which can be elucidated in the context of a life story, the concrete actions of a person are relevant. Do these actions show that the person can manage the situation? A judgement of competence requires that a person knows how to ar- 
range her life so that her choices fit into it. To be able to judge that, the behavioural pattern of the person needs to be investigated. Although she needs assistance from her caregivers, Jodie is able to deal with the food program in an adequate way. She uses it to structure her dietary choices and she is satisfied with the results. Her behaviour demonstrates a hold of the situation. Bob is able to understand the logic of the program. Yet, he does not use it to compose a balanced diet, but to propose constant changes and to find arguments for debate with his caregivers. His behaviour shows that the program does not actually help him to manage the situation, but makes him more agitated and angry. His pattern of behaviour around eating is not stable. He does not show the ability to handle the situation adequately.

From a practical perspective, a person is competent when she is able to handle the situation. This does not mean that she has to comply with the caregiver's views on what is healthy. The focus is on the way in which the person handles the situation, not on the actual decision she makes. Jodie can be judged competent in handling the program, not because she chooses specific (for instance healthy) food combinations, but because she integrates the program in her eating practice. The food she chooses with the help of the program might not be totally healthy (since she gains some weight), but this is not relevant for her competence. Likewise, Bob is incompetent, not because he chooses a specific kind of food (for instance unhealthy food). The reason for deeming him incompetent is that his way of handling the program does not contribute to a stable and balanced eating practice. Even if the food he would choose would be perfectly healthy, his continuous tendency of changing the diet and arguing about it would still make him incompetent. Of course, the fact that Bob is gaining weight will be a relevant factor for his caregivers to question his competency. But the focus should not be on Bob's concrete food choices, but on the way in which he handles the eating program. Even if Bob would not gain any weight, his constant tendency to argue about food should be regarded as a way of behaving that needs further attention and consideration.

An approach of competence in terms of emotions and practical rationality should focus on the life story of the person involved, as well as on her style of action (Higgs, 2004). Both aspects can be approached methodically, through discussions with the individual and his family and friends and through observations of his behaviour. In the practice of care for individuals with intellectual disabilities such activities are not unfamiliar. It is important to develop these further in a systematic way in order to judge competence. The focus should not be on assessing cognitive capacities, but on testing practical capabilities. Such tests require attention for practical behaviour in a socially supportive context. The test should not be presented as a barrier that has to be passed before people are allowed to make decisions, but as an interesting practice that one can learn to master. Such a way of testing may not be as standardised as a cognitive test, since it requires practical experience and subtlety on the side of the investigator. Yet, this does not make the procedure arbitrary. Giving or denying persons the right to decide on the basis of general cognitive tests may be regarded as more arbitrary and unjust than developing practice-based ways of assessing competency. 
Autonomy requires competence. In the care for persons with intellectual disabilities this is not different from health care in general. It is important that competence is related to the situation. A person can, dependent on the moment or the nature of the decision, be competent or not competent. A judgement of incompetence need not be valid forever or for each sort of decision.

In the literature four criteria of competence are distinguished. These criteria complement each other. Together these make high demands upon the capacities people need to have. For persons with intellectual disabilities this results quite often in a judgement of incompetence. Apart from the weight of the criteria, there is a strong emphasis on cognitive capacities. People with intellectual disabilities have more limited cognitive capacities. That means they do not easily meet the demands. The example of Jodie shows this clearly. Apart from that the question can be raised whether cognitive capacities are decisive when it comes to taking decisions. To be able to reason well does not mean that a person knows how to arrange her life. The story of Bob is an example of this.

Emotions and practical rationality form an alternative basis for the assessment of competence. This approach is more adequately to the care for persons with intellectual disabilities than the current cognitive criteria. It can be practically realized through the use of life stories and the observation of behavioural patterns. This approach offers the possibility to give a positive role to persons who are not able to reflect theoretically, but do have a hold on their lives in a practical way. On the other hand, it justifies intervention when cognitive capacities are not in line with practical experience.

As far as the practical implications of this alternative framework are concerned, being attentive to emotions and practical rationality involves more than looking at cognitive capacities when assessing competence. The expression of emotion (or the lack of it) may show how involved a person is in the situation and how it is experienced. Practical rationality, interpreted as an ability to integrate choice and decisions into your life, may be intact and adequate, while theoretical rationality is flawed or absent. The focus in the process of assessing competence is less on the ability of the person to understand his or her situation and to act on this understanding, then on the ability to handle the situation and to fit this into his or her life. 


\section{Note}

1 The food control program, the so-called 'dot diet', is an aid tool to eat healthy and prevent obesity. At a number of charts food products are depicted, in combination with coloured dots. The colour of the dot tells a person whether the food is healthy or not. Furthermore, the number of dots represents the amount of calories of that food product. Per day a certain amount of dots can be consumed. Within that number a person has a certain freedom of choice in what products to take. 


\section{References}

Appelbaum, P.S., \& Roth, L.H. (1982). Competency to consent to research: a psychiatric overview. Archives of General Psychiatry, 39, 951-8.

Appelbaum, P.S., Lidz, C.W., \& Meisel, A. (1987). Informed consent. Oxford University Press, New York.

Appelbaum, P.S., \& Grisso, T. (1995). The MacArthur treatment competence study. I: Mental illness and competence to consent to treatment. Law and Human Behavior, 19, 105-26.

Benaroyo, L., \& Widdershoven, G. (2004). Competence in mental health care: a hermeneutic perspective. Health Care Analysis, 12, 295-306.

Berg, J.W., Appelbaum, P.S., \& Grisso, T. (1996). Constructing competence: formulating standards of legal competence to make medical decisions. Rutgers Law Review, 48, 345-96.

Berghmans, R.L.P. (2001). Capacity and consent. Current Opinion in Psychiatry, 14, 491-9.

Berghmans, R.L.P., Dickenson, D., \& Meulen, R.H.J. ter (2004). Mental capacity: in search of alternative perspectives. Health Care Analysis, 4, 251-63.

Berghmans, R.L.P., \& Widdershoven, G.A.M. (2003). Ethical perspectives on decision-making capacity and consent for treatment and research. Medicine \& Law, 22, 391-400.

Buchanan, A.E., \& Brock, D.W. (1989). Deciding for others. The ethics of surrogate decision-making. Cambridge University Press, Cambridge.

Charland, L.C. (1998). Appreciation and emotion: theoretical reflections on the MacArthur Treatment Competence study. Kennedy Institute of Ethics Journal, 8, 359-76.

Charland, L.C. (2001). Mental competence and value: the problem of normativity in the assessment of decision-making capacity. Psychiatry, Psychology and Law, 2, 135-45.

Curfs, L.M.G. (1992). Psychological profile and behavioral characteristics in the Prader-Willi syndrome. In: Prader-Willi syndrome and other chromosome $15 q$ deletion disorders (Ed. S.B. Cassidy), pp. 211-221. Springer-Verlag, Berlin.

Grisso, T., \& Appelbaum, P.S. (1995). Comparison of standards for assessing patients' capacities to make treatment decisions. American Journal of Psychiatry, 152, 1033-7.

Grisso, T., Appelbaum, P.S., Mulvey, E.P., \& Fletcher, K. (1995). The MacArthur treatment competence study. II: Measures of abilities related to competence to consent to treatment. Law and Human Behavior, 19, 127-48.

Higgs, R. (2004). The contribution of narrative ethics to issues of capacity in psychiatry. Health Care Analysis, 12, 307-16.

Holland, A.J., Treasure, J., Coskeran, P., Dallow, J., Milton, N., \& Hillhouse, E. (1993). Measurement of excessive appetite and metabolic changes in Prader-Willi syndrome. International Journal of Obesity, 17, 527-32.

Holm, V.A., Cassidy, S.B., Butler, M.G., Hanchett, J.M., Greenswag, L.R., Whitman, B.Y., \& Greenberg, F. (1993). Prader-Willi syndrome: Consensus diagnostic criteria. Pediatrics 91, 398-402.

Meininger, H.P. (2005). Narrative ethics in nursing for persons with intellectual disabilities. Nursing Philosophy, 6, 106-18.

Nussbaum, M.C. (1990). Love's knowledge. Essays on philosophy and literature. Oxford University Press, New York.

Ryle, G. (1949). The concept of mind. Penguin, Harmondsworth.

Welie, S.P.K. (2001). Criteria for patient decision making (in)competence: a review of and commentary on some empirical approaches. Medicine, Health Care, and Philosophy, 4, 139-51.

Whittington, J., Holland, A., Webb, T., Butler, J., Clarke, D., \& Boer, H. (2004). Cognitive abilities and genotype in a population-based sample of people with Prader-Willi syndrome. Journal of Intellectual Disability Research, 48, 172-87.

Wikler, D. (1979). Paternalism and the mildly retarded. Philosophy \& Public Affairs, 8, 377-92. 



\title{
CHAPTER 6
}

\author{
THE ROLE OF EMPIRICAL ETHICS IN DEVELOPING
}

NORMATIVE THEORY

Hooren, R.H. van, Borne, H.W. van den, Curfs, L.M.G.,Widdershoven, G.A.M. Providing good care in the context of freedom restrictive measures: The case of prevention of obesity in youngsters with Prader-Willi syndrome. In: G.A.M. Widdershoven, J. McMillan, T. Hope, L. van der Scheer (Eds.), Empirical ethics and psychiatry. Oxford University Press, Oxford, in press. 

It is only in recent years that empirical data have been systematically collected in order to help develop or adjust ethical theories. Instead of attempting to clarify and explain moral dilemmas with the help of ethical theories, principles and rules, an increasing number of ethics projects study specific care practices with the aim of explicating those moral rules and convictions that are intrinsic to these practices (Ten Have and Lelie, 1998). This chapter reports one such project, a study of the ethical aspects of the prevention of obesity in young people with Prader-Willi syndrome. In this study both a qualitative and a quantitative approach were used to gather data. We will compare the qualitative and quantitative approaches and analyse the differences between them.

The conflict between providing good care and respecting the client's autonomy is central to caring for people with Prader-Willi syndrome. Achieving autonomy is an important goal in human life in general, and is no less important in the lives of people with intellectual disability. Recent developments in the care of people with intellectual disability emphasize the promotion of self-determination, freedom of choice and responsibility. However, caregivers may sometimes feel frustrated by this focus on autonomy. They may be confronted with situations in which there is a conflict between providing high-quality care and respecting the client's autonomy. It is not always easy to decide what to do when a client's wishes and interests conflict. Should one respect the autonomy of the intellectually disabled person, or should one protect them against the adverse consequences of their choices?

These conflicts are prominent in the care of people with Prader-Willi syndrome (PWS). This genetic disorder is associated with mild to moderate intellectual disability (Whittington et al., 2004). Excessive appetite is a prominent feature of PWS and this can easily lead to overeating. It has been suggested that in PWS the normal satiety response is impaired and delayed (Holland et al., 1993), possibly through a hypothalamic dysfunction (Swaab et al., 1995). This overeating frequently leads to obesity, which can be severe and may cause serious health problems. Should caregivers leave the persons themselves to choose how much to eat, or should they intervene to protect them against the adverse consequences of their eating?

One of the mothers interviewed in a study we undertook expressed this dilemma as follows:

"In some countries, it is said, let them eat themselves to death, then at least they have had a happy life. This is very radical. Can we ever determine that overeating will make them happy? If we look at our daughter, we are glad that she is not too fat. She seems to be happy when she is able to run a little, can play a ball game, take part in walking contests and fits in a normal bathing suit and so on. She does not have to be beautiful, if only she is able to feel comfort- 
able with herself. Well, that already is quite a battle, and for that it is necessary that people decide for her what she can and cannot eat."

Empirical ethics aims, amongst other things, at developing normative theories which do justice to the complex and unique character of situations and practices (Van der Scheer et al., 2004). In this chapter we explore the complexity of the care practice of dealing with the prevention of obesity in persons with Prader-Willi syndrome. We stress the importance of developing a normative framework within this specific practice, relevant to the problems that emerge within this context. We believe that a framework which is developed on the basis of empirical data will provide more perspectives on, and approaches to, the moral conflict between respecting autonomy and providing good care than those which emerge from purely theoretical debates alone.

\subsection{The qualitative study}

Since little was known about the care practice of dealing with the prevention of obesity in people with Prader-Willi syndrome, we began with a qualitative study. Parents, and professional caregivers, were interviewed about their views on the prevention of obesity, and on the practical ways in which they tried to manage the situation in everyday life. The interviews combined an open approach, encouraging the interviewees to give a narrative about their experience of caring, with more structured questions following the stories told by the interviewees. The structure was organised around several themes: daily social intercourse, food practice, interaction in general, and social environment.

These qualitative interviews were conducted with 23 parents and 14 professional caregivers of 18 persons with PWS. Nine (age range 8 to 17 years) out of these 18 people with PWS lived at home and nine (age range 13 to 38 years) lived in a group home. Initial contacts with parents and professional caregivers were made in cooperation with the Centre for Clinical Genetics in Maastricht, and with the Dutch PraderWilli Parent Association. The interviews were recorded on audiotape and later transcribed with the consent of the participants.

\subsubsection{The narrative analysis}

The interviews were first analysed using narrative analysis of the transcripts as a whole. This analysis was not structured but involved a comparison of all the cases as a whole with each other at a general level. We looked at the differences in the ways parents, professional caregivers and the children or adults with Prader-Willi syndrome communicated, and what kind of attitudes were apparent. Interviews were coded. Codes were grouped, compared and categorized into themes. In this first qualitative analysis (Van Hooren et al., 2002) we found that none of the caregivers opted to leave the choice for food intake entirely to the person with Prader-Willi syn- 
drome. Neither did they simply intervene without taking into account the wishes of the individual with the syndrome.

Interviewer: Do you think it is necessary to lock the kitchen?

Father: No, not in our case. We want him to learn to cope with it himself. We can talk about it with him very well, and he also is fairly wise. That doesn't mean he never takes something out of the cupboard secretly.

Mother: We try to stimulate as much as possible her own responsibility. For example, she needs to take care of her homework herself, we don't go after that. By stimulating her own responsibility in all these other areas, so that she feels she is being trusted, we try to ensure that she can cope with food in a better way.

In these examples autonomy is promoted, not by giving freedom of choice, but by fostering self-understanding and self-development. The focus is not on negative freedom, but on positive freedom (Berlin, 1969). Negative freedom refers to freedom of choice without external interference. Positive freedom refers to a perspective of autonomy that is not a matter of individual self-determination, but of self-realisation through the support of others. Being dependent is therefore not the opposite of being autonomous; individual autonomy can be enhanced through dependency on others.

The data show that the process of care cannot adequately be seen in terms of choosing between respecting autonomy through securing freedom of choice on the one hand, and paternalism on the other. That is too crude. The stories indicated that caregivers see other options and act in other ways. As a starting point we used the four kinds of physician-patient interaction outlined by Emanuel \& Emanuel (1992). These authors define not only a paternalistic and an informative model (which are based on the traditional dichotomy between paternalism and autonomy in terms of selfdetermination). They add two further possible approaches to the physician-patient model: the interpretive model and the deliberative model.

In the interpretive model, the physician helps to elucidate the patient's values, and to make clear what she or he actually wants. This model assumes that the patient's values are not always fixed and known to the patient. The deliberative model, like the interpretive model, sees the aim of the physician-patient interaction being to help the patient determine and choose the best values for his health. But unlike the interpretive model, the values of the patient not only need to be clarified, they are also open for development and revision through moral discussion and deliberation.

We analysed the interviews with parents and professional caregivers in terms of these four models. The focus was not on discrete decisions, but on the general patterns of interaction between caregivers and people with Prader-Willi syndrome. The focus was not merely on rational but also on emotional aspects. The results showed that there were few examples that clearly corresponded to the informative model. Accord- 
ing to this model a caregiver would fully inform the person with PWS of the dangers of overeating, but leave the choice of eating behaviour up to that person. The accounts given by the caregivers often had a paternalistic tone. In addition, however, there were also elements in the stories showing that the process of care was directed towards fostering self-understanding or moral development. The stories were never totally in accordance with only one model, although one of the models was quite often dominant within a specific interview. Thus, cases of paternalism, of interpretive interaction and of deliberative interaction could each be distinguished.

This narrative analysis showed that the care practice of prevention of obesity in persons with Prader-Willi syndrome goes beyond the dichotomy of either respecting the individual's choice or of acting paternalistically. The stories make clear that most caregivers are not inclined to leave decisions to the person with Prader-Willi syndrome alone. On the other hand, neither do they always act paternalistically. Caregivers are also interested in fostering self-understanding and moral development. They do this in ways less rational than are presupposed by Emanuel and Emanuel. The analysis, however, shows that the theoretical models of Emanuel and Emanuel can help to understand the practice of care for persons with Prader-Willi syndrome, but also need to be adjusted to do justice to specific elements of this practice.

\subsubsection{Grounded Theory analysis}

In addition to this narrative analysis of the data in terms of types of interaction between caregiver and care receiver, we carried out a structured analysis of the interviews, using the constant comparative method as described in Grounded Theory ${ }^{1}$ (Strauss \& Corbin, 1990). The purpose of this structured analysis was to aid the development of concepts and theory (Van Hooren et al., 2005). The interviews were coded, and the codes were grouped, compared, and categorized into concepts. This analysis resulted in a theoretical framework consisting of three layers: values, conditions and interventions (see Figure 1). First, several values emerged. These values characterise what caregivers saw as important and what motivated them in their behaviour towards the child or client. Second, conditions were found that either interfered with or enhanced these values. These conditions reflect social contexts and situations. Third, interventions were found that caregivers apply in order to realize their values. In figure 1 an overview is given of this theoretical framework. The arrows show the direct connections between elements of the three layers ${ }^{2}$. 
Values

Enabling (+) and

Interventions

limiting (-) conditions

not to eat either

(as caregiver)

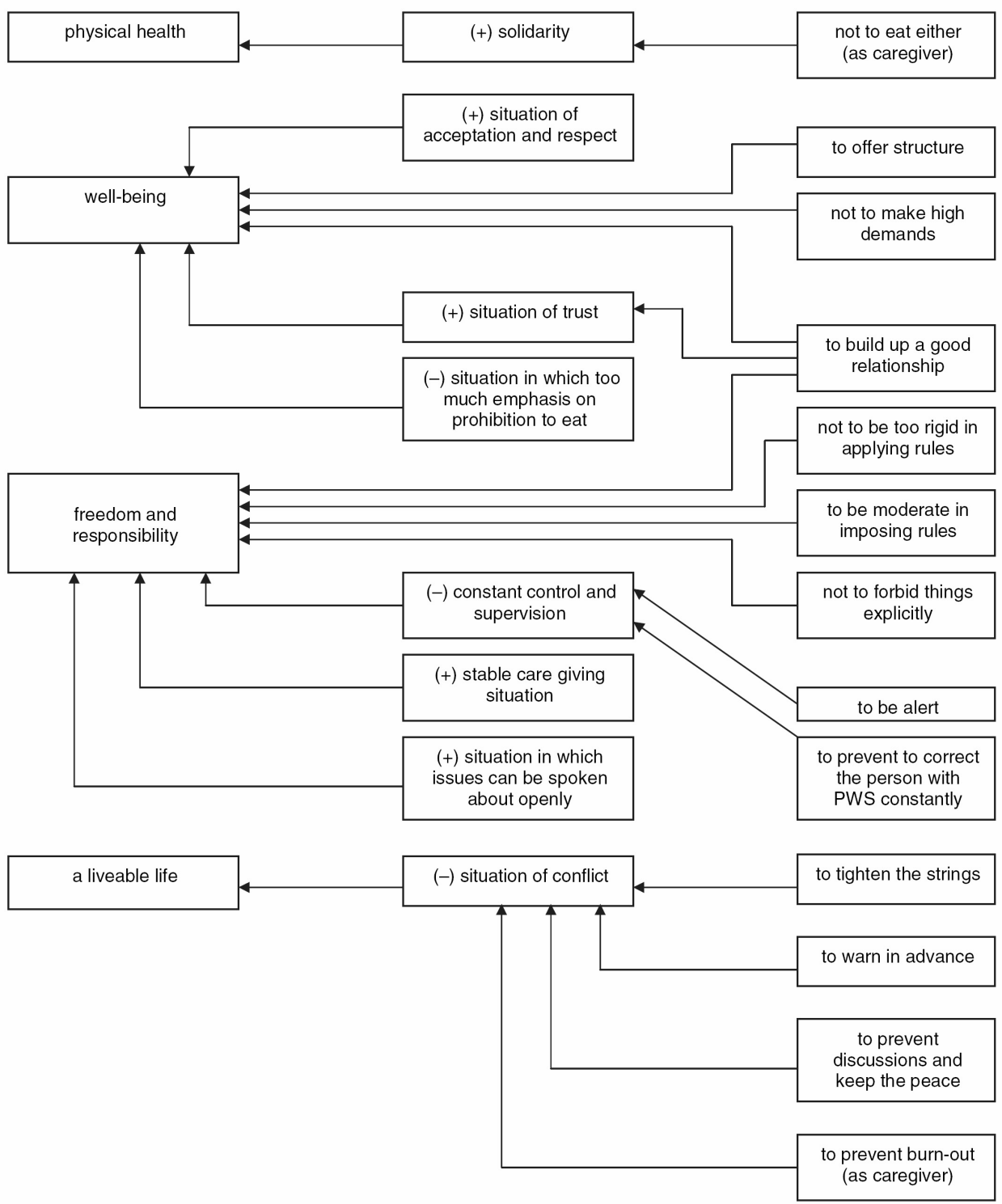

Figure 1. Theoretical framework. PWS, Prader-Willi syndrome. 
Several techniques were used in order to establish the different aspects of trustworthiness (Lincoln \& Guba, 1985). Prolonged engagement and persistent observation ${ }^{3}$ increased the chance that the research had high credibility. Peer debriefing, a review process in cooperation with colleagues and experts was carried out during the period of data analysis. The colleagues and experts had experience in grounded theory, health ethics and the Prader-Willi syndrome. Thick descriptions of cases were used to ensure transferability. Regular dependability audit meetings took place in order to guarantee the dependability of the different steps in the research process. In addition, regular confirmative audit meetings were held to guarantee the corroboration of the data. These meetings were also held with the experts, who read the transcripts of the interviews and checked the coding, categorization and interpretation of the data. These checks resulted in only small adjustments in each step of the process. The construction of a three-layer framework (Figure 1) resulted from the discussions with experts.

Various different values play a role in the care of people with Prader-Willi syndrome. A primary value is the health of the child or client. This is not surprising, as the urge to overeat can lead to significant obesity and hence damage to the person's health. In addition to this value on health, parents and professional caregivers consider it important for the person with Prader-Willi syndrome to feel good. Parents are happy when the child feels comfortable. Professional caregivers emphasize that the client needs to have a good quality of life. Thus, although it is important to try to prevent obesity, this should not be done at the expense of everything else. Happiness is more than health. A further value that caregivers considered important is that the person with Prader-Willi syndrome learns to lead his own life: a central value is freedom. This freedom is not conceived as being able to do what one wants, but being able to bear responsibility. A fourth important value is creating a liveable life for other people involved: parents, brothers or sisters, or other residents. Despite the emphasis on health, parents and professional caregivers clearly pay attention to the broader context in which the person with Prader-Willi syndrome lives. They emphasize the need of ensuring that life is bearable (under difficult circumstances) for all concerned, and taking care of the situation together. These values correspond to an ethics of care in which dealing with dependency through joint responsibility is central (Tronto, 1993; Walker, 1998). This shared responsibility means that room is created for coming to agreements together within a good caregiver-client relationship.

Parents and professional caregivers mentioned several conditions that influence the extent to which these desired values can be realized. Solidarity, a feeling of acceptance and respect and a situation in which issues can be discussed openly, play a positive role. Participants emphasised the relational character of such solidarity. A joint commitment and attention to the caring process has a positive influence on the shared values. On the other hand, constant supervision, and an obsessive concern with limiting the eating behaviour had a negative effect on promoting the key values. 
Caregivers described what actions they took in order to promote the values they see as important. They mentioned being alert, offering structure, being moderate in imposing rules, building up a relationship, keeping the peace, and spreading attention. These interventions have the character of a process. It is not a matter of choosing between being laissez faire or intervening, but of creating a context in which client and caregiver can develop a joint life. By offering structure the person with Prader-Willi syndrome can be helped to take responsibility for his behaviour. According to caregivers, interventions require tact and the ability to find the right balance. It is important to be alert without permanent control, and to offer structure without limiting the behaviour too rigidly. Furthermore, it is important to find a balance within the family or the group of residents. This requires finding a balance between attention for the person with Prader-Willi syndrome and for other family or group members. In that balance caregivers should also care for themselves.

In summary, caregivers do not focus only on the question of whether one should intervene or not. They try to create conditions for living that are acceptable and meaningful for everybody involved. They aim to maintain life by building up a relationship in which acceptance and respect are central. In this relationship a certain amount of independence and responsibility can be developed. In a permanent and stable context of care, in which there is room for creating trust, it is possible to deal with rules in a less rigid way and to look for where there is room for choices. This leads to a life that is characterized by a process of mutual commitment, support, care and shared responsibility.

\subsubsection{Conclusion}

Theoretical debates on the ethics of the prevention of obesity in Prader-Willi syndrome have focussed mainly on the question of whether one should intervene or not (Dykens et al., 1997; Holland \& Wong, 1999). These debates do not discuss sufficiently what an intervention should look like, or what good care means.

Both the narrative analysis and the grounded theory analysis show that there are limits to the individual freedom of choice for the person with Prader-Willi syndrome. Autonomy can, however, be conceived in a different way, in terms of positive freedom, instead of autonomy based on negative freedom. Both analyses show that from the perspective of autonomy as positive freedom the issue of preventing obesity can be approached in new ways, ways of interacting in which there is room for realizing and developing those values that are relevant to the client. This process of fostering autonomy requires a specific context of mutual trust, support, and openness. Instead of focusing on the question of whether or not to intervene, one should, according to this analysis, pay attention to various ways of intervening and to creating a context in which interventions help people to become more autonomous. 
We have argued that, in the prevention of obesity in Prader-Willi syndrome, the dichotomy between autonomy and paternalism is too crude and one-sided to do justice to the diversity and complexity of this care practice. More subtle ways of dealing with this issue can be distinguished. A further question is how parents and professional caregivers value these various approaches and which interventions they prefer in specific situations. In order to examine this question, several intervention strategies were formulated on the basis of the models of the physician-patient interaction developed by Emanuel and Emanuel (1992).

The intervention strategies formed the material for a quantitative study, which had two main aims. First, to see whether parents and professional caregivers understand and grasp the differences between the various intervention alternatives. Second to analyse the preferences of caregivers with respect to these approaches. We wanted to study whether parents and professional caregivers shared a preference for a specific intervention approach, and whether the sort of intervention was dependent on the nature of the situation and problem. The advantage of setting up a study with a quantitative nature is that it allows data to be collected from a greater number and range of caregivers and to look for systematic differences between groups. In two meetings, one with parents and one with professional caregivers, the four general types of intervention strategy were examined (paternalistic, informative, interpretive and deliberative strategies, see table 2). Eight cases, that focussed on a specific problem related to the Prader-Willi syndrome, were presented to parents and professionals. The cases were constructed on the basis of problematic situations identified in a previous study of the daily practice of care for individuals with Prader-Willi syndrome (Van Hooren et al., 2002; Van Hooren et al., 2005). As an illustration one of these cases is presented here.

\section{Leontien}

Leontien is a kind 17-year-old girl with Prader-Willi syndrome. She lives at home, together with her older sister. She has never been easy to get on with. She demonstrates clearly all features of the syndrome, according to her parents. In particular she cannot deal with changes. She easily gets upset. Even planning a trip with the family is very difficult.

Over the last few months tensions have risen very high. Leontien's mother feels she can no longer cope. Leontien's father avoids interactions with Leontien. Her mother and father have had a major row about whether Leontien can continue living at home. Her mother is thinking of moving Leontien out of the parental home, but her father does not want to do this yet. They contact a social worker to discuss possible solutions. Over the last few weeks Leontien can no longer be kept under control: she constantly steals food and her weight is 
increasing dramatically. Leontien's parents feel that things cannot go on like this any more.

Fourteen professional caregivers and 24 parents of people with Prader-Willi syndrome participated in this study (Van Hooren et al., 2006). The group of 14 professionals consisted of 2 psychologists, 3 teachers, 1 care coordinator, 5 personal caregivers and 3 caregivers connected to the group in which the client with Prader-Willi syndrome lives. The group of 24 parents consisted of 10 fathers and 14 mothers.

The parents and professionals were asked to rate four different intervention strategies (each with a short and a long version) according to their preferred way of dealing with the problem. The eight cases presented to parents and professionals varied on three dimensions: 1) eating problem versus behavioural problem, 2) acute versus chronic situation, 3) living at home versus living in community-based settings. The cases were shown to the participants twice: the first time before, and the second time after, an explanation and a discussion of the four models of Emanuel and Emanuel. All respondents were asked both times to rate their preference for the eight strategies in each of the eight cases. This was done to find out if an explicit explanation and discussion of the various interaction models created a learning effect.

On the basis of the four models, four sorts of strategies were developed. These are shown in Table 1. These were described in two lines on cards. For each strategy a short version and a long version were made. The participants were asked to lay out these cards in order of preference for each of the eight cases that were presented to them.

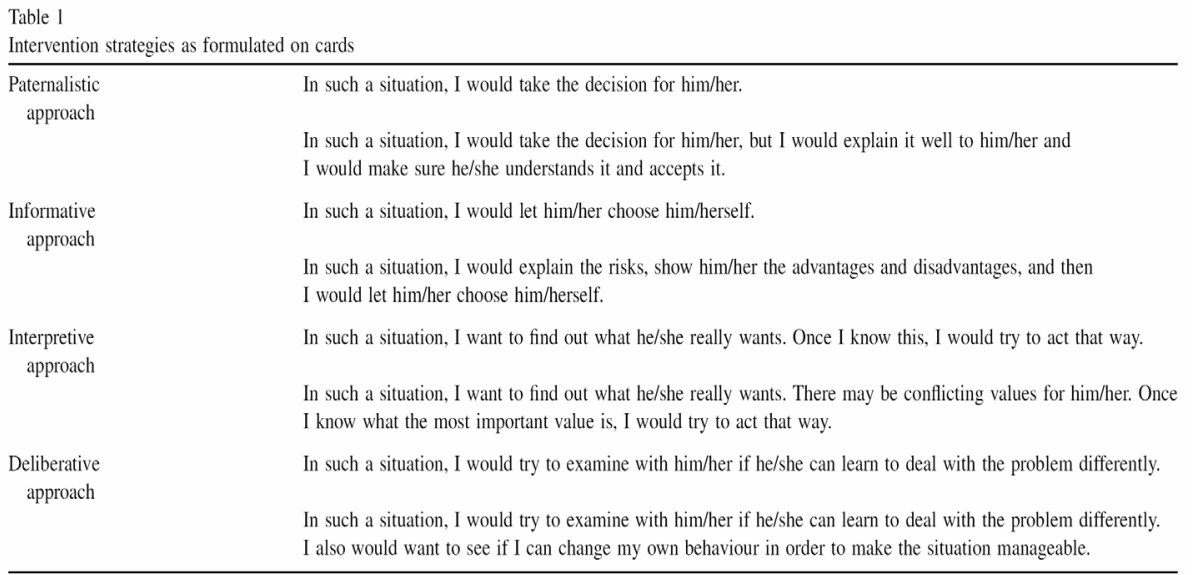


The data collected through preference rankings of the intervention strategies (Van Hooren et al., 2006) were subjected to a multidimensional scaling procedure (Alscal) (Cox \& Cox, 2001). This allows for exploring how parents and professional caregivers perceive the different interaction strategies and how they form their preferences for these different strategies. In this procedure dimensions are uncovered that account, as well as possible, for subjects' preferences for the different cases. For each individual ranking an ideal point is calculated. The ideal points form the dependent variable for further analyses. The ways in which the ideal points change in relation to the eight presented cases was investigated. Differences in ideal points between parents and professional caregivers were analysed. Furthermore, the ideal points in the measurement before and after the explanation of the four models were compared. Since there are multiple measurements (i.e. ideal point scores) within each subject, leading to dependencies among observations, multilevel analysis (Snijders \& Bosker, 1999) is an appropriate technique to investigate these issues. The following factors were included as independent variables in the model: acuteness of the situation (acute $=1$ versus chronic $=0$ ), type of problem (eating $=1$ versus behavioural $=0$ ), location of the situation (living at home $=1$ versus community-based setting $=0$ ), type of respondent (parent $=1$ versus professional caregiver $=0$ ), and explanation of the four models (before $=0$ or after the intervention $=1$ ).

\subsubsection{Results}

The Alscal analysis showed that $99 \%$ of the variance in the preference data could be explained with the choice of one dimension only The addition of more dimensions explained only a little more of the variance. Moreover, these extra dimensions were difficult to interpret.

The one dimension represents the amount of active intervention that parents and professional caregivers perceive with respect to the different interaction strategies. The scores and order of the different interaction strategies on these dimensions are given in Table 2.

Scores and ordering of intervention strategies on one dimension

\begin{tabular}{lccc}
\hline Intervention strategy & \multicolumn{2}{l}{ Scale value } & \\
\cline { 2 - 4 } & Total group & Parents & Professionals \\
\hline Paternalism (short version) & 1.6390 & 1.6446 & 1.9543 \\
Paternalism (long version) & 0.8638 & 0.7074 & 1.3851 \\
Deliberation (short version) & -1.1893 & -1.2502 & -1.3164 \\
Interpretation (long version) & -1.3443 & -1.3796 & -1.5082 \\
Deliberation (long version) & -1.3697 & -1.4031 & -1.5304 \\
Interpretation (short version) & -1.8124 & -1.8611 & -1.9138 \\
Information (long version) & -1.9215 & -1.8887 & -2.1096 \\
Information (short version) & -2.8001 & -2.8117 & -2.8996 \\
\hline
\end{tabular}


On average the two paternalistic strategies were placed first and the two informative strategies at the other extreme of the dimension. The deliberative and interpretive strategies were placed close to each other, between the other two strategies. The short and long versions of each strategy were placed close to each other. Both parents and professional caregivers situated the strategies in the same order.

In all cases the controlling intervention strategies were preferred over strategies in which the choice is left to the child or client. There were no significant differences between eating and behavioural problems in the preferred degree of control of the intervention as rated by professionals. Parents preferred more control in situations with eating problems than in situations with behavioural problems. Both parents and professionals preferred to intervene more actively in acute compared with chronic situations. This effect was stronger for parents than for professionals. Both parents and professionals preferred less control in community-based situations than in situations at home, although this difference was more marked in the case of parents. Professional caregivers did not show any clear differences in preferences between the first and second measurement, whereas parents preferred to control more actively at the second measurement compared with the first.

\subsubsection{Conclusion}

The results of this quantitative study show that both the parents and the professional caregivers preferred intervening over not intervening in dealing with problems in the care for persons with Prader-Willi syndrome. The informative approach, in which the choice is completely left to the child or client, was the least preferred model, and the paternalistic strategies were the most liked. The parents preferred intervening approaches to a greater extent than the professional caregivers. Parents preferred more controlling interventions in situations with eating problems than in situations with behavioural problems, whereas professional caregivers showed no difference between these situations.

For both groups the degree of preference for the more controlling interventions was less marked for chronic, compared with acute, situations.

\subsection{Discussion}

In order to deepen our understanding of the ethical issues in the care of people with Prader-Willi syndrome we conducted empirical research. The first step was a qualitative study which had the aim of gaining insight into the practice of how caregivers value and deal with the prevention of obesity in the care of people with Prader-Willi syndrome, including their experiences and moral concerns. The second step was a quantitative study, based on the findings of the qualitative project. 
The finding in the quantitative study that parents preferred interventions with a more active intervening character in situations with eating problems, and less active intervening approaches in situations with less prominent behavioural problems, was supported by the findings of the qualitative study (Van Hooren et al., 2002; Van Hooren et al., 2005). In both studies parents and professional caregivers saw more opportunities for deliberative processes when dealing with behavioural problems not related to eating. Furthermore, in the qualitative study both parents and professionals indicated that persons with Prader-Willi syndrome have great difficulty keeping control over their eating behaviour. This is a well documented phenomenon in the literature on this condition (Greenswag \& Alexander, 1995; Whittington \& Holland, 2004), for which a non-intervening approach is unlikely to be effective, and may be harmful to the health. The latter outcomes of the qualitative study are in line with the ordering in the quantitative study, in which the paternalistic strategies were placed first by both the parent and the professional groups.

Despite these correspondences between the qualitative and the quantitative study, there are also differences. The outcomes of the quantitative study showed less variety than we had initially expected. On the basis of the qualitative study, we had expected that caregivers would not only distinguish between intervening and not intervening, but also between taking over the decision (paternalism) and fostering selfunderstanding and moral development of the person with Prader-Willi syndrome. The latter distinction was not confirmed in the quantitative study.

The differences between the outcome of the qualitative and the quantitative studies may be due to the design of the quantitative study. The procedure of preference ranking of the four different kinds of intervention strategies may mask the nuances and subtleties of each of the underlying interaction models. Furthermore, the formulation of the cases may have had an effect on the outcomes. The cases focused on concrete problems, and respondents were invited to give a reaction in terms of what they would do in such a situation. This means that respondents were not triggered to think of developing a relationship with the person with Prader-Willi syndrome. The formulations of the strategies on the cards (see table 1) might have created an experimental situation that focuses too much on decisions, in which respondents react in terms of intervening or not, instead of focusing on the context. It might have created a situation with an emphasis on concrete actions rather than on processes that take place over time. Thus, processes of clarification and discussion, which are essential in the interpretive and deliberative models, may not have received sufficient attention. These processes are mentioned in the formulations of the strategies on the cards, but these formulations may not have led respondents to clearly see these models as processes in time.

An interesting possibility for future research may be the use of a questionnaire with more items representing the various elements from the models of Emanuel and Emanuel. With this approach it may be possible to interpret participants' responses in a more differentiated way. The influence of the specific questions on the results may 
be less marked in the qualitative study compared with the quantitative study since the main method of gathering the data was through open interviews, in which the interviewer followed the stories of the interviewees. A simplification of the data only started with the analyses of the interview transcripts, when the process of coding and categorization took place. This simplification could be undone at any time, returning to the complete transcripts of the open interviews. In contrast, in setting up the quantitative study some simplifying choices have to be made before data collection

The quantitative approach to gathering data does, however, have its benefits. A qualitative approach is useful to gain insight into a practice of which little is known, and is useful in order to make visible the complexity and diversity of this practice. Quantitative research, which ideally follows after and is based upon qualitative studies, is more appropriate to gathering data on a larger scale. By means of questionnaires and other methods, a larger group of respondents can be reached, making the results more representative. A quantitative study, furthermore, can focus on those factors that on the basis of previous research appear to be relevant.

No clear difference was found between the first and second measurement for the respondents. This might have been because the explanation and discussion of the various interaction models between the two measurements may not have been done effectively. It may be that the nature of the different models and their benefits have not been well understood by the respondents. The explanation and discussion that we carried out was aimed at an intellectual understanding of the differences between the models. To apply the models to a concrete situation might need more than just a cognitive understanding. If this conclusion is right, more attention should be paid to the implementation of the results of the qualitative study, if this is going to make a difference in daily practice.

\subsection{Conclusion}

This research, with both a qualitative and a quantitative approach, provides an example of how empirical ethics may contribute to the study of the moral conflict between respecting autonomy on the one hand and beneficence (providing high quality care) on the other. In our studies we focused on the experiences of caregivers within the specific practice of dealing with the prevention of obesity in people with Prader-Willi syndrome. What values are relevant to caregivers, and how do caregivers manage the problems of overeating in daily practice? The study of these experiences shows that caregivers do not, on the whole, tackle this moral issue as a problem of balancing two opposing principles, but seek imaginative ways of enhancing autonomy within a safe environment. From the experience of practitioners we may learn that there are more ways of dealing with moral issues in the prevention of obesity than those that are dominant in moral theory. This may lead both to conceptual and normative conclusions. Conceptually, we may conclude that a definition of autonomy, based on the notion of positive freedom can be relevant in the area of the prevention of obesity in the care of people with a Prader-Willi syndrome. The notion of autonomy as positive 
freedom can be elaborated using the work of Emanuel and Emanuel. Yet, this also implies the need to reflect on the rationalist way in which Emanuel and Emanuel describe autonomy as moral development, which seems to restrict this notion to competent adults. This conceptual conclusion also has a normative side. The notion of positive freedom can serve as a goal in this specific practice of care. Our study not only shows the moral relevance of this goal, but also makes clear those moral actions, attitudes and considerations that are necessary to achieve this goal, such as giving support and creating safety. Thus, our study confirms the conclusion by Van der Scheer et al. (2004), that empirical ethics can develop normative theories by means of an empirical inquiry into the practice relevant to specific practical problems.

\section{Notes}

1 The constant comparative method of Grounded Theory was only used as an analysis tool for the interview transcripts. The Grounded Theory approach usually also entails a constant (re)adjustment of the interview scheme during data collection, on the basis of the findings of the earlier interviews.

2 See Van Hooren et al. (2005) for an elaborate explanation of this framework and its elements.

3 Prolonged engagement means that the investigator invests sufficient time in examining empirical material in order to become totally familiar with it. This means knowing exactly which respondent said what and in which context etc.

The technique of persistent observation need not be direct visual observation but can also be observation of written data, which is the case here. The purpose of persistent observation is to identify those characteristics and elements in the situation that are most relevant to the problem or issue being pursued, and focusing on them in detail.

Prolonged engagement provides scope; persistent observation provides depth (Lincoln \& Guba, 1985). 


\section{References}

Berlin I. (1969). Four essays on liberty. Oxford University Press, Oxford.

Cox, T.F., \& Cox, M.A.A. (2001). Multidimensional scaling. Chapman \& Hall, London.

Dykens, E.M., Goff, B.J., Hodapp, R.M., Davis, L., Devanzo, P., Moss, F., Halliday, J., Shah, B., State, M. \& King, B. (1997). Eating themselves to death: Have "personal rights" gone too far in treating people with Prader-Willi syndrome? Mental Retardation, 35, 312-14.

Emanuel, E.J., \& Emanuel, L.L. (1992). Four models of the physician-patient relationship. Journal of the American Medical Association, 267, 2221-6.

Greenswag, L.R., \& Alexander, R.C. (1995). Management of Prader-Willi syndrome, 2nd Edition. Springer-Verlag, New York.

Have, H. ten, \& Lelie, A. (1998). Medical ethics research between theory and practice. Theoretical Medicine and Bioethics, 19, 263-76.

Holland, A.J., Treasure, J., Coskeran, P., Dallow, J., Milton, N., \& Hillhouse, E. (1993). Measurement of excessive appetite and metabolic changes in Prader-Willi syndrome. International Journal of Obesity, 17, 527-32.

Holland, A.J. \& Wong, J. (1999). Genetically determined obesity in Prader-Willi syndrome: the ethics and legality of treatment. Journal of Medical Ethics, 25, 230-6.

Hooren, R.H. van, Candel, M.J.J.M., Borne, H.W. van den, Curfs, L.M.G., Widdershoven, G.A.M. Between control and freedom in the care for persons with Prader-Willi syndrome: An analysis of preferred interventions by caregivers. Patient Education and Counseling, 63, 22331.

Hooren, R.H. van, Widdershoven, G.A.M., Borne, H.W. van den \& Curfs, L.M.G. (2002). Autonomy and intellectual disability: the case of prevention of obesity in Prader-Willi syndrome. Journal of Intellectual Disability Research, 46, 560-8.

Hooren, R.H. van, Widdershoven, G.A.M., Bruggen, H. van der, Borne, H.W. van den, Curfs, L.M.G. (2005). Values in the care of young persons with Prader-Willi syndrome: creating a meaningful life together. Child: Care, Health and Development, 31, 309-19.

Lincoln, Y.S. \& Guba, E.G. (1985). Naturalistic inquiry. Sage, Newbury Park.

Scheer, L. van der, Thiel, G. van, Delden, J. van, \& Widdershoven, G. (2004). Theory and methodology of empirical-ethical research. In: Engaging the world: The use of empirical research in bioethics and the regulation of biotechnology (Eds. S. Holm and M.F. Jonas), pp. 89-96. IOS Press, Amsterdam.

Snijders, T., \& Bosker, R. (1999). Multilevel analysis: An introduction to basic and advanced multilevel modelling. Sage, London.

Strauss, A., \& Corbin, J. (1990). Basics of qualitative research: grounded theory procedures and techniques. Sage, Newbury Park.

Swaab, D.F., Purba, J.S., \& Hofman, M.A. (1995). Alterations in the hypothalamic paraventricular nucleus and its oxytocin neurons (putative satiety cells) in Prader-Willi syndrome: a study of five cases. Journal of Clinical Endocrinology and Metabolism, 80, 573-9.

Tronto, J. (1993). Moral boundaries. A political argument for an ethic of care. Routledge, New York.

Walker, M. (1998). Moral understandings: A feminist study in ethics. Routledge, New York.

Whittington, J., \& Holland, A. (2004). Prader-Willi syndrome: Development and manifestations. Cambridge University Press, Cambridge.

Whittington, J., Holland, A., Webb, T., Butler, J., Clarke, D., \& Boer, H. (2004). Cognitive abilities and genotype in a population-based sample of people with Prader-Willi syndrome. Journal of Intellectual Disability Research, 48, 172-87. 



\section{CHAPTER 7}

ETHICS OF PREVENTION: AN INTERACTIVE COMPUTER-

TAILORED PROGRAM

This chapter appeared as: Hooren, R.H. van, Borne, H.W. van den, Curfs, L.M.G., Widdershoven, G.A.M. (2007). Ethics of prevention: An interactive computer-tailored program. Scandinavian Journal of Public Health, 35(5), 503-509. 


\begin{abstract}
Aim. This article describes the contents of an interactive computer-tailored program. The program is based on previous studies of the practice of care for persons with Prader-Willi syndrome. This genetic condition is associated with a constant overeating behaviour with the risk of obesity. The aim of the program is to start a process of awareness, reflection, and discussion by caregivers who are confronted with the moral dilemma of respect for autonomy versus restricting overeating behaviour. The program focuses on values (such as health and well-being) that are relevant to caregivers in daily practice. Furthermore, the focus is on various ways of interaction with the client. Caregivers were expected to focus mainly on health, and on both paternalistic and interpretive/deliberative forms of interaction.

Methods. Sixteen professionals and 12 parents pilot-tested the program contents. With a pre-test, responses on one central case were collected for tailored feedback; with a post-test, the effects of the program were measured.

Results. Significant correlations were found between the values of autonomy and consultation and between autonomy and well-being. In contrast to our expectations respondents valued all categories (autonomy, consultation, health, well-being, and liveability for others) as equally important in the pre-test. No significant changes in scores were found between pre- and post-test. The open answers and remarks of participants support the program contents.

Conclusions. Participants' responses support previous research findings, advocating a concept of autonomy in terms of positive freedom, through support by others. The promotion of the client's self-understanding and self-development is central in this concept.
\end{abstract}




\subsection{Background}

During the most recent decades, the view in society on individuals with an intellectual disability has changed. According to the current citizenship approach, persons with an intellectual disability are citizens like other members of society, and need to be supported as much as possible to realize their citizenship. Freedom of choice, selfdetermination and self-responsibility are emphasized. Although these developments seem beneficial to persons with an intellectual disability, they may confront caregivers with dilemmas. A major dilemma concerns the moral tension between respecting client autonomy and providing good care.

We have explored this dilemma empirically in persons with Prader-Willi syndrome (PWS) (Van Hooren et al., 2002; 2005; 2006). PWS is a genetic condition that, next to a mild to moderate intellectual disability (Whittington et al., 2004), is characterised by an excessive appetite, frequently associated with overeating behaviour. The normal satiety response after eating is impaired and delayed (Holland et al., 1993). Without intervention by parents and professional caregivers this overeating behaviour frequently leads to obesity and serious health problems. The focus of the study was on how caregivers deal with the moral dilemma of respecting the client's choices on the one hand, and providing good care and protecting the client against harmful effects of unhealthy (eating) behaviour on the other hand.

\subsection{Aims}

The present article describes the contents of an interactive computer-tailored program we developed on the basis of the empirical findings of our previous research. The program was created to give insights to caregivers in these findings, e.g. the values and attitudinal ways of intervening of parents and professionals, as a reflective guiding aid.

\section{The interactive computer-tailored program}

The general aim of the interactive computer-tailored program was to start a process of awareness, reflection and discussion in caregivers confronted with the moral dilemma of respect for autonomy versus providing good care to persons with Prader-Willi syndrome. We choose to create a computer tool because of the interactive benefits and possibilities of such a technological aid. The technological set-up provided options to offer relevant information directly tailored to the personal choices of the program users, increasing the chance of compliance. This computer-tailored program has the advantage of full-time availability on internet, so that users can start, continue or restart the program whenever they want to, in their own "safe" environment. Large target groups can be reached at relatively low cost. Furthermore, parts of the program can easily and quickly be adjusted or updated, and monitoring of responses to study long-term effects is possible. Internet interventions can fill the gap between intensive interventions with individual counselling and less intensive interventions, such as 
brochures (De Nooijer et al., 2005). To understand the contents of the computertailored program, we start with a brief summary of the findings of our previous research.

\section{Main findings of previous research}

Our previous research was based on in-depth qualitative interviews, conducted with parents and professional caregivers of persons with Prader-Willi syndrome (Van Hooren et al., 2002; 2005; 2006). The interviews were first analysed as case studies. Next to paternalist interventions, forms of interaction were found in which parents and staff tried to promote the person's autonomy by fostering self-understanding (interpretation) and self-development (deliberation) (Van Hooren et al., 2002). Next, a Grounded Theory analysis of the interviews was done, focusing on values. Parents and professional caregivers indicated four values to be relevant for the care of the person with Prader-Willi syndrome: physical health, well-being, freedom and responsibility, and a liveable life (Holland et al., 1993).

Despite these varieties in found interactions and values, our expectations in developing this computer-tailored program were that caregivers mainly focus on health, and both on paternalistic and interpretive/deliberative options.

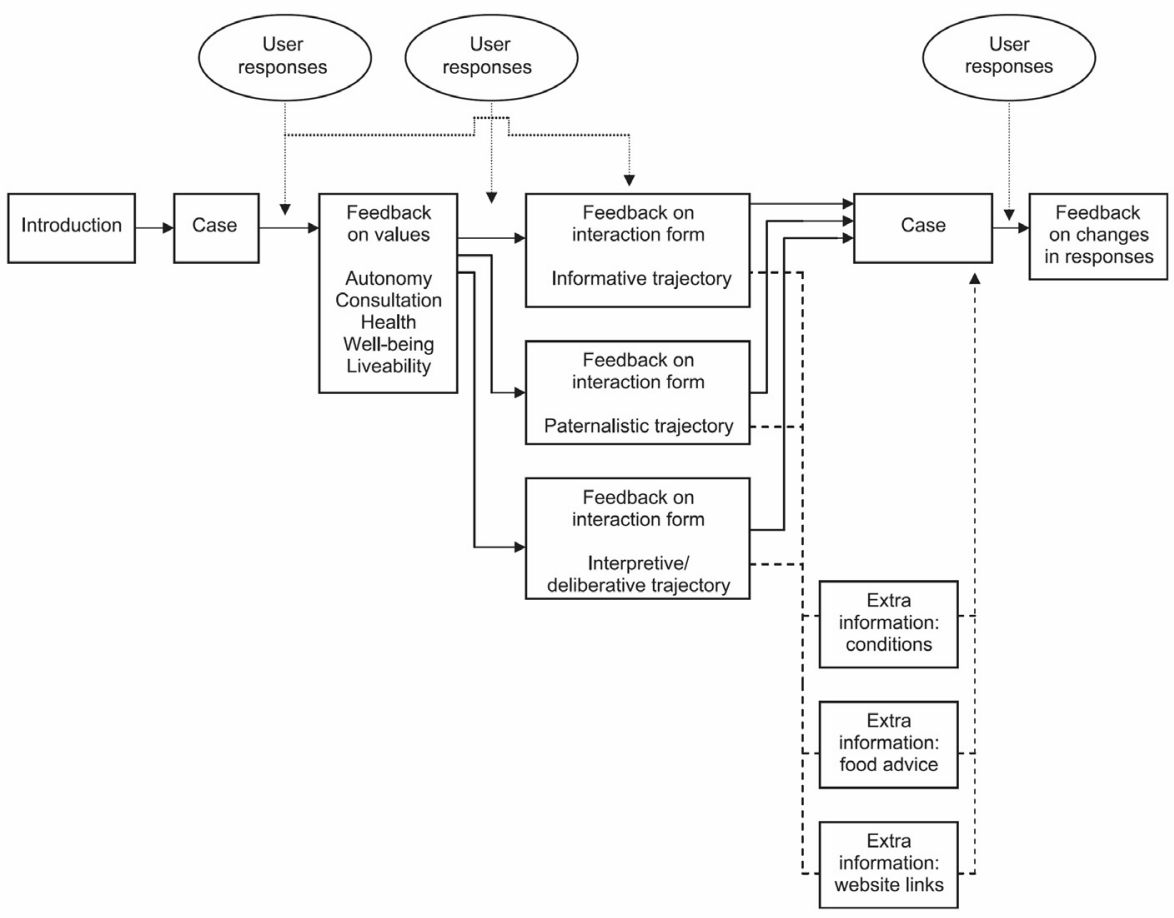

Figure 1. Schematic representation of program structure. 


\subsection{Material and methods}

\section{Design}

The program centred on a case constructed on the basis of interview data of our previous qualitative study (Van Hooren et al., 2002; 2005). After starting with this central case, the program continued with two parts. The first part dealt with values that may be relevant in caring for persons with Prader-Willi syndrome and their obesity problems. The second part of the program dealt with various ways of interaction to realise these values (see also Figure 1). In both parts of the program feedback is given by using quotes of parents and professionals who were interviewed in the previous study.

The following sections describe the contents and methods of the program in more detail.

\section{Case}

After starting with a short explanation about the content and the structure of the program, it started with the following case.

Piet is an 18-year-old young man with Prader-Willi syndrome, who has been living for several years in an institution. He has a mild intellectual disability. $\mathrm{He}$ is functioning quite independently (he works in the institution, organizes soccer matches etc.). Piet has a good relationship with his caregivers. If there are problems, these can always be discussed with him in a good way. In this his wishes are taken into account as much as possible. The caregivers don't make any decisions without involving Piet.

Piet has been gaining weight gradually for five months. It is getting more difficult for him to move around because of this weight increase. His personal caregiver sees a link with Piet's new girlfriend. He is very much in love with her and his girlfriend really cheers him up. However, through her he also gets outside the institution in his leisure time much more often. The caregiver suspects that in this way Piet more easily breaks with his dietary instructions. His girlfriend also regularly gives him biscuits, which Piet likes a lot.

The caregivers talk with Piet about his weight increase. In this conversation Piet indicates that though he is gaining weight, he now feels happier than ever before. To him, this is the only thing that matters. Nobody has the right to take away that happiness.

The caregivers get the feeling that, because of the problems with Piet, they have less time and attention for the other residents. 
In the end the caregivers don't see another possibility than to forbid Piet to see his girlfriend.

After the presentation of the case, the user was asked to describe in his or her own words what he or she thought was the main problem and how he or she would deal with this problem. The purpose of these questions was to ensure the user became adequately acquainted with the case information. Consequently, each information part of this case was presented as items in a list to be scored on a four-point Likert scale, with the purpose of prioritizing and balancing these parts by the user. A total of 16 items representing 5 categories could be scored: autonomy (5 items, for example 'Piet is functioning quite independently'), consultation ( 3 items, for example 'If there are problems, these can always be discussed with Piet in a good way'), health (4 items, for example 'It is getting more difficult for Piet to move around because of this weight increase'), well-being ( 3 items, for example 'Though Piet is gaining weight, he now feels happier than ever before') and liveability for others ( 1 item: 'The caregivers get the feeling that they have less time and attention for the other residents').

Based on the sum of the item scores of each category a decision was made whether the user valued this category as important or not. The cut-off point for this decision was determined by the mean of the maximum number of points of the category (for example, for the category health, with 4 items, a maximum of 12 points could be scored on the Likert scales; a sum score on this category of 6 to 12 points resulted in the decision that the user saw health as important). The user was provided with feedback specified for each of the 5 categories. The responses on these 16 items were also taken as a pre-test, and were offered again at the end of the program as a post-test to study the effects of the program.

Reliability analysis of the categories reveals satisfactory Cronbach's alphas, ranging from 0.66 to 0.77 (see Table I).

\section{Part I: Values}

The first part of the program focused on the values. The value of health, well-being, respect for autonomy, consultation, and liveability for others were explained using interview fragments in the tailored feedback. Consultation refers to involving the client in the decision process. Liveability for others refers to the well-being of the client's caregivers, other family members and residents. A one-sided focus on health alone may entail the risk that other values are neglected and the food obsession is stimulated. The relevance of respect for autonomy and consultation is supported by the argument of preventing disagreement and resistance by the client.

\section{Part II: Forms of interaction}

The second part focused on various ways in which values can be realized. Three forms of interaction were elaborated, explaining three ways of dealing with a person's 
wishes. These forms of interaction correspond with the findings from our qualitative study. In this study, we found forms of interaction corresponding with models of physician-patient interaction, elaborated by Emanuel and Emanuel (1992). Apart from paternalistic interaction, in which parents and staff themselves take the decision for the client, and informative interaction, in which the decision is left to the client, other ways of interaction could be found. In these dialogical forms of interaction the values of the person with the syndrome were the object of further investigation. Parents and staff not only tried to elucidate these values (interpretative interaction), but also to question them and develop them further (deliberative interaction). Thus, they tried to promote autonomy by fostering the client's self-understanding and self-development (Van Hooren et al., 2002).

These ways of interacting were translated into three trajectories: an informative, a paternalistic, and an interpretive/deliberative route. Arguments were illustrated with interview quotes.

The second part of the program started with three quotes from caregivers reflecting on the case of Piet. The user of the program was asked to choose which quote he agreed with most. On the basis of this choice, one of the three trajectories was followed in the program. The following quotes were presented:

Caregiver 1: "If Piet says he feels happy with his girlfriend, and nobody has the right to take his happiness away from him, then we should leave him free and not interfere with him - even if he has the possibility to eat too much by seeing his girlfriend and gain weight.

Caregiver 2: "Piet can say he is happy, but he doesn't know what is best for him. The only possibility is to intervene and to forbid him to see his girlfriend. Otherwise he continues to eat, which is not good for him."

Caregiver 3: "It is important that Piet feels happy and that he continues to feel so. The question, however, is whether it is love for his girlfriend or that Piet is with her because in that way he can get food. I would like to discuss with Piet whether he really likes her for who she is. The question then is whether he could be happy with her without eating too much? I would like Piet to become aware of how he can do nice things with his girlfriend without a focus on food."

If the user chose the informative trajectory, he/she was questioned on his choice to leave Piet totally free and not to interfere at all. He/she was confronted with the consequences of serious overweight such as the difficulty in moving, a worsened physical condition, aching joints, a higher risk of diabetes, and finally risks of heart disease and respiratory problems.

Furthermore, the user was asked to consider the suggestion to intervene to make sure Piet complies with the dietary instructions. The negative effects of a continued high level of control and supervision, and of a one-sided focus on food, that cause other 
relevant aspects to be lost to sight, were discussed. Emphasis was put on not applying rules too rigidly, and on not explicitly forbidding things, which is ineffective. All these elements were supported by interview quotes from perceptions of caregivers. Consequently, the benefits of involving the client in the decision making process were elaborated, emphasizing the benefit of client agreement and diminished risk of resistance.

In the paternalistic trajectory the user was first confronted with the fact that his/her interventions are based upon what he/she thinks is best for the other, the client. Consequently, as in the informative trajectory, the benefits of involving the client in the decision making process were discussed. Furthermore, the user was asked to go along with the suggestion to let Piet comply with the dietary instructions, and the same parts of the program were shown as in the informative trajectory.

Both the informative and the paternalistic trajectory ended with the following fragment, illustrating a deliberative approach.

Caregiver: "Piet continues to be occupied with food. He should think whether this can go on. Of course Piet wants to eat, but it would be good if he realizes that there are limits in eating. To me it would be good if he becomes aware of that. My ideal would be to talk about that with him, and to make arrangements with him and his girlfriends about it."

This deliberative approach was explained, emphasizing that values are not always directly clear to a person and are not fixed. Through a dialogue values can be developed. The user was asked whether he/she considered it useful to start a conversation with Piet to try and make him aware of the limits to his eating behaviour. In the program a possibility was built in for the user to write down his/her arguments to explain his/her answer to this question.

In the interpretive/deliberative trajectory, first the interpretive approach was analysed and explained. The benefits of a joint decision-making process were discussed. Furthermore, it was explained that it is often not directly clear what a client really wants. The relevance of creating a situation of trust in which things can be discussed in an open way were emphasized.

This trajectory was continued with the step from interpretation to deliberation. It was explained that it is not only important to elucidate the values of the client, but also to critically examine them in a discussion. This was illustrated with an interview fragment that ends the informative and the paternalistic trajectories. Subsequently, the issue of dialogue was further elaborated. It was explained that a dialogue not only can take place in a verbal argumentative way but can also take a non-verbal, emotional form.

Normative aspects of the program

The program did not merely inform the user about values and interaction forms. Several normative "messages" were included in the program, like the issue that one should not only focus on health, and that paternalism can be useful, but because of a 
risk of disagreement and resistance of the client other forms of interaction should also be considered by the caregiver. When the user of the program indicated viewing an aspect as not important, he or she was confronted with information showing that it could nevertheless be important. This confronting information was presented through interview quotes of several parents and professional caregivers who have these differing thoughts.

When in the second part of the program the user chose the informative or paternalistic trajectory, information was adapted to that choice. However, at the end of both trajectories the user was confronted with the deliberative interaction form. By explaining the benefits of this approach, using an interview quote, the user was asked to consider this form of interaction.

With this normative "soft push" an attempt was made to do what is an important task of ethics: to show what ways there are to approach a certain dilemma, to illustrate that an issue can be more complex than one initially thinks, and to clarify which other possibilities may exist to solve a moral problem. In the end, the ethicist should not present the sole and perfect solution, but should give a broader and more varied perspective, based on experiences from practice, so that decisions can be made in a more well-considered way.

\subsection{Results}

The computer program was pilot-tested by a group of 16 professional and 12 parental caregivers of persons with PWS. These caregivers were selected in cooperation with the Prader-Willi / Angelman parent association and contacted by phone. After agreement the website address of the computer program and instructions were emailed to them. These caregivers also received by email an evaluation questionnaire about the contents of the computer program. Quantitative and qualitative evaluation results of this pilot group are presented here.

\section{Quantitative results}

Statistically significant high correlations were found in the pre-test between autonomy and consultation $(r=0.49 ; p<0.01)$ and between autonomy and well-being $(r=$ $0.51 ; p<0.01)$. In the post-test similar significant high correlations between these categories were found ( 0.55 and 0.59 respectively). Table I summarizes the mean scores for the total group, both parents and professionals, on the pre- and post-test. 
Table I. Mean pre-test and post-test scores, standard deviations, $t$-values, and significance level for changes in values of the total group of caregivers $(n=28)$ of people with Prader Willi syndrome.

\begin{tabular}{lcccccc}
\hline Category & $n$ of Items & Cronbach's alpha & $\begin{array}{c}\text { Mean pre-test } \\
\text { score (SD) }\end{array}$ & $\begin{array}{c}\text { Mean post-test } \\
\text { score (SD) }\end{array}$ & $t$-value & Significance \\
\hline Autonomy & 5 & 0.77 & $1.793(0.66)$ & $1.900(0.54)$ & -1.268 & 0.216 \\
Consultation & 3 & 0.66 & $2.512(0.49)$ & $2.583(0.48)$ & -1.441 & 0.161 \\
Health & 4 & 0.75 & $2.438(0.51)$ & $2.357(0.63)$ & 1.104 & 0.279 \\
Well-being & 3 & 0.66 & $2.333(0.54)$ & $2.262(0.64)$ & .812 & 0.424 \\
Liveability & 1 & & $1.46(0.92)$ & $1.39(0.99)$ & .528 & 0.602 \\
\hline
\end{tabular}

Differences in mean scores between pre- and post-test (post- minus pre-test scores) were analysed for the total group with $t$-tests. As table I shows no significant changes were found between the pre-test and the post-test. Although for a separate analysis of changes for parents and professionals the numbers of participants are small, these groups separately also suggest no significant changes before and after use of the program.

In the second part of the program, 27 of the 28 participants choose the interpretive/deliberative trajectory; one participant choose the informative trajectory. None of the participants changed this choice in the post-test.

The evaluation questionnaire was returned by 14 of the 28 participants $(50 \%)$. In total, 12 of the 14 caregivers perceived the contents of the computer program as meaningful, 9 of the 14 also as instructive.

\section{Qualitative analyses}

The program offered the possibility to fill in open answers and remarks. In a qualitative analysis of these answers several themes emerged. A mother remarked:

"It is assumed that people with PWS are driven by a craving for food. By emphasizing problems no room is left for solutions."

In the open answers and remarks several solutions were proposed. A theme that was emphasized by four professionals is the relevance of learning: learning how to deal with eating problems, the need to enhance the client's understanding, and to enhance the client's knowledge of his own limitations. A professional stated:

"To enhance Piet's understanding is more effective in the long run than ad hoc solutions."

Five professionals and one parent commented on the value of respect for autonomy; they emphasized the relevance of involving the client in the decision-making process, giving him the feeling of deciding himself, providing sufficient self-determination, and valuing his wishes as much as possible. 
With regard to health and well-being two professionals and two parents expressed the difficult moral tension between these values. Two professionals emphasized that the client can be happy without food, two professionals and one parent underlined the relevance of a balance between health and well-being, and three parents indicated in their remarks that a feeling of happiness decreases when health problems become worse.

Finally, four professionals and two parents focused in their remarks on the relevance of a structured and explicit management and framework in caring for persons with PWS.

\subsection{Discussion}

Analysis of the responses of parents and professional caregivers reveals strong associations between the categories of autonomy and consultation and between autonomy and well-being. Though these associations cannot reveal causality, it is not unlikely that in the perception of caregivers an increase in autonomy leads to an increase in well-being, and thus a higher quality of life. In future research, this relationship could be examined further.

The association between autonomy and consultation corresponds with the preferences of the parents and professionals for the interpretive and deliberative interaction model. In these models the interaction with the client is relevant to elucidate and discuss the client's values.

In contrast to our expectations, in the pre-test respondents valued all categories (autonomy, consultation, health, well-being, and liveability for others) as equally important, and no significant changes were found between pre- and post-test. The computer program did not result in a clear differentiation or specification between the various categories. This may be due to the contents of the module, e.g. the user was not asked at any point to weigh, balance or prioritize any value above others. For future use of the program adding such a prioritization is recommended. In the evaluation questionnaire, the majority of the respondents perceived the contents of the program as meaningful and instructive.

Though analyses of pre- and post-test scores didn't reveal significant changes, the open answers and remarks of the participating caregivers support the contents of the program. All but one chose an interpretive/deliberative trajectory of interaction. This choice underlines the relevance of our previous findings (Van Hooren et al., 2002; 2006), according to which autonomy is enhanced by promoting the client's selfunderstanding and self-development. The participants' remarks on the relevance of a structured and explicit management in preventing obesity, and the fact that only one participant preferred an informative trajectory in which choices are left totally to the client, support our previous findings that in the case of PWS, autonomy should be defined in relational terms (MacKenzie \& Stoljar, 2000), referring to positive freedom (Berlin, 1969). Autonomy does not imply freedom of choice independent of others, but finding meaningful solutions together, supported by others. 


\section{References}

Berlin I. (1969). Four essays on liberty. Oxford: Oxford University Press.

Emanuel, E.J., \& Emanuel, L.L. (1992). Four models of the physician-patient relationship. Journal of the American Medical Association, 267, 2221-6.

Holland, A.J., Treasure, J., Coskeran, P., Dallow, J., Milton, N., \& Hillhouse, E. (1993). Measurement of excessive appetite and metabolic changes in Prader-Willi syndrome. International Journal of Obesity, 17, 527-32.

Hooren, R.H. van, Candel, M.J.J.M., Borne, H.W. van den, Curfs, L.M.G., Widdershoven, G.A.M. Between control and freedom in the care for persons with Prader-Willi syndrome: An analysis of preferred interventions by caregivers. Patient Education and Counseling, 63, 22331.

Hooren, R.H. van, Widdershoven, G.A.M., Borne, H.W. van den \& Curfs, L.M.G. (2002). Autonomy and intellectual disability: the case of prevention of obesity in Prader-Willi syndrome. Journal of Intellectual Disability Research, 46, 560-8.

Hooren, R.H. van, Widdershoven, G.A.M., Bruggen, H. van der, Borne, H.W. van den, Curfs, L.M.G. (2005). Values in the care of young persons with Prader-Willi syndrome: creating a meaningful life together. Child: Care, Health and Development, 31, 309-19.

Mackenzie C. \& Stoljar N. (Eds.) (2000). Feminist Perspectives on Autonomy, Agency, and the Social Self. Oxford University Press, Oxford.

Nooijer, J. de, Oenema, A., Kloek, G., Brug, H., Vries, H. de, Vries, N. de. (2005). Bevordering van gezond gedrag via internet: $n u$ en in de toekomst [Promoting healthy behaviour via internet: now and in future]. Optima Grafische Communicatie, Rotterdam.

Whittington, J., Holland, A., Webb, T., Butler, J., Clarke, D., \& Boer, H. (2004). Cognitive abilities and genotype in a population-based sample of people with Prader-Willi syndrome. Journal of Intellectual Disability Research, 48, 172-87. 


\section{CHAPTER 8}

\section{GENERAL DISCUSSION AND CONCLUSIONS}



In this final chapter the broader meaning and implications of the findings of this study are discussed. The research questions, which were introduced in the first chapter, will be addressed. The main question of this study regards the meaning of good care for parents and professional caregivers dealing with the prevention of obesity in persons with Prader-Willi syndrome ( $\S 8.2$ ). In $\S 8.3$ the consequences of the findings of the present study for ethics of care will be investigated. The implications of the study for practice will then be discussed in $\S 8.4$. Focus will be on the current paradigm of full citizenship, on normative aspects of prevention, and on the role of empirical research in ethics. Finally, some recommendations will be given for future research $(\S 8.5)$.

\subsection{Good care}

In the ethics of care approach care is seen as a social practice (Sevenhuijsen, 1998; Walker, 1998; Tronto, 1993). Ruddick (1989) describes a practice as a 'collective human acting form, which can be distinguished by its characteristic goal and by its resulting requirements that are imposed upon persons who in their action commit to accomplishing goals'. Notions of good care are embedded in actions and in judgements of agents in practices, while actions in practice are inspired by notions of the good (Sevenhuijsen, 1998).

To understand what 'good care' means in a specific practice, insight is needed in the moral experiences of the persons involved in the care process in that practice (Sevenhuijsen, 1998; Walker, 1998). This study explored the moral considerations within daily care practice, focusing on the use of freedom restricting measures in the prevention of obesity in young persons with Prader-Willi syndrome. The aim was to investigate moral values and considerations, and ways of interaction parents and professional caregivers preferred in their daily management of obesity prevention in their children and clients with this genetic condition. Since caregivers often make moral considerations in daily practice in an implicit way, the aim of the study was to make these moral considerations explicit. This was done by using an open qualitative approach to look at the stories of caregivers' experiences.

Good care implies a plurality of values

The main question was what good care means to these parental and professional caregivers. As the Grounded Theory analysis revealed, it is essential for good care to create and maintain a meaningful balance between several values. The most important value that caregivers held was the value of (physical) health, e.g. the prevention of obesity. Yet, good care is not solely focused on the promotion of physical health, though it is an important value to strive for since the health risks of obesity should never be underestimated. The risk of a one-sided focus on physical health and the 
prevention of obesity is that other relevant values may lose attention or be undervalued. As the analysis in chapter 2 shows well-being, freedom and responsibility, and a liveable life also emerged as relevant values for caregivers in the studied practice; parents and professional caregivers see it as important that their child or client feels comfortable, has a certain amount of freedom in which he learns to take a responsibility next to their responsibility as caregivers. Furthermore, the efforts of caregivers are aimed at preventing the problem behaviour of the person with Prader-Willi syndrome from becoming a burden for the people around her or him, such as other members in the family or other residents.

As the Grounded Theory analysis shows these values are related to specified enabling and limiting conditions and to several possible interventions. The enabling conditions entail creating a situation of trust and openness in which relationships can be strengthened and rules are not applied too rigidly. In a supportive social environment in which structure is offered, a caregiver can be moderate in imposing rules, and does not need to go to the extreme of forbidding things explicitly. In a stable social environment situations of conflict can be avoided.

Finding and maintaining a balance is a process of continuous effort and struggle for caregivers in their daily care. Their efforts are aimed at creating conditions for living that are acceptable and meaningful for everyone involved. The focus is on keeping the situation manageable and liveable despite the food related and behavioural features of the syndrome.

Parent associations, that provide support and advice to parents and professionals, offer all kinds of guidelines and information for managing food and other problems that are associated with Prader-Willi syndrome (see Butler et al., 2006). Guidelines and information can be useful but the question remains how to apply checklists in individual situations. This research suggests that guidelines need to be part of a broader process of balancing, taking into account the specific context and moral experiences of those involved in a concrete situation to define what good care means for an individual with Prader-Willi syndrome and for his or her caregivers.

Good care implies interventions providing support and fostering joint learning

Prader-Willi syndrome is a genetic condition associated with mild to moderate intellectual disabilities but also with a biological driven appetite due to a diminished production of satiation hormones. No optimal treatment is available yet for the resulting overeating behaviour. The intellectual disabilities are chronic. Certain problem behaviours are characteristic and specifically associated with this genetic syndrome. According to Dosen (2007) 'biological reductionism still prevails in the field of intellectual disability, arguing that the basic neurobiological processes are the only valid factors for understanding psychiatric disorders among these persons'. Such a biological reductive reasoning also is seen in debates about Prader-Willi syndrome. Symptoms and behaviour can be reduced to the underlying chromosomal causes and the resulting abnormalities in cerebral hormonal systems. However, for caregivers it is more relevant to find ways of supporting the persons with Prader-Willi syndrome than to focus on the cognitive and syndrome related limitations of their child or client. Fur- 
thermore, it is relevant to these caregivers to find ways to help persons with PraderWilli syndrome learn to deal with their syndrome and its restrictions.

As this study shows, for both parents and professionals good care is not about whether they should intervene or not, but how they should intervene. None of the caregivers would choose to leave choices totally to the person with Prader-Willi syndrome. For caregivers of persons with Prader-Willi syndrome it is not a matter of intervening or not. The question is how interventions can best be realized and which interventions are appropriate.

The caregivers in this study use interventions to make life liveable and teach the child or client to deal with his or her own drive for food. This implies a concept of freedom that differs from the concept of autonomy in principle-based ethics with its emphasis on self-determination. Instead of freedom of choice, identification with the situation and feeling at home in it are relevant. This concept of freedom is called positive freedom (Berlin, 1969), in contrast to the concept of negative freedom. A concept of positive freedom goes beyond the question whether to intervene or not. Of importance is how care can be realized despite the existing limitations, to create and maintain a liveable situation for everyone involved, both for the client and for the caregiver. Social support is not a threat to personal autonomy, but should rather be a necessary condition to enhance autonomy (Mackenzie \& Stoljar, 2000). The perspective of positive freedom and of realizing care despite existing limitations comes to the fore in the alternative approaches that caregivers indicate besides paternalism and letting clients decide for themselves. The alternative interactions of interpretation and deliberation aim at realizing those values that are relevant to clients but at the same time critically question those values in the light of what is best for the client. The notion of positive freedom is also relevant for the concept of competence. Competence is not primarily related to being able to choose on the basis of intellectual understanding, but to being able to identify with and live in the situation.

Caregivers do not leave the choice to the child or client; they try to find subtle ways of interacting with their child or client in which opportunities can be created to make choices together. This shared decision-making process creates opportunities for the person with Prader-Willi syndrome to make choices in eating issues, within healthy limits. Gaining insight into the values of the individual with the syndrome is relevant for caregivers, but these values are also open to moral debate. This moral deliberation is aimed at fostering a learning process for the child or client, but also for the caregiver who learns from both the verbal and nonverbal behaviour of the care receiver. Optimizing a supportive social environment by building up a relation of trust and at the same time providing a structure with clear limits enhances this learning process.

Reinders (2000a) and Meininger (2002) underline a relational view on care, assuming interdependence and emphasizing involvement. They focus on the professional skill of 'hermeneutic competence' (Reinders, 1996), relevant to assess the care needs of the client. For them, hermeneutic competence aims at understanding the meaning of the client's behaviour. The attitude that corresponds to the skill of hermeneutic competence is 'imaginative anticipation', the ability to empathize with a person (Meininger, 1997). Hermeneutic competence through imaginative anticipation thus seems relevant to the interpretative interaction with the client, which is aimed at understanding the 
client. However, Reinders and Meininger do not elaborate how these skills also may be used to critically question the client's values. The purpose of this critical questioning is to provide the client with opportunities to learn and potentially modify their values and goals. Reinders and Meininger ${ }^{2}$ do not pay attention to this aspect of moral learning by the client.

\subsection{Consequences for ethics of care}

The practice of care to persons with Prader-Willi syndrome is an educational practice. It is a care practice in which parents raise their child, introduce him or her to parental moral values to enable the child and learn moral judgement in order to develop their own set of moral values. Within the safe circle of the family, parents create an environment in which their child can feel comfortable. Residential care settings are similar, for professional caregivers also aim at fostering the development of the client and creating and maintaining an environment for creating an optimal quality of life. Given the lifelong consequences of Prader-Willi syndrome on eating behaviour, the persons involved in the care practice need to cooperate to keep the life that they live together a good life. For parents and professionals, as well as for clients, this is a continuous learning process. On the basis of their experiences in educating and caring for persons with Prader-Willi syndrome, they in turn developed their values and opinions on what a good life and good care means, and when they see intervening as justified.

What can be learned from moral experiences in this practice for ethics of care? In order to answer this question, a comparison with other practices can be helpful. According to Walker, reflective analysis of forms of moral life is an important part of moral philosophy. In order to discern what distinguishes particular life-ways, this reflection needs objects of comparison. Comparison is important because moral philosophers inevitably reflect on morality from within life-ways embodying particular forms of morality, and from a particular position within those life-ways (Walker, 1998, p.11). Another task for moral philosophy is critical reflection on features and conditions of specific forms of moral life, to test whether moral understandings really are intelligible and coherent to those who enact them, whether they are similarly so from diverse points of view within them, and whether they are the kinds of understandings that can be so (id.).

In the interest of comparison, the practice of care to persons with Prader-Willi syndrome can be compared to the practice of daily care for cancer patients, as studied by Smits (2004). Although the two practices are different, Smits found similar aims and interventions as this study. The nurses' activities to meet patients' needs were aimed at making the patient's life more bearable, given the burden of the (life-threatening) disease and of the consequences of the intrusive treatment and of the hospital stay. Smits' findings show that making the patient's existence bearable is not self-evident. Meeting patients' needs for care is a complex process because it is not always clear, both to patient and caregivers, what it takes to make one's life bearable. Patients' needs are dependent on the individual, on her or his physical, mental and social situa- 
tion, and these needs can change in the course of the disease and in the process of coping. These needs require interpretation.

Nurses also may experience uncertainty, because they influence the way needs for care develop. Nurses are very much aware of this process and they worry about whether their influence is appropriate. Nurses also may differ in their opinions about how to act and what can be considered good care for a particular patient. These opinions also may differ from the physicians' opinions. Making life more bearable to patients forms the basis for the nurses' actions to deal with this uncertainty, as long as differences in opinions are not large enough to undermine that bearability. From that perspective, nurses sometimes do not comply with patients' requests, especially if their requests can be harmful to their health. The nurses assume that the pressure they put on patients will lead to a more bearable life for the patients in the long term. They try to realize this by establishing a good relationship, in which trust and understanding can be built, seeking for agreement or trying to convince patients. Nurses thus sometimes act from their own point of view on what they perceive as the best way to shape care, with the aim of changing the views of patients. Smits refers with regard to this kind of involvement to the concept of 'compassionate interference' (see Verkerk, 1999). Though this practice differs from the care practice of Prader-Willi syndrome, the similarity is the aim and effect of maintaining liveability. More importantly, the efforts of nurses are aimed at helping the patients by morally questioning their wishes in order to foster development within the limiting circumstances. In these respects, the two practices are similar. This gives rise to the conclusion that liveability and learning are elements of care that are not restricted to the prevention of obesity in persons with Prader-Willi syndrome.

Gremmen (1995) explored the ethics of home care. She focused on the question how professional homecare providers express their ethical considerations as they deal with moral issues in their work. Gremmen found that acting by rules and instructions is not sufficient to provide good care in specific situations. Restoring or preserving clients' independence and making life more comfortable are central values to professionals who work in home care. The professionals report they sometimes try to realize changes although clients do not ask for this explicitly. The professionals see these attempts as legitimate, when the changes are part of a formal assignment or when they stem from their ambition to make the client's life more comfortable. In line with the findings of the present study, the homecare professionals perceived winning the trust of clients and building up a relationship as a necessary condition for establishing changes. Respect, understanding and personal attention are important aspects of their attitude towards their clients. A continuous process of thinking, communicating in an open and clear way and deliberating with clients and colleagues is relevant for finding a balance between the expectations and wishes of clients and their own wishes and professional aims. In trying to realize changes, professionals in home care aim for enhancing the autonomy of clients, restoring or maintaining their independence. Interpreting the clients' values and trying to develop these values are relevant aspects in this process. This is again in line with the present study, and thus suggests that the specific values and interventions may be generalised. 
Roovers (2004) studied the values of professionals in the field of care of persons with intellectual disabilities. In sessions with professional caregivers, taking place in the form of a game, personal moral values and attitudes were explored. Case examples and questions were used to start and stimulate discussion. Issues raised included dealing with sexual desires of clients, letting clients free or giving them more space, and responding to clients who want to stay lying in bed all weekend. The views of caregivers show that they intervene in the client's life from a perspective of involvement and responsibility. Roovers interprets this intervention as an infringement of the client's autonomy. However, from a perspective of autonomy as positive freedom, the considerations of the participating professionals show that their interventions are aimed at enhancing the client's autonomy by making them more responsible for their own actions and by stimulating their abilities to learn and develop themselves.

In the practices described above, various intervening actions of caregivers can be distinguished, based upon specific moral values and considerations. What they have in common is the aim of making clients understand what may be really important, or making clients realize and learn to see things from a different perspective; giving them more opportunities to get control over their disease, improving their independence or making them feel more comfortable, or letting them grow and develop themselves. This is in line with the findings of the present study. It may be concluded that fostering liveability and helping clients to develop new views on moral responsibility is a general goal of care for dependent persons. This shows that central notions of ethics of care are relevant for a variety of care practices. By comparing the fundamental values in the practice of care for persons with Prader-Willi syndrome with that of other practices, it was possible to reflect upon these values, and critically assess them at the same time. Since the found values and interventions (paternalism, interpretation and deliberation) are not restricted to the specific care practice, but are also relevant to other care practices, they can be regarded as important from various points of view, which enhances their intelligibility and coherence.

\subsection{Implications for practice}

The results of this study have relevance for care practice. In the following the implications for the practice of care for people with intellectual disabilities will be discussed first. It will be argued that the notion of citizenship should be replaced by the notion of partnership. Next the practice of prevention will be focused on. A plea will be made for an approach to prevention that focuses on dialogue and empowerment of people with Prader-Willi syndrome. Finally the practice of ethics is focused on. The need of empirical ethics will be emphasized, focusing on establishing a dialogue between ethical theory and moral practice.

From citizenship to partnership

At present the paradigm of full citizenship dominates the field of care for persons with intellectual disabilities. Persons with intellectual disabilities should live in soci- 
ety as equal citizens with equal rights as any other citizen. Freedom of choice and selfdetermination are strived for in this 'new vision' (Reinders, 2000b). As the eating problems in Prader-Willi syndrome show, full citizenship in terms of freedom of choice and self-determination is problematic. In line with criticism of Reinders (1994; 1997), it can be questioned whether a perspective based on rights can be adequately used for persons with intellectual disabilities. 'This is not to say that persons with intellectual disabilities should not have equal rights, but that the moral basis of care for disabled does not lie only and even not in the first place in their rights. From a moral point of view the position of intellectually disabled persons in our society is not created by their equal rights, but has a different foundation that can be described in terms of responsibility and solidarity' (1994, p. 83). When dealing with a condition like Prader-Willi syndrome, rights do not provide a morally relevant perspective. All caregivers interviewed in the present study expressed that it is difficult to give persons with Prader-Willi syndrome a 'right to eat whatever they want'. Full citizenship is based on liberal notions like independence and individual decision-making, which do not correspond adequately with the structure of care for people with Prader-Willi syndrome.

An alternative can be found in the notion of 'partnership' instead of 'citizenship'. The essence of partnership lies in shared decision-making. Decisions are made in a joint dialogue between caregiver, client and the client's family or friends. Viewing persons with intellectual disabilities as equal to persons without such disabilities entails not only that disabled persons have equal rights. The partnership notion entails that persons with intellectual disabilities should also be taken seriously. This implies making them conscious of their own responsibilities as an equal partner involved in a dialogue. As the deliberative form of interaction shows, it is not only relevant to elucidate the values of the client but also to question these values with the aim of creating opportunities for learning. Caregivers thus should not take the role of supporter of the client to enhance the client's individual decision-making abilities but take the role of participant in a dialogical process of shared decision-making together with the client. In the caring context of solidarity, trust, acceptance and respect, the caregiver can take the deliberative role of friend and teacher in moral discussions on values and (unhealthy) behaviour. This care environment provides opportunities for moral development ${ }^{3}$.

Since shared decision-making is essential to partnership, negotiation is a necessary condition. The importance of the concept of negotiation is underlined by Moody (1992). Negotiation leaves room for steering through persuasion in discussing the values and is preferable over more coercive measures in which caregivers make the decision for the client. An important goal of discussing values is the promotion of self-development in clients. Sometimes deliberation can also lead to a learning process in caregivers who can learn from resistance from a client. Clients can show resistance both in words and in behaviour, which can be interpreted as a sign that caregivers should change their attitude or way of (inter)acting.

According to Moody persuasion can be effective only if the reasons offered make sense to the client. Persuasion is not simply an 'intervention' or a 'technique' for producing compliance. Persuasion involves relationship, a two-way process of communication -speaking and listening- which is the core of communicative ethics (Moody, 
1992, p.152). This two-way process of communication is the essence of the deliberative form of interaction in which next to the values of the client also the values of the caregivers play a role in the dialogue. It needs to be said that communicative processes with clients with intellectual disabilities not only involve verbal interaction but also interaction on the basis of emotional and behavioural responses. Furthermore, caregivers should be critical when clients consent to the options they offer. Is this consent really the result of agreement of the client or is this consent on the basis of habituation or indolence (Abma et al., 2007)? Caregivers thus also need to elucidate the underlying reasons for this consent, through discussion and consult with the client.

This evokes the question whether partnership is possible in relationships between caregivers and persons with intellectual disabilities, for caregivers have an advantage in knowledge over clients. There may be an authority relation. Cain (2004) argues that paternalism and power are not compatible with the concept of partnership, for collaboration is absent and a lack of respect is involved. 'Where a person's will is overridden for what is perceived to be their own good, then the exercise of power is paternalistic' (id, p.281). Yet he also states that that 'authority and partnership are not incompatible, since inequality in knowledge is consonant with moral equality, and willing compliance does not preclude collaboration' (id., p.280). In deliberative forms of interaction, where influence is based upon collaboration, not on the use of power, partnership is a possibility.

Although he sees negotiation as the ideal way of communication, Moody does not exclude paternalistic interventions. If negotiation does not result in agreement, and if the consequences are serious, paternalism might be indicated. The results of the study in chapter 4 show that both parents and professionals preferred more active intervening strategies (paternalistic options) over strategies with a less direct intervening attitude (interpretive and deliberative strategies) in situations with eating problems compared to situations with other behavioural problems, and more in acute than in chronic situations. This is in line with Moody's statement that 'negotiation cannot resolve all the problems that arise because the pressure of reality - time, money, regulations, human frailty - intervenes and then necessity takes over. [...] Perhaps the most important advantage of thinking of decisions as matters of negotiation is that we are urged to keep exploring options and maintain an open mind. But when necessity intervenes, then the pressure to act becomes irresistible and negotiation comes to an end' (Moody, 1992, p.168).

A question that remains unanswered is when intervention is justified. Holland and Wong (1999) conclude that 'the determination of the capacity of a person with PraderWilli syndrome to make decisions about his/her eating behaviour and to control that behaviour is of particular importance [...]. If the person is found to lack capacity, the common law principles of acting in a person's "best interests" using "the least restrictive alternative" may be helpful'. In the Dutch Psychiatric Hospitals (Compulsory Admissions) Act, in contrast to similar legislation in the UK and other countries, capacity is not relevant to the decision to intervene or not against the wish of the patient. The only criterion in the Psychiatric Hospitals Act relevant to this issue is whether or not a clear danger is present. What falls under 'danger' is not defined clearly in the Act, but is left to practitioners and jurisprudence to be defined. Capacity 
does play a role in the Dutch Act on the Medical Treatment Contract which is part of the Civil Code; in the context of this Act a professional is allowed to interfere when capacity is lacking in the patient in case of serious harm. However, the Medical Treatment Act only is applicable to somatic conditions, and only aims at short term removal of the harming situation. It is questionable whether a lifelong genetic condition such as Prader-Willi syndrome can be defined as a somatic condition.

Next to these legal difficulties, the plea for an alternative approach to competence in chapter 5 shows another perspective may be needed to answer the intervention question. Assessing competence from a perspective of emotions and practical rationality leads to the conclusion that intervention in case of a lack of practical rationality does not only focus on protection, but also on support in the process of developing competence. The justification of an intervention is then the promotion of autonomy. From a care perspective, intervention is not seen as an infringement to a person's autonomy and thus a return to paternalism, but as 'compassionate interference' (Verkerk, 1999; 2001) that aims at attaining autonomy and fostering development. It is the responsibility of the caregiver to be attentive to the needs of the care-receiver, instead of abandoning him or her. Interference is not just one step, but is part of an ongoing care process. The notion of partnership implies that interventions should not only (and not primarily) aim at the avoidance of harm, but at the continuation of the relationship, and the fostering of the person's autonomy.

Prevention, empowerment and dialogue

In managing obesity problems in persons with Prader-Willi syndrome (physical) health is not the only relevant value. The values of well-being, freedom and responsibility, and a liveable life also play a role. This has implications for prevention activities. The focus of preventive activities should not only be on the weight of the person with Prader-Willi syndrome. Emphasizing control over weight and food intake may be negatively related to the feelings of well-being of the child or client, and negatively related to the values of freedom and responsibility and of liveability. In developing prevention activities it is important to have insight into the values, considerations and preferences of people within the practice at which these activities are aimed. Often a discrepancy can be seen between people within a practice on the one hand and policy makers and prevention workers on the other hand in normative thoughts about health, well-being and quality of life (see Horstman \& Houtepen, 2005).

In the field of health promotion, new health policies and activities to promote health are planned on the basis of the characteristics of the risk group. The beliefs, needs and health behaviour of the population are studied to ensure that the health promoting activities fit to and are adopted by the recipients (see Myers \& Midence, 1998; Green \& Kreuter, 1999; Tones \& Green, 2004). Health promotion 'is not so much concerned with adherence but rather with facilitating choice and gaining client cooperation' (Tones, 1998, p.152). In the light of the results of this study, it can be argued that the emphasis should be not on facilitating choice (as negative freedom), but on fostering cooperation (positive freedom). Gaining client cooperation can be achieved through empowerment. In health promotion, empowerment is a process through which peo- 
ple gain greater control over decisions and actions affecting their health. Empowerment may be a social, cultural, psychological or political process through which individuals and social groups are able to express their needs, present their concerns, devise strategies for involvement in decision-making, and achieve political, social and cultural action to meet those needs. Through such a process people will come to see a closer correspondence between their goals in life and a sense of how to achieve them, and a relationship between their efforts and life outcomes (WHO, 1998). Learning processes and change may be enhanced too through client participation and empowerment. Methods to achieve attitude and behaviour change through dialogical group processes need further scientific attention. Responsive evaluation (Abma, 2006) is an example of such an approach. Responsive evaluation has been developed as an alternative to the shortcomings related to an overreliance on experimental methods, the lack of attention to the process and implementation of programs, and the distant relationship with stakeholders and subjects (Abma, 2006, p.32). Responsive evaluation focuses on stakeholder issues and engages stakeholders in dialogues about the quality of their practice. The aim is to heighten the personal and mutual understanding of stakeholders as a vehicle for practice improvement. The interactive computer-tailored program and group discussions in the experiment with intervention strategies in the present study were examples of such a learning process. The assessment of the values and considerations of caregivers and the feedback to them about these insights form the basis for further dialogical learning processes.

Empirical ethics: dialogue between theory and practice

The use of empirical data to develop or adjust theories is a relatively new development within the field of ethics. What role can empirical research play in ethics? How can the practice of ethics be improved by using empirical research?

To make ethical debates concrete, input from empirical data is necessary. The empirical study of the practice of care to persons with Prader-Willi syndrome has led to insights in the moral values, considerations and actions of caregivers in managing obesity problems in daily life. Ethical debates about how to deal with obesity in PraderWilli syndrome focus on the question whether people have the right to intervene or not. The empirical study of the practice shows that caregivers do not think about this question. They all prefer intervention, based upon their view that they cannot leave choices to the person with the syndrome. However, the question for these caregivers is how they can keep the situation liveable and bearable for everyone involved, and what joint solutions can be found to keep life good for everyone involved despite the existing limitations. These insights can offer a concrete and contextualized meaning to abstract ethical debates on ethical justifications for intervention.

Furthermore, empirical research can lead to new ideas and concepts. With respect to the topic of care for persons with Prader-Willi syndrome, no structured scientific studies were done so far to get insight in this moral practice. The Grounded Theory approach was chosen for two reasons; this approach offers a well-described, wellstructured and acknowledged methodology for analysis and it aims at theory development and building. The Grounded Theory analysis showed that more values play a 
role in practice than health alone. The prevention of obesity or management of weight problems is thus not the only focus for caregivers. Making the relations between the values, conditions and interventions in the three-layer framework in care more explicit, offers a nuanced insight in the complexity of this moral practice. The use of a narrative analysis also led to new ideas. As the analysis shows, in practice subtler ways of interaction play a role that transcends paternalistic interventions. Caregivers seek imaginative ways of enhancing autonomy within a safe environment. The variations in interactions that emerged out of the interviews with parents and caregivers could be categorized according to the models of physician-patient interaction which Emanuel and Emanuel (1992) developed on the basis of empirical research on physician's ideals regarding the physician-patient relationship. The cases in practice showed examples that corresponded with the interpretive and deliberative models. The analysis in the present study is thus an example of combining empirical data and theoretical models. This not only made it possible to see patterns in the empirical material, but also gave rise to changes on a theoretical level. The approach of Emanuel and Emanuel was extended in two ways. Firstly, the interaction aspect of the models was stressed. Secondly, it was shown that the models were applicable to the area of care for people with intellectual disabilities. This is even the case for the deliberative model, which Emanuel and Emanuel reserved for dealing with intellectually competent patients.

An important question that can be posed is whether more differentiated ethical theories can have normative consequences for practice. Grounded Theory in first instance is descriptive of nature, aiming for theory development. Yet, the values and interventions which were found in the present study have an ideal character, and thus are normative. Emanuel and Emanuel (1992, p.2225) also draw normative conclusions from their empirical study of models of the physician-patient relationship, claiming that 'descriptively and prescriptively [...] the ideal physician-patient relationship is the deliberative model.' Of course, the claim that a model found in practice is normatively right needs further arguments. One way to develop such arguments is to engender a discussion with practitioners about their views of what is good care. Such a discussion can be structured with the help of a dialogical method, for instance the method of responsive evaluation (Abma, 2006).

Van der Scheer and Widdershoven (2004) have made a plea for an integration of empirical research and ethics. They outline an integrated empirical-ethical research, a 'new discipline with its own premises, theories, topics and methods. Integrated empirical ethics should embody what might be called theoretical hybridization: proactively creating a new breed of theory by consciously commingling the cores of two disciplines'. In the integrated approach, research 'looks for normative points of view in an empirical way and evaluates those normative points of view by focusing on observable consequences' (Van der Scheer \& Widdershoven, 2004, p. 72). In the present study, normative notions of good care were developed on the basis of empirical research into the values of people in practice, but also on the processes of learning which could be recognised in the care practice they described. This can be regarded as an example of the integration of empirical research and ethical analysis. 
The subject of this study was the prevention of obesity in the practice of care for persons with Prader-Willi syndrome. Obesity is a growing problem in the Western world. This is not only true for the general population, but also for people with intellectual disabilities. Prevention is becoming more and more important. Therefore, ethical issues of prevention of obesity gain relevance. A question for further research is whether the results of this study can be extrapolated to similar situations, such as care for people with intellectual disabilities different from Prader-Willi syndrome, or other conditions that are characterised by limited capacities, such as mental illnesses or aging conditions. Exploring these other care practices would clarify whether the found moral values also play a role in those conditions, and whether caregivers in these practices have similar moral considerations and choose similar approaches to realize these values. A caregiver of a client with Down syndrome who wants to smoke for example, is confronted with the same moral tension of respecting a person's autonomy in relation to his professional responsibility to provide good care. Professionals dealing with anorexia nervosa patients experience similar ethical concerns about respect for the client's autonomy versus protection. Are the values found in this study relevant for these caregivers, and would they value the interaction approaches in the same way?

As elaborated in this study, the interpretive and deliberative forms of interaction are not only based on verbal dialogues but also on emotional responses, for persons with intellectual disabilities often express themselves through behaviour. This study was limited to persons with Prader-Willi syndrome, who have intelligence levels in the mild to moderate disability range. To further explore the benefits and limitations of these dialogical processes in the care for persons with intellectual disabilities, future research should also include persons with other especially more severe intellectual disabilities.

The designs used in this study can be improved in future research. One example is the preference ranking design. In the preference ranking the interaction models were compared on a general level and by using formulations on cards that reflected the essence of each model. Since the interpretive and deliberative intervention strategies appeared to be located close to each other on the dimension that represented the amount of active intervention, it would be interesting to study further which elements of these models are discriminative. This can be investigated in a qualitative way with structured interviews, asking questions about these elements or in a quantitative way with questionnaires, by setting up items on the elements. More generally, the results of the studies could be discussed with the stakeholders, making the research process more truly dialogical in nature (Abma \& Widdershoven, 2005; 2006).

The educational part of this study focused on creating awareness, broadening perspectives and offering alternatives for attitudes and behaviour. The method was based on gaining individual feedback to caregivers about their preferences, and confronting them with stories of other caregivers, emphasizing different values and using different approaches. Although this method was based on a dialogical model of learning, the dialogue was virtual rather than real. The actual dialogue needs further study 
in future research. New technological developments on Internet present intriguing new possibilities for fostering an actual dialogue between caregivers.

\section{Notes}

1 The importance of the value of liveability, not only for the client but also for supporting others, like family or professional caregivers, is in line with developments in research on quality of life. For many years now the quality of life of individuals with intellectual disabilities is studied. In recent years however, both researchers and policy makers began to realize that attention should not only focus on the needs of the child or the parents, but that it is relevant to pay attention to the needs of the family as a whole. The role of informal support by family and friends is more and more discerned (Silvis, 2004). Furthermore, policies need to be developed that are responsive to the age-related needs of family carers (Hogg et al., 2000). Therefore scientific interest has shifted recently from studying the quality of life of individual clients towards the study of 'Family Quality of Life'. Family quality of life is defined by Turnbull et al. (2004) as 'conditions where the family's needs are met, and family members enjoy their life together as a family and have the chance to do things which are important to them'. On the basis of qualitative research 10 domains of family quality of life are identified. These domains include both an individual orientation (advocacy, health, productivity, emotional wellbeing, physical environment, social well-being) and a family orientation (daily life, family interaction, financial well-being, parenting) (Park et al., 2003; Poston et al., 2003).

2 In his inaugural lecture (May 2007) in which Meininger outlined a narrative ethical perspective on social integration of persons with intellectual disabilities, he emphasizes that a true dialogue asks for radical openness. Of importance to a dialogue is not an exchange relation, but a response relation. 'It is the difference, the strangeness, the lack of equality, the asymmetry in experience, social position and language, the feared infringement on the ethos, the always incomplete response to the appeal of the other and the astonishment about a possible new perspective are moving forces behind the dialogue. When a dialogue is held like that, persons with intellectual disabilities are full partners. [...] Persons with intellectual disabilities are actors in processes of social integration. Processes of social integration can only be established and flourish in combined action with other actors. The burdens of this process should not be transferred one-sidedly on persons with intellectual disabilities. The undergoing learning process also is a learning process to all those others in society who do not carry the label 'intellectual disabled'.'

3 Frederiks (2007) pleads, especially in discussing the use of freedom restrictive measures, for an alternative legal framework that not focuses on the right to selfdetermination. If the focus would shift to a right to good care and a right to development, the legal position of persons with intellectual disabilities might improve. 


\section{References}

Abma, T. A. (2006). The practice and politics of responsive evaluation. American Journal of Evaluation, 27, 31-43.

Abma, T.A., Frederiks, B.J.M., Hooren, R.H. van, Widdershoven, G.A.M., Wijmen, F.C.B. van, Curfs, L.M.G. (2007). Freedom restrictions: how to improve day-to-day care. Submitted to Journal of Applied Research in Intellectual Disabilities.

Abma, T.A., \& Widdershoven, G.A.M. (2005). Sharing stories. Narrative and dialogue in responsive nursing evaluation. Evaluation \& The Health Professions, 28, 90-105.

Abma, T.A., \& Widdershoven, G.A.M. (2006). Moral deliberation in psychiatric nursing practice. Nursing Ethics, 13, 546-557.

Berlin, I. (1969). Four essays on liberty. Oxford University Press, Oxford.

Butler, M.G., Lee, P.D.K., Whitman, B.Y. (2006). Management of Prader-Willi syndrome (3rd edition). Springer, New York.

Cain, P. (2004). "Partnership" is not enough: Professional-client relationships revisited. In: K.W.M. Fulford, D.L. Dickenson, T.H. Murray (Eds.), Healthcare ethics and human values. An introductory text with readings and case studies. Blackwell, Malden, Mass.

Dosen, A. (2007). Integrative treatment in persons with intellectual disability and mental health problems. Journal of Intellectual Disability Research, 51, 66-74.

Emanuel, E.J., \& Emanuel, L.L. (1992). Four models of the physician-patient relationship. JAMA, 267, 2221-6.

Frederiks, B.J.M. (2007). The rights of people with an intellectual disability in the Netherlands: From restriction to development. European Journal of Health Law, 14, 1-15.

Green, L.W., \& Kreuter, M.W. (1999). Health promotion planning: An educational and ecological approach [3rd edit.]. Mayfield Publishing Company, Mountain View, California.

Gremmen, I. (1995). Ethiek in de gezinsverzorging: Gender en de macht van zorg [Ethics in home care: Gender and the power of care]. Van Arkel, Utrecht.

Hogg, J., Lucchino, R., Wang, K., Janicki, M.P., \& Group, W. (2000). Healthy ageing: Adults with intellectual disabilities: Ageing and social policy. World Health Organization, Geneva.

Horstman, K., \& Houtepen, R. (2005). Worstelen met gezond leven: ethiek in de preventie van hart- en vaatziekten [Struggling with healthy living: ethics in the prevention of coronary heart disease]. Het Spinhuis, Amsterdam.

Mackenzie, C., \& Stoljar, N. (2000). Relational autonomy: Feminist perspectives on autonomy, agency, and the social self. Oxford University Press, New York / Oxford.

Meininger, H.P. (1997). Als u zelf: een theologisch-ethische studie van zorg voor verstandelijk gehandicapten [Like yourself: a theological-ethical study of care to intellectually disabled]. 's Heeren Loo, Amersfoort.

Meininger, H.P. (2002). Zorgen met zin. Ethische beschouwingen over zorg voor mensen met een verstandelijke handicap [Care with meaning. Ethical considerations about care for persons with intellectual disability]. SWP, Amsterdam.

Meininger, H.P. (2007). Verhalen verbinden. Een narratief-ethisch perspectief op sociale integratie van mensen met een verstandelijke handicap [Binding stories. A narrative ethical perspective on social integration of persons with intellectual disabilities]. Inaugural lecture, VU University, Amsterdam.

Moody, H.R. (1992). Ethics in an aging society. John Hopkins University Press, Baltimore.

Myers, L.B., \& Midence, K. (1998). Adherence to treatment in medical conditions. Harwood Academic Publishers, Amsterdam [etc.].

Park, J., Hoffman, L., Marquis, J., Turnbull, A.P., Poston, D., Mannan, H., Wang, M., \& Nelson, L.L. (2003). Toward assessing family outcomes of service delivery: validation of a family quality of life survey. Journal of Intellectual Disability Research, 47, 367-84. 
Poston, D., Turnbull, A.P., Park, J., Mannan, H., Marquis, J., \& Wang, M. (2003). Family quality of life: a qualitative inquiry. Mental Retardation, 41, 313-28.

Reinders, H. (1994). De grenzen van het rechtendiscours [The limits of the rights discourse]. In H. Manschot, M. Verkerk (Eds.), Ethiek van de zorg: een discussie [Ethics of care: a discussion]. Boom, Amsterdam.

Reinders, J.S. (1996). Wat niets kan worden, stelt niets voor. Mensen met een verstandelijke handicap in het licht van de hedendaagse gezondheidsethiek [What can be nothing, means nothing. Persons with intellectual disability in the light of contemporary health ethics]. 's Heeren Loo, Amersfoort.

Reinders, H.S. (1997). The ethics of normalization. Cambridge Quarterly of Healthcare Ethics, 6, 4819.

Reinders, J.S. (2000a). Ethiek in de zorg voor mensen met een verstandelijke handicap [Ethics in the care for persons with an intellectual disability]. Boom, Amsterdam.

Reinders, J.S. (2000b). The good life for citizens with intellectual disability. Journal of Intellectual Disability Research, 46, 1-5.

Roovers, M. (2004). Mensbeelden en moreel handelen in de zorg voor verstandelijk gehandicapten. Een empirisch-ethische studie. [Ideas of man and moral action in the care for intellectually disabled. An empirical-ethical study.] Valkhof Pers, Nijmegen.

Ruddick, S. (1989). Maternal thinking: Towards a politics of peace. Ballantine, New York.

Scheer, L. van der, \& Widdershoven, G. (2004). Integrated empirical ethics: Loss of normativity? Medicine, Health Care and Philosophy, 7, 71-9.

Sevenhuijsen, S.L. (1998). Citizenship and the ethics of care. Feminist considerations on justice, morality and politics. Routledge, London.

Silvis, H. (2004). In de context van het gezin [In the context of the family]. In M. Kersten, D. Flikweert (Eds.), Onderzoek over grenzen [Research across borders]. NGBZ en LKNG/NIZW, Utrecht.

Smits, M-J. (2004). Zorgen voor een draaglijk bestaan: Morele ervaringen van verpleegkundigen [Caring about a bearable existence: Moral experiences of nurses]. Aksant, Amsterdam.

Tones, K. (1998). Health promotion: Empowering choice. In L.B. Myers \& K. Midence (Eds.), Adherence to treatment in medical conditions. Harwood Academic Publishers, Amsterdam [etc.].

Tones, K., \& Green, J. (2004). Health promotion: planning and strategies. Sage, London.

Tronto, J. (1993). Moral boundaries. A political argument for an ethic of care. Routledge, New York.

Turnbull, A.P., Brown, I., \& Turnbull, H.R. (Eds.). (2004). Families and people with mental retardation and quality of life: International Perspectives. American Association on Mental Retardation, Washington DC.

Verkerk, M. (1999). A care perspective on coercion and autonomy. Bioethics, 13, 358-68.

Verkerk, M. (2001). The care perspective and autonomy. Medicine, Health Care and Philosophy, 4, 289-294.

Walker, M.U. (1998). Moral understandings. A feminist study in ethics. Routledge, New York.

WHO (1998). Health promotion glossary. WHO, Geneva. 


\section{Appendix A Interview scheme}

\section{Short introduction - explanation of the research aims}

\section{General - situation}

Can you tell something about [name child / client]?

What kind of person is [name child / client]?

Leisure interests / daily activities.

Point for attention: - Quality of life

Relationship with parents / family members / friends?

Why has [name client] come to live here?

\section{Daily social interaction}

Can you tell something about how you go about with [name child / client]? How do you ensure everything is going fine? Can you give examples?

In what ways is this the same compared to brothers/sisters / other residents? Why? Are there aspects in that interaction that are different? Which? Why different? Can you explain this, can you give an example of this difference?

Point for attention with parents:

- What kind of education do parents prefer? What is important in that education to parents? Why?

- How much value do parents attach to the promotion of independence of the child? How much room to do this do they see and in what way this is realized?

- What is the future vision of parents on the maximum that is possible with regard to the capabilities of the child? How can that vision be found in the current interaction?

Point for attention with caregivers:

- What kind of care do caregivers prefer? What is important in that care to caregivers? Why?

- How much value do caregivers attach to the promotion of independence of the client? How much room to do this do they see and in what way this is realized?

- Relationship care - policy?

- What is the future vision of caregivers on the maximum that is possible with regard to the capabilities of the client? How can that vision be found in the current interaction? 


\section{Food practice}

How are things going with eating?

How is/was the composition of the diet?

What is important to you in the composition of the diet?

What is good about this diet to your opinion? Why is it good?

What is less good about the diet? Why?

Has the weight of [name child / client] always been the same?

\section{Point for attention:}

- If weight has decreased, in what way realized? Why that approach?

If weight has increased, what is the cause? To what extent is the approach of the parent I caregiver of influence on this?

How much freedom can you give [name child / client] in making choices about food? Why? How do you approach this?

When it is / is not possible? Can you give an example?

Point for attention:

- How much freedom has the child / client in choosing himself what to eat?

- Is the child / client capable himself to weigh in food matters?

- Is this allowed by parent / caregiver?

If [name child / client] complies well with the diet, how do you deal with that?

Point for attention:

- Reward: which, why, when / when not? Different types of reward?

Does it happen some time [name child / client] doesn't agree with the diet / with what he/she gets to eat? Can you give an example?

How do you deal with that?

Point for attention:

- Are disagreements discussed with child / client? How and to what extent are whishes of child I client taken into account? How are these whishes realized?

Does it happen some time [name child / client] eats more than you want / agreed upon?

How do you react to that? Why?

Point for attention:

- Punishment? When / when not? Why? How? Different types of punishment?

- role of feelings of guilt parents / caregivers 
For caregivers: How do parents think about the interaction with [name client] with regard to eating?

\section{Point for attention:}

- How is the relationship between caregiver and parents / family members of the client?

- Communication between parties

- Influence of vision parents / family members on interaction of caregiver with client?

How do other caregivers think about the interaction with [name client] with regard to eating?

Point for attention: - Difference in vision between caregivers?

What would you advice other caregivers?

General points for attention:

- How does the freedom of the client relate to eating? How dependent is the client from the caregiver?

- Restrictions as a consequence of policy

\section{Interaction in general (not directly related to eating)}

Are there besides the problems with eating other matters that are difficult in the interaction with [name child / client]?

Point for attention:

- Specific behavioural problems Prader-Willi syndrome

- Intellectual disability

\section{-Social environment}

What does your social environment (other family members, friends, neighbours etc.) think of your interaction with [name child / client]?

Do they always agree with you? Can you give examples?

Do you have contact with professional caregivers? Who? What for?

How satisfied are you with the work of these caregivers? What do you think is good about how they interact with you child? What do you think is less good? Can you explain this by giving examples?

Final (summarizing) question

What advice would you give to other parents / caregivers? 


\title{
Appendix B Case descriptions
}

\author{
Case $1 \quad$ Jan
}

Central to this case is the story of Jan, a 20-year-old young man with Prader-Willi syndrome. Jan has left his parental home several years ago. Until a short time ago, he lived in a large institution for persons with an intellectual disability. He was supported well and everything went fine. Jan has a strong desire to eat. The caregivers knew well how to deal with him and his syndrome. Everything was put behind bars and Jan was controlled a lot.

At a sudden moment, however, the question was raised whether Jan could move to a group home outside the institution, a move to a 'normal' residential quarter. After a lot of discussion, he was given the benefit of the doubt. Jan moved.

In the beginning -despite the fact that both Jan and his new caregivers had to get used to the new situation- everything went quite well with him. In the group home, everything was different, a lot less strict and with less control.

But at a sudden moment it became clear that Jan was not feeling as comfortable as before the move out of the institution. Jan's behaviour became more and more problematic. The new caregivers admit they do not know much about Prader-Willi syndrome, and they do not know well how to deal with Jan's temper tantrums that occur more and more often lately, and become more and more intense. Jan also increasingly gets problems with the other residents, who have more and more trouble with him. They do not feel safe and avoid Jan. The team thinks it is definitely time for Jan to move back to his old place at the institution, but Jan does not want this at all.

\section{Case $2 \quad$ Marieke}

The life of Marieke looks quiet and well. This 18-year-old girl lives with her parents, together with her 4-year younger brother. Marieke is a nice and social child that feels comfortable with herself. It is, however, the case that because of her syndrome Marieke gives her parents no end of trouble. Because of the always present desire for food, they always had to keep an eye on things. Her mother has always taken pity on her daughter with love.

Now the parents are faced with the decision to let Marieke go to another school, that is not in their village, but is in the adjacent town. Marieke always has been quite a clever girl, but her mother is somewhat concerned about the step to this new school. At the smaller school in the village everybody knows her and everybody knows Marieke was not allowed to eat too much. Marieke has been walking to school alone 
the last years. Also the baker and the personnel from the small supermarket in the village where Marieke passes daily know her very well.

Now, however, the parents see the dangers loom ahead quickly, thinking of the big school in the town. The parents consider the school a better place for Marieke's further development, but this should not lead to the development of overweight. When the parents took a look at this school, they were startled by the fact in the central hall there were sweets machines. Also there was a big supermarket behind the playground. Her mother wanted she could bring Marieke to school herself and stay with her at school to keep an eye on her, but that was not realistic she realized herself.

\section{Case $3 \quad$ Piet}

Piet is a 30-year-old young man with Prader-Willi syndrome, who has been living in an institution for twelve years. He has a mild intellectual disability and is functioning quite independently (he works in the institution, organizes soccer matches etc.). Piet has a good relationship with his caregivers. If there are problems, these can always be discussed with him in a good way. In this, his wishes are taken into account as much as possible. The caregivers also have regular contact with his mother who, after her husband died, does not want to thwart Piet.

Piet has been gaining weight gradually for 5 months. His personal caregiver sees a link with Piet's new girlfriend. He is very much in love with her and his girlfriend really cheers him up. However, through her he also gets outside the institution in his leisure time much more often. The caregiver suspects that in this way Piet more easily breaks with his dietary instructions. His girlfriend also regularly gives him biscuits, which Piet likes a lot.

The caregivers talk with Piet about his weight increase, although Piet does not want to change his opinion at this point. Though he is gaining weight, he now feels happier than ever before. To him, this is the only thing that matters. Nobody has the right to take away that happiness.

\section{Case 4}

Janneke

Janneke has been living for a considerable time in an institutional living facility. At age 26 and with a mild intellectual disability, she is quite a clever girl. At a sudden moment Janneke indicates she is tired of the fact that if she wants to go into town with the bus there is always a caregiver going with her: "I am not a small child anymore!". The caregivers discuss this and talk with her, and it is decided that Janneke can also go into town alone. She gets pocket-money, and clearly the agreement is made she will not buy food for it. 
After a while, the caregivers notice that she wants to go into town more and more often. She asks her caregivers more and more often for money. They have the impression she thinks up the strangest things she wants to buy, just to have a reason to go into town.

Case 5

Remko

Central to this case is a family with two children, Remko of 10 years with Prader-Willi syndrome and the 3-year older daughter Iris. Remko is a difficult child, who asks a lot of attention from both parents. The parents try as well as possible to give Iris attention too. Especially, now Iris is reaching the age of puberty and is showing dissatisfaction with her brother more often. It is, however, not easy at all; Remko can whine for hours. He also is not very flexible; he clings to customs and he has all kinds of 'rules' in his head, even for little things.

His mother cannot deal with it anymore. The past holidays were very tiring to her and her husband. His father is much more patient, he can see things more in perspective.

But now also the daughter Iris begins to show more and more resistance. She always was able to understand everything well and tolerate her brother. Lately, however, everything starts to get under her skin; even the fact that Remko is watching cartoons, that he has seen a hundred times but still enjoys, on TV all day long. In the past she could always secretly joke about it, now she grumbles about it a lot. Remko does not like his sister reacting in an irritated way to him. He is very fond of her. "Cannot we be a normal family for just once?!", she reacts very annoyed. Tensions within the family are rising. Remko can no longer be kept at home.

Case 6

Nathalie

Nathalie is a 16-year-old girl with Prader-Willi syndrome that lives at home with her parents. She is their only child, and her parents are very fond of her. Nathalie always has been a bit heavy, but because of her parents' great efforts her weight has remained stable through the years. She is a happy girl. Everybody calls her 'a sunbeam in the house'. Now, it has become clear she has diabetes and her parents have agreed, in consultation with the family doctor and the dietician, upon introducing a stricter and sugar-free diet. Nathalie is told this and at first she does not object against it.

After 2 months, however, Nathalie starts to show more and more problem behaviour. Her cheerful mood has turned into mood swings with fierce temper tantrums. She complaints she does not like it as much anymore as 'in the old days', when she did not have diabetes. At a sudden moment her father catches Nathalie secretly stealing chocolate out of the cupboard in the kitchen. When he discusses this with Nathalie, it turns out that this is not the first time Nathalie takes things from the kitchen without 
her parents knowing it. Her parents do not trust their daughter anymore and they are very worried because of their daughter's diabetic condition. The stealing and temper tantrums do not decrease, they only worsen. Her father and mother consider putting a lock on the cupboards in the kitchen.

\section{Case $7 \quad$ Kees}

Kees is a 13-year-old young man with Prader-Willi syndrome. Kees has been living in a child group home for 2 years now. At home everything was going well with him. Eating never was a problem, Kees never asked for more food than what he got. His weight has always been quite normal. However, because his parents are getting older and because they think that Kees' development would benefit more if he would leave the parental home, it was decided in consultation with Kees that he would move out and go to a child group home. At first things worked out well. Kees very soon felt happy and had a good contact with the other residents. The caregivers consult the parents a lot, and Kees always is present in those consultations. Together everything is discussed constantly so that everyone can go on satisfied.

Lately, however, since he reached the age of puberty, Kees' behaviour is more difficult. More and more often he opposes his caregivers and also with the other residents he quarrels often. Kees does not want to participate anymore to all kinds of group activities. He now sees the games he used to like as childish. He prefers to be alone in his own room, playing at his computer or with music. The caregivers see that Kees isolates himself too much and their efforts to improve the contact between Kees and the other residents and to find a way to deal with Kees' behaviour fail.

\section{Case $8 \quad$ Leontien}

Leontien is a kind 17-year-old girl with Prader-Willi syndrome. She lives at home, together with her older sister. She never has been easy to get on with. She demonstrates clearly all features of the syndrome, according to her parents. In particular she cannot deal with changes. She easily gets upset. Just planning a trip with the family is nearly impossible.

The last months' tensions rise very high. Her mother can no longer deal with it for quite some time. Her father starts to avoid interaction with Leontien. Her mother and father have a flaming row about the question whether Leontien can continue living at home. Her mother is thinking of a move of Leontien out of the parental home, her father does not want to let things go so far yet. They contact a social worker to find a solution, to see how things can go on with Leontien. The last couple of weeks she cannot be kept under control at all; she constantly steals food, her weight is increasing dramatically. It just cannot go on like that anymore. 


\section{Summary}

In the past decades, the way we view persons with intellectual disabilities has changed dramatically. Nowadays, the paradigm of citizenship dominates the field of care. According to this view, persons with intellectual disabilities can and should live in society as equal citizens. A good quality of life for each citizen is the main aim to strive for. The development of freedom of choice, self-determination and responsibility of persons with intellectual disabilities can on the one hand be seen as beneficial. On the other hand, caregivers are aware of the fact that these individuals need support. This need of support may mean that their choices should not be taken for granted, but should be critically assessed in the light of the person's well-being. Persons with intellectual disabilities sometimes behave or want to make choices that may be harmful to their health. Even for persons without intellectual disabilities today's society poses many potential risks. It is not always easy to decide what to do when whishes and interests of individuals with intellectual disabilities conflict with one another.

Such conflicts are very prominent in the care for persons with Prader-Willi syndrome. This genetic disorder, which is taken as the central case in this study, is associated with mild to moderate intellectual disabilities. A prominent feature in Prader-Willi syndrome is an excessive appetite, frequently associated with overeating behaviour. It has been suggested that in Prader-Willi syndrome the normal satiety response is impaired and delayed. This overeating behaviour frequently leads to obesity, which without any dietary intervention can be severe and lead to serious health problems. How should parents and professional caregivers deal with this situation? What does full citizenship mean for these individuals, given the syndrome specific eating characteristics? Is it a violation of clients' rights if caregivers lock up food, restrict clients' social contacts and limit their expenditures for the sake of their health and quality of life? In what way do persons with Prader-Willi syndrome need to be supported?

The present study started with in-depth qualitative interviews with parents and professional caregivers of persons with Prader-Willi syndrome. To answer the main question, what good care means in this specific care practice, the moral considerations of these caregivers were explored. The focus was on the use of freedom restricting measures in the prevention of obesity of young persons with the syndrome. With an open qualitative approach the moral values and considerations, and preferred ways of interaction of caregivers in their daily management of obesity prevention in their children and clients were made explicit.

Chapter 2 presents the Grounded Theory analysis of these interview data. For good care it is essential to create and maintain a meaningful balance between several values. The most important value that caregivers brought forward was the value of (physical) health, e.g. the prevention of obesity. Yet, good care is not solely focused on the promotion of physical health, though it is an important value to strive for since the health risks of obesity should never be underestimated. Furthermore, well-being, freedom and responsibility, and a liveable life also emerged as relevant values for caregivers in the studied practice; parents and professional caregivers see it as important that their 
child or client feels comfortable, has a certain amount of freedom in which she or he learns to take a responsibility next to their responsibility as caregivers. Furthermore, the efforts of caregivers are aimed at preventing that the problem behaviour of the person with Prader-Willi syndrome becomes a burden for the people around her or him like other members in the family or other residents.

In a theoretical framework, constructed on the basis of the Grounded Theory analysis, it is shown that these values are related to specified enabling and limiting conditions and to several possible interventions. The enabling conditions entail creating a situation of trust and openness in which relationships can be strengthened and rules are not applied too rigidly. In a supportive social environment in which structure is offered, a caregiver can be moderate in imposing rules, and need not go to the extreme of forbidding things explicitly. In a stable social environment situations of conflict can be avoided. The efforts of caregivers are aimed at keeping the situation manageable and liveable for everyone involved, despite the food related and behavioural features of syndrome.

In chapter 3 the interview data are analysed using a narrative analysis. A comparison was made of all the cases as a whole with each other at a general level. In the narrative analysis the differences were looked at in the ways parents, professional caregivers and the persons with Prader-Willi syndrome communicated, and what kind of attitudes were apparent. None of the caregivers opted to leave the choice for food entirely to the person with the syndrome. Neither did they simply intervene without taking into account the wishes of the individual with Prader-Willi syndrome. Autonomy is promoted, but not by giving freedom of choice. Instead of individual selfdetermination, emphasis is on self-realisation through the support of others. Focus thus is not on negative but on positive freedom.

The data show that the process of care cannot adequately be seen in terms of choosing between respecting autonomy through securing freedom of choice on the one hand, and paternalism on the other. That is too crude. The stories indicated that caregivers see other options and act in other ways. As a starting point the four kinds of physician-patient interaction outlined by Emanuel and Emanuel (1992) were used. These authors define not only a paternalistic and an informative model (which are based on the traditional dichotomy between paternalism and autonomy in terms of selfdetermination). They add two further possible approaches to the physician-patient model: the interpretive model and the deliberative model.

In the interpretive model, the physician helps to elucidate the patient's values, and to make clear what she or he actually wants. This model assumes that the patient's values are not always fixed and known to the patient. The deliberative model, like the interpretive model, sees the aim of the physician-patient interaction being to help the patient determine and choose the best values for his health. But unlike the interpretive model, the values of the patient not only need to be clarified, they are also open for development and revision through moral discussion and deliberation.

The analysis showed that there were few examples in the interview cases that clearly corresponded to the informative model. According to this model a caregiver would fully inform the person with Prader-Willi syndrome of the dangers of overeating, but leave the choice of eating behaviour up to that person. The accounts given by the 
caregivers often had a paternalistic tone. In addition, however, there were also elements in the stories showing that the process of care was directed towards fostering self-understanding or moral development. The stories were never totally in accordance with only one model, although one of the models was quite often dominant within a specific interview. Thus, cases of paternalism, of interpretive interaction and of deliberative interaction could each be distinguished.

Chapter 4 reports on a quantitative study to explore how caregivers value the various interaction models of Emanuel and Emanuel (1992) and which interventions they prefer in specific situations. In order to examine this, several intervention strategies were formulated on the basis of the physician-patient interaction models. Eight cases, that focussed on a specific problem related to Prader-Willi syndrome, were presented to a group of parents and of professionals. Central to the cases was either an eating or a behavioural problem, an acute or a chronic problem and was situated either at home or in a community-based setting. The results of this quantitative study show that both the parents and the professional caregivers preferred intervening over not intervening in dealing with problems in the care for persons with Prader-Willi syndrome. The informative approach, in which the choice is completely left to the child or client, was the least preferred model, and the paternalistic strategies were the most liked. The parents preferred intervening approaches to a greater extent than the professional caregivers. Parents preferred more controlling interventions in situations with eating problems than in situations with behavioural problems, whereas professional caregivers showed no difference between these situations. For both groups the degree of preference for the more controlling interventions was less marked for chronic, compared with acute, situations.

In chapter 5 the issue of competence is addressed. The current criteria for competence set a high standard, emphasizing cognitive capacities: people have to be able to communicate a decision, to understand information, to apply information to their situation and to reason about all aspects of the decision. This cognition based approach of competence may lead to an improper marginalisation of people with intellectual disabilities in the decision making process. An alternative approach is proposed, focusing on emotions and practical rationality. It is argued that this approach, which makes use of life story work and observations of behavioural patterns, is more adequate for the care for persons with intellectual disabilities.

It is only in recent years that empirical data have been systematically collected in order to help develop or adjust ethical theories. Instead of attempting to clarify and explain moral dilemmas with the help of ethical theories, principles and rules, an increasing number of ethics projects study specific care practices with the aim of explicating those moral rules and convictions that are intrinsic to these practices. In chapter 6 both the qualitative and quantitative approaches to gather data in this ethical project are discussed and compared. As discussed in the chapter, from the experience of practitioners may be learned that there are more ways of dealing with moral issues in the prevention of obesity that those that are dominant in moral theory. This may lead both to conceptual and normative conclusions. Conceptually, it may be concluded that a definition of autonomy, based on the notion of positive freedom can be relevant in the area of the prevention of obesity in the care of people with a Prader- 
Willi syndrome. The notion of autonomy as positive freedom can be elaborated using the work of Emanuel and Emanuel. Yet, this also implies the need to reflect on the rationalist way in which Emanuel and Emanuel describe autonomy as moral development, which seems to restrict this notion to competent adults. This conceptual conclusion also has a normative side. The notion of positive freedom can serve as a goal in this specific practice of care. The present study not only shows the moral relevance of this goal, but also makes clear those moral actions, attitudes and considerations that are necessary to achieve this goal, such as giving support and creating safety.

Chapter 7 describes the contents of an interactive computer-tailored program, that was developed on the basis of the gathered data in this study. The aim of the program is to start a process of awareness, reflection and discussion by caregivers. The program is centred around one case and provides on the basis of the responses of users tailored feedback. The program focuses on values relevant to caregivers in daily practice and on various ways of interaction with the client. Three trajectories were worked out, a paternalistic, informative and an interpretive/deliberative route. Although no significant changes were found in preferences of users, at the end of the module in comparison with the beginning, their responses do support previous research findings. These findings advocate a concept of autonomy in terms of positive freedom, through support of others, to which the promotion of self-understanding and selfdevelopment is central.

The final chapter of this thesis discusses the broader meaning and implications fo the findings of this study. Addressing the main research questions, the meaning of good care is discussed for parents and professional caregivers dealing with the prevention of obesity in persons with Prader-Willi syndrome. Good care implies a plurality of values, besides a focus on physical health. Good care also implies interventions that provide support and foster joint learning. The consequences of the findings of the present study for ethics of care are discussed. And the implications of the study for practice are addressed. Instead of citizenship, a plea is held for partnership, in which decisions are made in a joint dialogue. Persons with intellectual disabilities not only should have equal rights, but should also be aware of their own responsibilities. Not only is it relevant to elucidate the values of the client but also to critically question these values with the aim of creating opportunities for learning.

For the field of health promotion, the results of this study show that the emphasis should be not on facilitating choice but on fostering client cooperation and empowerment.

The integrated role of empirical research and ethics is discussed. In this integrated approach, research looks for normative points of view in an empirical way and evaluates those normative points of view by focusing on observable consequences.

Since (childhood) obesity is a growing problem in our Western society, for future research it is relevant to see whether the results of this study can be extrapolated to similar situations. To further explore the benefits and limitations of dialogical processes like interpretation and deliberation, persons with other especially more severe intellectual disabilities should be included in future research. New and modern ways should be explored to study the beneficial aspects of a promotion of an actual dialogue. 


\section{Samenvatting}

De wijze waarop we mensen met verstandelijke beperkingen zien is dramatisch veranderd gedurende de laatste decennia. Tegenwoordig domineert het paradigma van burgerschap het zorgveld. In deze visie kunnen en moeten mensen met verstandelijke beperkingen leven in de maatschappij als gelijkwaardige burgers. Een goede kwaliteit van bestaan voor iedere burger is het hoofddoel dat nagestreefd wordt. De ontwikkeling van keuzevrijheid, zelfbepaling en verantwoordelijkheid voor mensen met verstandelijke beperkingen kan enerzijds als positief gezien worden. Anderzijds zijn zorgverleners zich ervan bewust dat deze individuen ondersteuning nodig hebben. Deze behoefte aan ondersteuning kan betekenen dat hun keuzes niet vanzelfsprekend zijn, maar kritisch vastgesteld dienen te worden in het licht van het welzijn van de persoon. Mensen met verstandelijke beperkingen vertonen soms gedrag of willen keuzes maken die schadelijk kunnen zijn voor hun gezondheid. Zelfs voor mensen zonder verstandelijke beperkingen schuilen in de hedendaagse maatschappij vele potentiële risico's. Het is niet altijd gemakkelijk te beslissen wat te doen wanneer wensen en belangen van mensen met verstandelijke beperkingen tegenstrijdig zijn met elkaar.

Zulke tegenstrijdigheden komen naar voren in de zorg voor mensen met Prader-Willi syndroom. Bij deze genetische aandoening, die centraal staat in deze studie, komen lichte tot matige verstandelijke beperkingen naar voren. Een opvallend kenmerk van Prader-Willi syndroom is een overmatige eetlust, die vaak leidt tot overeten. Bij Prader-Willi syndroom is de normale verzadigingsrespons verstoord en vertraagd. Het overeet gedrag leidt vaak tot obesitas, die zonder dieet interventies ernstig kan zijn en grote gezondheidsproblemen tot gevolg heeft. Hoe zouden ouders en hulpverleners hiermee moeten omgaan? Wat betekent volwaardig burgerschap voor deze individuen, gezien de specifieke eetkenmerken van dit syndroom? Worden cliëntrechten geschonden als zorggevers voedsel wegsluiten, hun sociale contacten en hun uitgaven beperken in het belang van hun gezondheid en kwaliteit van leven? Op welke manier moeten mensen met Prader-Willi syndroom ondersteund worden?

Deze studie startte met open interviews met ouders en hulpverleners van mensen met Prader-Willi syndroom. Om een antwoord te vinden op de hoofdvraag, wat goede zorg in deze specifieke zorgpraktijk inhoudt, werden de morele overwegingen van zorggevers bestudeerd. De nadruk lag op het gebruik van vrijheidsbeperkende maatregelen in de preventie van overgewicht bij jongeren met dit syndroom. Met een open, kwalitatieve benadering werden morele waarden en overwegingen, en manieren van interactie die de voorkeur hadden van zorggevers in hun dagelijkse omgang met het voorkomen van obesitas bij hun kinderen en cliënten expliciet gemaakt.

Hoofdstuk 2 presenteert de Grounded Theory analyse van deze interview gegevens. Voor goede zorg is het belangrijk een betekenisvolle balans te creëren en handhaven tussen verscheidene waarden. De meest belangrijke waarde die zorggevers naar voren brachten was de waarde van (fysieke) gezondheid; met andere woorden, het voorkomen van overgewicht. Goede zorg is echter niet alleen gericht op het bevorderen van de fysieke gezondheid, ofschoon het een belangrijke waarde is om na te stre- 
ven gezien het feit dat de gezondheidsrisico's van overgewicht nooit onderschat moeten worden. Ook welzijn, vrijheid en verantwoordelijkheid, en leefbaarheid kwamen naar voren als relevante waarden voor zorggevers in de bestudeerde praktijk. Ouders en hulpverleners zien het als belangrijk dat hun kind of cliënt lekker in zijn vel zit, een bepaalde hoeveelheid vrijheid heeft waarbinnen hij of zij leert een verantwoordelijkheid te nemen naast de verantwoordelijkheid van zorggevers. De inspanningen van zorggevers zijn er verder op gericht dat het probleemgedrag van de persoon met Prader-Willi syndroom geen last wordt voor degenen om hem of haar heen, zoals andere familieleden of andere bewoners. In een theoretisch kader, geconstrueerd op basis van de Grounded Theory analyse, wordt getoond hoe deze waarden samenhangen met gespecificeerde bevorderende en belemmerende condities en met verscheidene mogelijke interventies. De bevorderende condities omvatten het creëren van een omgeving van vertrouwen en openheid, waarbinnen relaties verstevigd kunnen worden en regels niet rigide toegepast worden. In een ondersteunende sociale omgeving waarbinnen structuur aangeboden wordt, hoeft een zorggever minder regels op te leggen en niet tot het uiterste te gaan om zaken expliciet te verbieden. In een stabiele sociale omgeving kunnen conflictsituaties voorkomen worden. De inspanningen van zorggevers zijn erop gericht de situatie hanteerbaar en leefbaar te houden voor alle betrokkenen, ondanks de eetgerelateerde en gedragskenmerken van het syndroom.

In hoofdstuk 3 worden de interviewgegevens geanalyseerd met behulp van een narratieve analyse. Alle casus als geheel werden vergeleken met elkaar op een algemeen niveau. In de narratieve analyse werden de verschillen bekeken in de manier waarop ouders, hulpverleners en personen met Prader-Willi syndroom communiceerden en welk soort attituden aanwezig waren. Geen van de zorggevers koos ervoor de keuze rondom eten in zijn geheel over te laten aan de persoon met het syndroom. Ze intervenieerden echter ook niet simpelweg zonder rekening te houden met de wensen van de persoon met Prader-Willi syndroom. Autonomie wordt bevordert, maar niet door keuzevrijheid te geven. In plaats van individuele zelfbepaling, lag de nadruk op zelfrealisatie door middel van ondersteuning door anderen. De nadruk ligt dus niet op negatieve maar op positieve vrijheid.

De gegevens laten zien dat het zorgproces niet adequaat bezien kan worden in termen van kiezen tussen het respecteren van autonomie als een waarborg van keuzevrijheid aan de ene kant, en paternalisme aan de andere kant. Dat onderscheid is te grof. De verhalen gaven aan dat zorggevers andere opties zien en op andere manieren handelen. Als startpunt werden de vier vormen van arts-patiënt interactie gebruikt, die Emanuel en Emanuel (1992) beschreven hebben. Deze auteurs definiëren niet alleen een paternalistisch en een informatief model (die gebaseerd zijn op de traditionele dichotomie tussen paternalisme en autonomie in termen van zelfbepaling). Ze voegen twee andere mogelijke benaderingen toe aan het arts-patiënt model: het interpretatieve en het deliberatieve model.

In het interpretatieve model helpt de arts de patiënt diens waarden te verhelderen om duidelijk te krijgen wat hij of zij echt wil. Dit model gaat ervan uit dat de waarden van een patiënt niet altijd vastliggen en bekend zijn voor de patiënt. Het deliberatieve model ziet, net als het interpretatieve model, als doel van de arts-patiënt interactie om de patiënt de beste waarden helpen te bepalen en kiezen voor zijn gezondheid. Maar 
in tegenstelling tot het interpretatieve model worden de waarden van de patiënt niet alleen verhelderd, maar staan deze ook open voor ontwikkeling en herziening door morele discussie en overleg. De analyse van de gegevens laat zien dat er slechts weinig voorbeelden in de interview casus waren die duidelijk overeen kwamen met het informatieve model. Volgens dit model zou de zorggever de persoon met PraderWilli syndroom volledig informeren over de gevaren van overeten, maar de keuze rondom diens eetgedrag aan hem overlaten. De beschrijvingen en verhalen van zorggevers hadden vaak een paternalistische toon. Bovendien waren er in hun verhalen echter elementen die lieten zien dat het zorgproces gericht was op het bevorderen van zelfbegrip of morele ontwikkeling. De verhalen bleken nooit helemaal in overeenstemming met een enkel model te zijn, ofschoon een van de modellen vaak domineerde binnen een specifiek interview. Er konden dus casus van paternalisme, van interpretatieve en van deliberatieve interactie onderscheiden worden.

Hoofdstuk 4 doet verslag van een kwantitatieve studie om te bekijken hoe zorggevers de verschillende modellen van Emanuel en Emanuel (1992) waarderen en welke interventies in specifieke situaties de voorkeur verdienden. Om dat te onderzoeken werden verscheidene interventie strategieën geformuleerd op basis van de artspatiënt interactie modellen. Acht casus, die focusten op een specifiek aan Prader-Willi syndroom gerelateerd probleem, werden aan een groep ouders en een groep hulpverleners aangeboden. Centraal in de casus was een eet- of gedragsprobleem, een acuut of chronisch probleem en was gesitueerd in een thuissituatie of een uitwonende situatie. De resultaten van deze kwantitatieve studie laten zien dat zowel ouders als hulpverleners interveniëren de voorkeur gaven boven niet-interveniëren in het omgaan met problemen in de zorg voor mensen met Prader-Willi syndroom. De informatieve benadering, waarbij de keuze geheel overgelaten wordt aan het kind of de cliënt, was het minst geprefereerde model, en de paternalistische strategieën kregen de meeste voorkeur. De ouders prefereerden interveniërende benaderingen meer dan hulpverleners. Ouders gaven meer de voorkeur aan controlerende interventies in situaties met eetproblemen dan in situaties met gedragsproblemen, terwijl hulpverleners geen verschil tussen deze situaties lieten zien. Voor beide groepen was de mate van voorkeur voor de meer controlerende interventies minder in chronische, in vergelijking met acute situaties.

In hoofdstuk 5 wordt de kwestie van competentie behandeld. De huidige criteria voor competentie stellen een hoge drempel, waarbij de nadruk ligt op cognitieve capaciteiten: mensen moeten een beslissing kunnen communiceren, informatie begrijpen, informatie toepassen op hun eigen situatie en alle aspecten van de beslissing kunnen beredeneren. Deze benadering van competentie die gebaseerd is op cognitie kan leiden tot een onjuiste marginalisatie van mensen met verstandelijke beperkingen in het beslissingsproces. Een alternatieve benadering wordt voorgesteld die zich richt op emoties en praktische rationaliteit. Het wordt beargumenteerd dat deze benadering, die gebruik maakt van levensverhalen en het observeren van gedragspatronen, meer past in de zorg voor mensen met verstandelijke beperkingen.

Pas in recente jaren worden empirische gegevens systematisch verzameld om ethische theorieën te helpen ontwikkelen of bijstellen. In plaats van te proberen om morele dilemma's te verhelderen en verklaren met behulp van ethische theorieën, principes 
en regels, bestudeert een groeiend aantal ethische projecten specifieke zorgpraktijken met het doel om die morele regels en overtuigingen te expliciteren, die intrinsiek zijn aan die praktijken. In hoofdstuk 6 worden zowel de kwalitatieve als de kwantitatieve benaderingen om gegevens te verzamelen besproken en vergeleken. Zoals in het hoofdstuk besproken wordt, kan van de ervaringen van betrokkenen uit de praktijk geleerd worden dat er meerdere manieren zijn dan die die de morele theorie domineren om om te gaan met de morele kwesties in het voorkomen van overgewicht. Dit kan tot zowel conceptuele als normatieve conclusies leiden. Conceptueel gezien kan geconcludeerd worden dat een definitie van autonomie die gebaseerd is op een opvatting van positieve vrijheid relevant kan zijn binnen het gebied van preventie van overgewicht in de zorg voor mensen met Prader-Willi syndroom. De opvatting van autonomie als positieve vrijheid kan verder ontwikkeld worden door gebruik te maken van het werk van Emanuel en Emanuel. Dit impliceert echter ook de behoefte te reflecteren op de rationele manier waarop Emanuel en Emanuel autonomie beschrijven als morele ontwikkeling, dat deze opvatting lijkt te beperken tot competente volwassenen. Deze conceptuele conclusie heeft ook een normatieve kant. De opvatting van positieve vrijheid kan als doel dienen in deze specifieke zorgpraktijk. Deze studie laat niet alleen de morele relevantie van dit doel zien, maar maakt ook die morele handelingen, attitudes en overwegingen duidelijk die nodig zijn om dat doel te bereiken, zoals het geven van ondersteuning en het creëren van veiligheid.

Hoofdstuk 7 beschrijft de inhoud van een interactief computergestuurd programma dat ontwikkeld werd op basis van de gegevens die in deze studie werden verzameld. Het doel van het programma is om een proces van bewustzijn, reflectie en discussie bij zorggevers op te roepen. Het programma is gecentreerd rondom een casus en geeft gerichte feedback op basis van de antwoorden van gebruikers. Het programma richt zich op waarden die relevant zijn voor zorggevers in de dagelijkse praktijk en op verschillende manieren van interactie met de cliënt. Er zijn drie trajecten uitgewerkt, een paternalistisch, een informatief en een interpretatief/deliberatief traject. Ofschoon er geen significante veranderingen gevonden werden in de voorkeuren van gebruikers aan het einde van het programma in vergelijking met het begin, ondersteunen hun reacties wel eerdere onderzoeksbevindingen. Deze bevindingen steunen een concept van autonomie in termen van positieve vrijheid, met behulp van steun van anderen, waarbij de bevordering van zelfbegrip en zelfontwikkeling centraal staat.

Het laatste hoofdstuk van deze thesis bespreekt de bredere betekenis en implicaties van de bevindingen van deze studie. Bij het behandelen van de hoofdvragen wordt de betekenis van goede zorg voor ouders en professionele zorggevers besproken in het omgaan met de preventie van overgewicht bij personen met Prader-Willi syndroom. Goede zorg impliceert een veelheid aan waarden, naast de focus op fysieke gezondheid. Goede zorg brengt ook interventies met zich mee die steun bieden en gezamenlijke leerprocessen bevorderen. De consequenties van deze bevindingen voor zorgethiek worden besproken. En de implicaties van deze studie voor de praktijk worden behandeld. In plaats van burgerschap wordt een pleidooi gehouden voor partnerschap, waarbij beslissingen in een gezamenlijke dialoog worden genomen. Personen met verstandelijke beperkingen zouden niet enkel dezelfde rechten moeten hebben, maar zouden zich ook bewust moeten zijn van hun eigen verantwoordelijk- 
heden. Het is niet alleen belangrijk de waarden van de cliënt te verhelderen maar deze waarden ook kritisch te bevragen met het doel gelegenheden te creëren om te leren.

Voor het veld van gezondheidsbevordering laten de resultaten van deze studie zien dat de nadruk niet op het faciliteren van keuzes moet liggen, maar op cliënt medewerking en empowerment.

De geïntegreerde rol van empirisch onderzoek en ethiek wordt besproken. In deze geïntegreerde benadering zoekt onderzoek op empirische wijze naar normatieve standpunten en evalueert deze normatieve standpunten door zich op observeerbare consequenties te richten.

Aangezien (jeugd)obesitas een groeiend probleem is in onze Westerse samenleving is het relevant voor toekomstig onderzoek om te kijken of de resultaten uit deze studie geëxtrapoleerd kunnen worden naar vergelijkbare situaties. Om de voordelen en beperkingen van dialogische processen zoals interpretatie en deliberatie verder te bestuderen, zouden mensen met andere, met name meer ernstige verstandelijke beperkingen betrokken moeten worden in toekomstig onderzoek. Nieuwe en moderne manieren zouden verkend moeten worden om de voordelige aspecten te bestuderen in het bevorderen van een effectieve dialoog. 



\section{Dankwoord}

"Life is what happens to you, while you're busy making other plans" zong John Lennon ooit, tegenwoordig een veelgebruikte quote. Ik was bezig met andere plannen tijdens mijn afstuderen in de psychologie, toen ik gevraagd werd voor een tweejarig onderzoeksproject op het gebied van de gezondheidsethiek. Van ethiek had ik toentertijd slechts vage associaties in mijn hoofd. Als iemand toen voorspeld had dat ik een dissertatie op dit vlak zou afronden, had ik deze persoon wellicht verminderd toerekeningsvatbaar verklaard. Deze afronding heeft toch plaatsgevonden. Een mijlpaal die ik niet had kunnen bereiken zonder de hulp en ondersteuning van een aantal mensen. Een woord van dank ben ik hen dan ook zeker verschuldigd.

Prof.dr. Widdershoven. Beste Guy, als hoogleraar ethiek was je mijn belangrijkste houvast. Dankzij je sterke analytische vermogens wist je me altijd weer verder te helpen op momenten dat ik dacht volledig vast te zitten. Meer kan een promovendus zich niet wensen. Heel veel dank voor al je inspanningen en begeleiding. Met plezier denk ik ook terug aan alles wat we meegemaakt hebben, niet in de laatste plaats in het kader van EACME, waarbij we op veel plekken en met soms heel bijzondere mensen in contact kwamen.

Prof.dr. Curfs. Beste Paul, als hoogleraar in de zorg voor mensen met een verstandelijke beperking heb je altijd een belangrijke schakel gevormd met dit zorgveld. Ons contact begon al ruim voor ik aan dit promotietraject begon, jij toentertijd als tweede begeleider van mijn afstudeeronderzoek in de neuropsychologie, gericht op PraderWilli syndroom. In deze fase liet je me, ondanks de cognitieve insteek van het onderzoek, al kennismaken met de psychosociale problematiek van zowel ouders, hulpverleners als van de personen zelf met deze genetische aandoening. Een goede voorbereiding, bleek later, op het promotie onderzoek. Met name je managementkwaliteiten heb je ten volle moeten benutten om mijn soms wat chaotische karaktertrekken in toom te houden. Heel veel dank voor al je inzet.

Prof.dr. Van den Borne. Beste Bart, als hoogleraar patiëntvoorlichting was je een derde promotor die op iets meer afstand betrokken was, maar niet minder belangrijk. Op iedere vraag mijnerzijds wist je me altijd weer antwoorden aan te reiken, en ieder concept dat ik doorstuurde nam je met even veel aandacht en oog voor detail door. Ook jou ben ik zeer erkentelijk voor al je inspanningen. Een bijzondere dank ook aan je vrouw Mieke, voor het aanpassen van mijn soms veel te moeilijk geschreven teksten voor de internet module.

Dr. Van der Bruggen. Beste Harry, als expert op het gebied van Grounded Theory ben je een onmisbare steun geweest in de kwalitatieve analyses van de interview transcripten. Je frisse kijk op een moment dat ik deze transcripten bijna letterlijk kon opdreunen heeft een positieve bijdrage gevormd aan het eindresultaat. Veel dank voor je inzet.

Dr. Candel. Beste Math, van statistiek dacht ik genoeg te weten maar een oplossing voor het analyseren van volgordetesten had ik niet. Ik ben je erg dankbaar voor je statistische hulp en inspanningen. 
Josh Moll, dank voor al je technische hulp en je meedenken in het opzetten van de internet module voor ouders en begeleiders van mensen met Prader-Willi syndroom. Zonder jou was de realisatie van de module simpelweg niet gelukt.

Prof.dr. Geraedts. Beste Joep, je vertrouwen en inzet op een cruciaal moment heeft het mede mogelijk gemaakt dat ik door kon gaan met mijn onderzoek. Daarvoor ben ik je dankbaar.

Prof.dr. Reinders en prof.dr. Meininger. Beste Hans en Herman, vanaf het eerste uur waren jullie als discussiepartners op afstand betrokken bij mijn activiteiten. Altijd bereid tot uitleg en overleg, altijd opbouwende en waardevolle kritiek. Heel veel dank hiervoor.

Het ontbreekt me aan ruimte om een ieder van de volgende mensen individueel te bedanken voor hun advies, hulp, collegialiteit en vriendschap maar voor mij zeker niet minder waardevol:

Tineke Abma, Arnold van Alphen, Arie van de Arend, Ron Berghmans, Paulus van Bortel, Wil Buntinx, Lindy Dullens, Els Geelen, Minke Goldsteen, Angelique Heijnen, Hellen Heutz, Tony Holland, Klasien Horstman, Harm Hospers, (grote) Rob Houtepen, Anne Huizinga, Loes Kater, Ineke Klinge, Anja Krumeich, Henny Lantman, Ingrid Lathouwer, Francis van der Lubbe, Marian Maaskant, Agnes Meershoek, Ruud ter Meulen, Albine Moser, Marianne Potting, Ireen Proot, Machteld 'Granny' Roede, Lieke van der Scheer, Ada van de Scheur, Marie-Jose Smits, Rein Vos, Sander Welie, Guido de Wert, Joyce Whittington, Frans van Wijmen, Nynke Wilbrink.

Waardering ook voor alle ouders, begeleiders en jongeren met Prader-Willi syndroom voor hun medewerking en openhartigheid. In het bijzonder de Prader-Willi / Angelman oudervereniging. Zonder jullie had ik dit onderzoek niet kunnen uitvoeren.

Er zijn mensen die niet bij naam genoemd hoeven te worden, en eigenlijk ook geen dankwoord behoeven, namelijk mijn vrienden. Vaak hebben jullie me - op aangename wijze - van mijn werk afgehouden maar ook de kracht gegeven om door te zetten en verder te gaan. Ik hoop dat dat nog lang zo moge blijven.

Een vriend wil ik toch expliciet noemen, namelijk Niels Maier. Niels, super bedankt voor alle uren die je gestoken hebt in het ontwerpen van de mooie omslag.

A special word of appreciation for Jacinta Tan, for correcting parts of the text of this thesis. I am very grateful for your cooperation and efforts.

Een bijzonder woord van waardering ook voor mr.dr. Frederiks. Beste Brenda, dank voor al je hulp, collegialiteit en vriendschap. Ik vind het erg leuk dat je ook als paranimf, samen met Frits, weer aan mijn zijde staat.

De meeste dank ben ik verschuldigd aan mijn familie en schoonfamilie voor al hun hulp en ondersteuning. In het bijzonder mijn ouders. $\mathrm{Pa}$, ma, jullie hebben me de waarden en normen meegegeven die ervoor gezorgd hebben dat ik ben wie ik nu ben. Ook hebben jullie me altijd vrij gelaten in de keuzes die ik wilde maken, en me hierin gesteund. Het is moeilijk in woorden te vatten hoe dankbaar ik jullie ben.

En tot slot, mijn allergrootste maatje Wiet. Om in het onderwerp van dit proefschrift te blijven: door dik en dun mijn grootste steun en toeverlaat. Dank voor al je geduld. Ik hoop dat we nog heel veel jaren samen gelukkig mogen zijn! 


\section{Curriculum Vitae}

Rob van Hooren werd op 20 september 1975 geboren te Maastricht. In 1993 behaalde hij het gymnasium- $\alpha$ diploma aan de Stedelijke Scholengemeenschap te Maastricht. De daarop volgende jaren studeerde hij psychologie aan de Katholieke Universiteit Brabant, de huidige Universiteit van Tilburg. In het kader van zijn afstudeerspecialisatie in de klinische neuropsychologie, kwam hij voor onderzoek naar de Stichting Klinische Genetica te Maastricht. Zijn afstudeeronderzoek richtte zich op het bestuderen van het cognitief functioneren van jongeren met Prader-Willi syndroom. Vanaf januari 1999 kwam hij als junior onderzoeker in dienst van de sectie Gezondheidsethiek en Wijsbegeerte aan de Universiteit Maastricht, waar hij tot december 2004 werkte op twee onderzoeksprojecten die de basis vormden voor dit proefschrift. Verder is hij van april 2005 tot augustus 2006 als junior onderzoeker vanuit dezelfde afdeling betrokken geweest bij een onderzoeksproject gericht op het opzetten van kwaliteitscriteria en zorgvuldigheidseisen rondom vrijheidsbeperkende maatregelen bij mensen met een verstandelijke beperking. Vanaf september 2005 is hij als docent verbonden aan het Departement Medische, Klinische en Experimentele Psychologie (thans Clinical Psychological Science) van de Universiteit Maastricht. Verder was Rob van 2001 tot 2006 de editor van de Newsletter van de European Association for Centers for Medical Ethics (EACME). Sinds oktober 2004 is hij voorzitter van de ethische commissie van Stichting Pepijn en Paulus, een zorgorganisatie in Midden-Limburg voor mensen met een verstandelijke beperking. Sinds juni 2006 is hij hier ook werkzaam als extern vertrouwenspersoon inzake grensoverschrijdend gedrag en seksueel misbruik. 



\section{List of publications}

Borne, H.W. van den, Hooren, R.H. van, Gestel, M. van, Rienmeijer, P., Fryns, J.P., Curfs, L.M.G. (1999). Psychosocial problems, coping strategies, and the need for information of parents of children with Prader-Willi syndrome and Angelman syndrome. Patient Education and Counseling, 38, 205-216.

Hooren, R.H. van, Widdershoven, G.A.M., Borne, H.W. van den, Curfs, L.M.G. (2001). Ethische aspecten van preventiemaatregelen. Preventie van overgewicht bij Prader-Willi syndroom. SNZB, Cadier en Keer.

Hooren, R.H. van, Widdershoven, G.A.M., Borne, H.W. van den, Curfs, L.M.G. (2002). Autonomy and intellectual disability: the case of prevention of obesity in Prader-Willi syndrome. Journal of Intellectual Disability Research, 46 (7), 560-568.

Hooren, R.H. van, \& Widdershoven, G.A.M. (2004). Ethiek en zorg voor mensen met een verstandelijke handicap: De spanning tussen het streven naar autonomie en goede zorg (pp. 1070-1-14). Vademecum Zorg voor verstandelijk gehandicapten. Bohn Stafleu Van Loghum, Houten/Diegem.

Widdershoven, G., \& Hooren, R. van (2004). Gelijkwaardigheid in de zorg voor mensen met een verstandelijke handicap. Enkele ethische thema's onder de loep genomen. (pp. 159-164) In: M. Kersten, D. Flikweert (Red.), Onderzoek over grenzen. Thematische rapportages en beschouwingen naar aanleiding wan het 12de IASSID congres, Montpellier 2004. NGBZ en LKNG/NIZW, Utrecht.

Hooren, R.H. van, Widdershoven, G.A.M., Bruggen, H. van der, Borne, H.W. van den, Curfs, L.M.G. (2005). Values in the care for young persons with Prader-Willi syndrome: creating a meaningful life together. Child: Care, Health and Development, 31, 309-19.

Abma, T.A., Frederiks, B.J.M., Hooren, R.H. van, Widdershoven, G.A.M., Wijmen, F.C.B. van, Curfs, L.M.G. (2005). Verantwoorde vrijheidsbeperking: communicatie als kwaliteitscriterium. Nederlands Tijdschrift voor de Zorg aan mensen met verstandelijke beperkingen, 3, 147-61.

Hooren, R.H. van, Widdershoven, G.A.M., Candel, M.J.J.M., Borne, H.W. van den, Curfs, L.M.G. (2006). Between control and freedom in the care for persons with Prader-Willi syndrome: An analysis of preferred interventions by caregivers. Patient Education and Counseling, 63 (1-2), 223-31. 
Abma, T.A., Frederiks, B.J.M., Hooren, R.H. van, Widdershoven, G.A.M., Wijmen, F.C.B. van, Curfs, L.M.G. (2006). Kwaliteitscriteria voor vrijheidsbeperking in de zorg voor mensen met een verstandelijke beperking. Gouverneur Kremers Centrum, Maastricht.

Abma, T.A., Frederiks, B.J.M., Hooren, R.H. van, Widdershoven, G.A.M., Wijmen, F.C.B. van, Curfs, L.M.G. (2006). Schipperen tussen niet helpen en overrulen: kwaliteitscriteria voor vrijheidsbeperking van mensen met verstandelijke beperkingen, Journaal Ggz en recht, Nieuwsbrief voor de psychiatrie, verstandelijk gehandicaptenzorg en psychogeriatrie, Den Haag: Sdu uitgevers, december 2006, 2 (8), 171-175.

Abma, T.A., Frederiks, B., Hooren, R.H. van, Widdershoven, G.A.M., Wijmen, F.C.B. van, Curfs, L.M.G. (2007). Morele dilemma's in de zorg voor mensen met verstandelijke beperkingen. Kwaliteitscriteria voor vrijheidsbeperkende interventies. Maandblad Geestelijke volksgezondheid, 62 (3), 195-207.

Hooren, R.H. van, Borne, H.W. van den, Curfs, L.M.G., Widdershoven, G.A.M. (2007). Ethics of prevention: An interactive computer-tailored program. Scandinavian Journal of Public Health, 35 (5), 503-509.

Hooren, R.H. van, Borne, H.W. van den, Curfs, L.M.G., Widdershoven, G.A.M. Providing good care in the context of restrictive measures: The case of prevention of obesity in youngsters with Prader-Willi syndrome. In: G.A.M. Widdershoven, J. McMillan, T. Hope, L. van der Scheer (Eds.), Empirical ethics and psychiatry. Oxford University Press, Oxford, in press.

Abma, T.A., Frederiks, B.J.M., Hooren, R.H. van, Widdershoven, G.A.M., Wijmen, F.C.B. van, Curfs, L.M.G. From self determination to self development. Improving the quality of freedom restrictions in the care for persons with intellectual disability. Submitted to Journal of Applied Research in Intellectual Disabilities.

Widdershoven, G.A.M., Hooren, R.H. van, Berghmans, R.L.P., Curfs, L.M.G. Competence in the care for persons with intellectual disabilities: An alternative view. Submitted to Journal of Applied Research in Intellectual Disabilities. 